\title{
DIAGNÓSTICOS E INTERVENÇÕES DE ENFERMAGEM EM PACIENTES COM HIPERTENSÃO ARTERIAL EM ACOMPANHAMENTO AMBULATORIAL
}

\section{Isabel Cristina Kowal Olm Cunha}

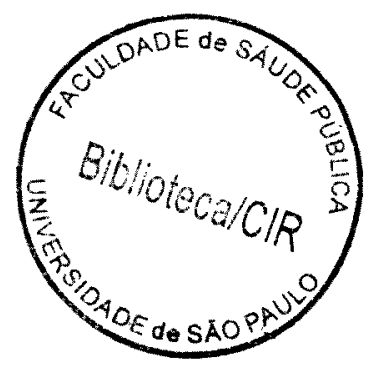

Tese de Doutorado apresentada ao Departamento de Práticas de Saúde Pública da Faculdade de Saúde Pública da Universidade de São Paulo para obtenção do Grau de Doutor.

Área de Concentração : Administração Hospitalar

\author{
ORIENTADOR : PROFA. DRA. VITÓRIA \\ KEDY CORNETTA
}

São Paulo

1999 
Autorizo, exclusivamente para fins acadêmicos e científicos, a reprodução total ou parcial desta tese, por processos fotocopiadores.

Assinatura :

Data : 
Para Goongia, Larissa e Juliana que no futuro dirato com orgulho que

- fol a mamấ que escreveu..." 


\section{AGRADECIMENTOS}

À Profa. Dro. Viłoria Kedy Cornetła, pelo incentivo na elaboração deste trabalho e pela carinhosa acolhida como orientadora num momento difícil;

À Profa. Dra. Tamara lwanow Cianciarullo, pelo alto astral, orientações precisas e pelo estímulo constante à minha titulação;

Às Enfermeiras Maria lsabel Sampaio Carmagnani e Lígia Mara Canteras pela disponibilidade em revisar 0 material da pesquisa, emprestando-me conhecimentos e juizo de valores;

Às Enfermeiras Rosana Iglesias, Sania Almeida Prado, Alessandra Rocha Lima e Patrícia Costa de Maraes pela preciosa ajuda na coleta de dados;

À equipe do Centro de Saúde Escola na pessoa da Dra.Maria Cristina Faria da Silva Cury, pelo auxílio e apoio local para as entrevistas com os pacientes;

À Ângelo Tavares Paes, do Laboratório de Epidemiologia e Estatística do Instituto Dante Pazzanese de Cardiologia, pelo empenho na análise estatística dos dados;

À Enfermeiro Alessandro Racho Limo, minha companheira na jornada hospitalar, pelo extenso e cansativo trabalho de digitação, formatação e revisão destes originais;

As colegas Isabel, Maria, Magaly, Euisa, Lydia e Mitie, da Disciplina Administração aplicada à Enfermagem do Departamento de Enfermagem da Universidade Federal de São Paulo, por oferecerem condições para o término deste trabalho;

Aos amigos Cris, Pawlo $e$ Juliane, pela amizade sincera, pelo incentivo e pela inesgotável partilha de emoções até a conclusão deste trabalho;

Ao Dr. George Washington Bezerra da Cunha, meu marido, que sempre valorizando o meu trabalho e as minhas conquistas, muito assumiu na vida doméstica para assegurar-me tempo para este estudo. 


\section{RESUMO}

Cunha ICKO. Diagnósticos e intervenções de Enfermagem em pacientes com hipertensão arterial em acompanhamento ambulatorial . São Paulo ; 1999. I Tese de Doutorado - Faculdade de Saúde Pública da USP ] .

Objetivo. Sendo a hipertensão arterial uma doença que está afetando cerca de vinte por cento da população mundial, e existindo a necessidade crescente dos enfermeiros estarem capacitados a participar do acompanhamento destes clientes dentro de uma abordagem multiprofissional, realizou-se estudo com o objetivo de identificar os diagnósticos de enfermagem e propor intervenções para pacientes com hipertensão arterial em acompanhamento ambulatorial. Métodos. Pesquisou-se junto a pacientes adultos hipertensos em tratamento num Centro de Saúde-Escola da cidade de São Paulo. O estudo incluiu quatro fases : a) entrevista e exame físico dos pacientes $(\mathrm{n}=50)$ b) identificação dos diagnósticos de enfermagem utilizando a taxonomia I revisada e traduzida da North American Nursing Diagnosis Association c) análise dos diagnósticos e tratamento estatístico com associação de variáveis d) proposição das intervenções de enfermagem. Resultados. Foram identificados 197 diagnósticos de enfermagem em 29 categorias dentro de 8 padrões de resposta humana da NANDA, juntamente com 364 características definidoras em 96 categorias e 271 fatores relacionados em 63 categorias. O padrão de resposta humano TROCAR teve a maior frequência de diagnósticos. O déficit de conhecimento sobre a doença é o diagnóstico mais frequente, aparecendo em $96 \%$ dos pacientes, seguido de distúrbio no padrão do sono (52\%), nutrição alterada :ingestão maior do que as necessidades corporais (50\%) e disfunção sexual (42\%). Foram encontradas associações estatísticamente significantes entre sexo e nutrição alterada, sexo e disfunção sexual, uso de metildopa e excesso de volume de líquidos, cansaço e disfunção sexual, cansaço e constipação, pressão arterial alterada e constipação. Foram propostos um conjunto de 44 categorias de intervenções de enfermagem para os diagnósticos identificados. Conclusões. Os diagnósticos mais identificados estão relacionados entre outros aspectos, à pouca orientação do paciente, a fatores de risco, a adesão do paciente ao tratamento e aos efeitos colaterais dos medicamentos, que 
apontam a necessidade de maior atuação dos profissionais de saúde. Das intervenções de enfermagem propostas, a maior parte delas (79\%), diz respeito à ações de orientação e supervisão do cliente. Estas intervenções podem direcionar o enfermeiro para atuar junto a esta clientela em especial.

Descritores : Hipertensão arterial. Diagnóstico de Enfermagem Intervenções de Enfermagem . Sistematização da Assistência de Enfermagem. 


\section{SUMMARY}

Cunha ICKO. Diagnósticos e Intervenções de Enfermagem em pacientes com Hipertensão Arterial em acompanhamento ambulatorial . [ Nursing Diagnosis and Interventions of patients with hypertension in ambulatory treatment ] . São Paulo ( BR ) ; 1999. [ Tese de Doutorado - Faculdade de Saúde Pública da Universidade de São Paulo ].

Objetive. Considering that arterial hypertension is a disease that affects about $20 \%$ of world population, and that there is a necessity of health professionals in developing ways that encourage patients compliance to treatment, the aim of this study was to define nursing diagnosis and interventions for hypertenses patients with ambulatorial accompanying. Methods. This research was performed in hypertense adult of a School Health Center of São Paulo City. The study was composed of 4 steps: a) interview and physical examination $(n=50)$ b) To identify the nursing diagnosis using taxonomy I revised from North American Nursing Diagnosis Association. c) Statistical analysis with sample caracterization and variable correlation d ) Nursing interventions propositions. Results. 197 nursing diagnosis were described.and 364 defining characteristics and 271 related factors in 8 pattem. The knowledgement deficit was the most frequent diagnosis rising in $96 \%$ of patients, following by sleep pattern disturbance $(52 \%)$, altered nutrition:more than body requirements $(50 \%)$ and sexual dysfunction (42\%). Significant associations were found between some diagnosis and variables. A group of 44 category of nursing interventions was proposed for the diagnosis . Conclusions. The nursing diagnosis more identifyed were .with a few health orientations. Interventions that should direct nurses actions were estabilished in order to increase hypertensive patients compliance to the treatment. New researches were suggested in order to improve and validate this knowledge.

Descriptors: Arterial Hypertension. Nursing Diagnosis. Nursing Interventions. Nursing Process. 


\section{RELAÇÃO DE TABELAS}

Página

Tabela 1 - Anti-hipertensivos utilizados no tratamento da Hipertensão Arterial..15

Tabela 2 - Diuréticos utilizados no tratamento da Hipertensão Arterial. .16

Tabela 3 - Distribuição da percentagem de pacientes segundo o sexo

Tabela 4 - Distribuição do número de pacientes segundo a faixa etária.

Tabela 5 - Distribuição da percentagem dos pacientes segundo o estado civil......42

Tabela 6 - Distribuição da percentagem dos pacientes segundo a escolaridade....42

Tabela 7 - Distribuição da percentagem dos pacientes quanto ao trabalho.

Tabela 8 - Distribuição da percentagem dos pacientes segundo a faixa salarial...43

Tabela 9 - Distribuição da percentagem dos pacientes segundo a profissão

Tabela10- Distribuição dos valores de idade, peso e altura apresentados pelos pacientes segundo o cálculo da média, mediana, desvio padrão, mínima e máxima..45

Tabela 11 - Distribuição do número e percentagem de pacientes segundo os problemas de saúde

Tabela 12 - Distribuição da percentagem dos pacientes segundo os fatores de risco identificados.

Tabela 13 - Distribuição do número e percentagem dos pacientes segundo os antecedentes familiares de doenças.

Tabela 14 - Distribuição do número e percentagem dos pacientes segundo as queixas verbalizadas.

Tabela 15 - Distribuição do número e percentagem dos pacientes segundo o fixar o olhar na entrevista analisado pela enfermeira

Tabela 16 - Distribuição do número e percentagem dos pacientes segundo a presença de movimentos na entrevista analisado pela enfermeira.

Tabela 17 - Distribuição do número e percentagem dos pacientes segundo a expressão facial na entrevista analisado pela enfermeira.

Tabela 18 - Distribuição dos valores de PressãoArterial,Pulso,Respiração segundo 
Tabela 19 - Distribuição do número e percentagem dos pacientes segundo os medicamentos que fazem uso.

Tabela 20 - Distribuição da percentagem dos pacientes segundo os Padrões de Resposta Humana identificados.

Tabela 21 - Distribuição do número e percentagem dos pacientes segundo os Diagnósticos de Enfermagem identificados.

Tabela 22 - Relação dos Padrões de Resposta Humana, Diagnósticos de Enfermagem, Características Definidoras, outros Problemas Relacionados e as Intervenções de Enfermagem.

Tabela 23 - Associação entre Diagnósticos de Enfermagem e o sexo dos pacientes

Tabela 24 - - Associação entre Diagnósticos de Enfermagem e faixa etária dos pacientes

Tabela 25 Associação entre Diagnósticos de Enfermagem e uso do Medicamento Metildopa.

Tabela 26 Associação entre Diagnósticos de Enfermagem e uso do Medicamento Hidroclorotiazida.

Tabela 27 - Associação entre Diagnósticos de Enfermagem e uso do Medicamento Clortalidona.

Tabela 28- Associação entre Diagnósticos de Enfermagem e Diabetes como problema de saúde.

Tabela 29 - Associação entre Diagnósticos de Enfermagem e o salário dos pacientes.

Tabela 30 - Associação entre Diagnósticos de Enfermagem e a queixa de cansaço.

Tabela 31 Associação entre Diagnósticos de Enfermagem e expressão facial dos pacientes.

Tabela 32-Associação entre Diagnósticos de Enfermagem e a Pressão Arterial normal ou alterada.

Tabela 33 -Associação entre o problema Bronquite e a queixa de Dispnéia relatada pelos paciente. 
Tabela 34 - Associação entre o problema Diabetes e a queixa de Cansaço relatada

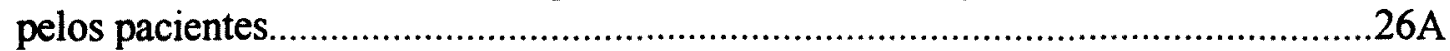

Tabela 35 - Associação entre pressão arterial normal e alterada e queixas dos pacientes. 


\section{ÍNDICE}

$\begin{array}{lc}\text { Agradecimentos } & \text { III } \\ \text { Resumo } & \text { IV } \\ \text { Summary } & \text { VI } \\ \text { Relação de Tabelas } & \text { VII }\end{array}$

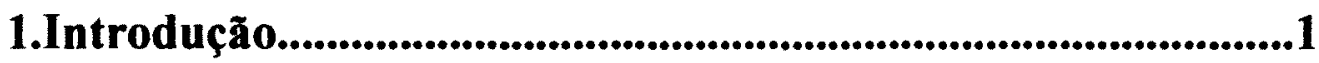

1.1. Considerações sobre a Hipertensão Arterial......................9

1.2. Considerações sobre o Diagnóstico de Enfermagem.......18

2.Objetivos do Estudo.....................................................................28

\section{Metodologia}

2.1. População e Amostra.............................................29

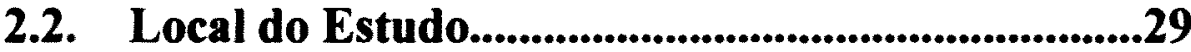

2.3. Coleta de Dados.....................................................30

2.4. Instrumentos da Pesquisa

I - EntrevistadeEnfermagem.................................32

II - Exame físico......................................................33

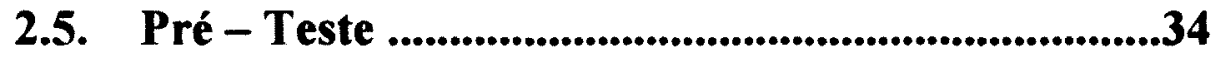

2.6. Elaboração dos Diagnósticos.....................................34

2.7. Tratamento Estatístico..........................................37

4.Resultados e Discussão.............................................................

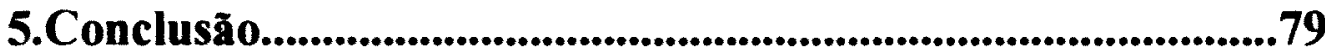

6.Referências Bibliográficas................................................................81

7.Anexos

I - Autorização para coleta de dados...................................2A

II - Taxonomia I revisada da NANDA....................................3A

III - Instrumento de Coleta de Dados.....................................7A

IV - Registro dos Diagnósticos.............................................14A

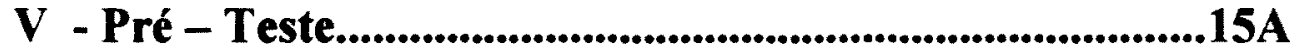

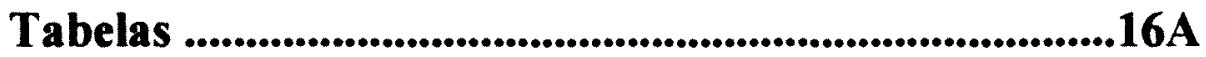




\section{INTRODUÇÃO}

Desde a década passada, diferentes enfoques têm sido discutidos sobre o conceito de saúde, existindo porém unanimidade em se dizer que ela depende de inúmeros fatores como desenvolvimento, educação, condições de vida e não apenas a simples ausência de doenças. É aceito ainda que o contexto sócio - econômico atua como um fator facilitador ou dificultador para adquiri-la (Archer e Fleshman, 1982; Clark,1984 ; Viniegra, 1985; Malik, 1989). A qualidade de vida está hoje atrelada ao estado de saúde que pressupõe, segundo Cianciarullo (1998), ..."o reconhecimento e salvaguarda dos direitos do indivíduo, como sujeito das ações e serviços de assistência em saúde".

Em 1978 a Organização Mundial de Saúde (OMS), durante realização da Conferência de Alma-Ata, reconheceu que cerca de metade da população mundial não recebia assistência de saúde adequada e que os serviços existentes não eram suficientes para atender a demanda (OMS,1981), estabelecendo a meta de "saúde para todos no ano 2000 ". Destacou ainda que para se atingir esta meta, mudanças profundas deveriam ser provocadas nos sistemas de atenção à saúde, basicamente substituindo os atuais - com tecnologia sofisticada e altos custos - por outros que fossem mais acessiveis a todos e organizados à partir das reais necessidades da população. Para isso, os países deveriam basear seus 
programas na atenção primária à saúde (OMS,1980), que consiste em "assistência sanitária essencial baseada em métodos e tecnologias práticas, cientificamente fundamentadas e socialmente aceitável, colocadas ao alcance de todos os indivíduos e familias da comunidade" (OMS,1978).

Apesar destes esforços, pode-se constatar que hoje, decorridos mais de vinte anos da Conferência em Alma-Ata e às vésperas do ano 2000 , a população mundial continua não recebendo assistência adequada e novas e velhas doenças ameaçam a saúde das pessoas .

Na região das Américas, apesar do direito à saúde ou à atenção médica constarem das legislações dos diferentes países, fatores de ordem econômica, entre outros, têm contribuído para o não atendimento a estes princípios. Um diagnóstico da Organização Pan-Americana de Saúde sobre os sistemas de saúde na América Latina e Caribe, revela que há ineqüidade, medida pela falta de acessibilidade a serviços básicos de cerca de 140 milhōes de pessoas e ineficiência do setor, mensurada por um desperdício de cerca de $25 \%$ de seus gastos de funcionamento, ou seja 10 bilhões de dólares (Novaes e Paganini, 1994).

Macedo em 1989 alertava para o aumento significativo da população da América Latina e Caribe, que chegaria ao ano 2000 com cerca de 550 milhões de pessoas que exigiriam o direito à saúde. 
Oguisso, em publicação de 1998, ressalta que "a expressão reforma ou mudanças do setor saúde vem sendo utilizada com frequência cada vez maior na literatura e parece haver um acordo entre as suas dimensões, âmbito e objetivos nos países mais industrializados. O Banco Mundial em 1993 especifica que a mudança no Sistema de Saúde é necessária para melhorar a saúde das populaçōes".

A assistência à saúde em muitos países centralizou-se na medicina curativa e nos hospitais. Isto causou distorções profundas no sistema, resultando em superlotação dos hospitais que passaram a atender casos simples que poderiam ser resolvidos em unidades básicas de saúde.

No Brasil, o sistema de saúde foi caracterizado como sendo no setor público um modelo anárquico, pouco eficiente e eficaz, gerando descrédito na população, e no setor privado um modelo predominante de interesses da área médico-hospitalar (Brasil, 1986). O atual sistema não comporta o atendimento de sua demanda, pois tem a parte maior do seu atendimento centrado na medicina curativa e nos hospitais. Somados à isso estão os altos custos dessa assistência cada vez mais sofisticada tecnologicamente, a eterna carência de leitos, a superpopulação dos hospitais, o sucateamento da rede pública, e o aumento das doenças "curativas". Em países como o nosso, onde somados aos baixos investimentos nesta área vemos 0 aumento significativo das doenças crônicodegerativas e do envelhecimento da população (Mendes, 1994 ), 
a tendência é nos próximos anos termos parcela razoável destas dependendo de assistência curativa em saúde.

Todas as pessoas deveriam ter acesso e igualdade de assistência, todavia não há ainda estrutura para isso. O atendimento assim, não é integral, sendo priorizado o curativo desvinculado das ações preventivas e de reabilitação. Desta maneira o paciente ainda é tratado quando adoece, sendo pouco orientado quanto à prevenção, desconhecendo cuidados posteriores à internação hospitalar e não sendo preparado para se auto-cuidar.

$\mathrm{Na}$ tentativa de se traçar caminhos para a melhoria das açōes à saúde, tem-se dado enfoque cada vez maior à assistência ambulatorial e domiciliária dos pacientes. Sem dúvida se pensarmos que pacientes portadores de doenças crônicas e degenerativas e os que apresentam incapacidade funcional, devem viver com essas limitações de saúde, por que não oferecer-Ihes infra-estrutura a fim de que sejam atendidos nos ambulatórios e em suas próprias casas quando necessitarem?

As doenças cardiocirculatórias tais como o infarte do miocárdio, a insuficiência cardíaca, as hemorragias e embolias cerebrais dentre outras, constituem-se na principal causa de mortalidade em nosso 
meio desde a década de sessenta (Cury Jr,1996). Lotufo $(1993,1996)$ citado por Barros (1998, p.17), afirma que estas constituem-se "a principal causa de morbimortalidade na população adulta do Estado de São Paulo" e sua "prevalência na cidade de São Paulo é maior que a de países industrializados da Europa e América do Norte”.

Smith (1993) relata que os fatores de risco para as doenças cardiovasculares podem ser separados em duas categorias, podendo-se assim identificar mais claramente as pessoas com maior risco de desenvolvê-las. São eles: fatores não modificáveis como idade avançada, sexo masculino e história familiar de cardiopatia prematura; e os fatores potencialmente modificáveis como tabagismo, pressão sanguínea elevada, nível sanguíneo elevado de colesterol, diabetes, obesidade, sedentarismo e fatores psicológicos.

À propósito destes fatores de risco, diversos autores são unânimes em afirmar que aquele que se reveste de importante significado, pela possibilidade de abordagem é a hipertensão arterial (Baise et.al., 1995; Cury Jr, 1996 ; Santello, Krasilsic e Mion, 1996).

A hipertensão arterial é uma doença crônica que se caracteriza pelo aumento dos valores da pressão sistólica e/ou diastólica, afetando cerca de $20 \%$ da população mundial adulta (Mion Jr e Tinucci, 
1991) . No Brasil, embora inexistam estudos intensos, Araújo (1999) afirma que a estimativa é de que existam quase vinte milhões de pessoas com esta alteração.

Diversos autores indicam abordagens que podem ser desenvolvidas visando atingir os pacientes hipertensos, na tentativa de sua adesão ao tratamento e consequente controle da doença( Cury Jr,1996; Santello, Krasilsic e Mion, 1996). Neste contexto, Cury Jr (1996) afirmou que " a abordagem do paciente hipertenso deixa, portanto, de ser da competência de uma única especialidade, e numa visão mais ampla, até mesmo de um único profissional".

O enfermeiro como profissional de saúde responsável pela assistência preventiva e cuidativa necessita estar preparado para assistir a esta clientela específica, direcionando-a para o auto-cuidado, objetivando o controle da hipertensão e consequente melhoria da qualidade de vida . E qualidade de vida hoje é um " indicador competente do resultado dos serviços de saúde prestados ao cliente" (Cianciarullo, 1998).

A responsabilidade do enfermeiro na promoção, proteção e recuperação da saúde do individuo, família e comunidade, torna-o peça fundamental na somatória de esforços para atingir a meta de saúde para todos. $\dot{E}$ o enfermeiro que deve como agente de mudanças trabalhar para "adaptar a 
organização, a gestão, a esfera de ação e a prestação da atenção à saúde às características sociais, econômicas, educacionais e culturais da comunidade e aos recursos desta". Deve ainda desenvolver modelos de serviços que permitam aplicar outros métodos na atenção primária de saúde visando equilibrar custos e eficiência (OMS, 1981).

Processo de enfermagem é o método utilizado pelo enfermeiro para planejar e implementar a assistência de enfermagem. Segundo Horta (1979), "é a dinâmica das ações sistematizadas e interrelacionadas, visando a assistência ao ser humano. Caracteriza-se pelo inter-relacionamento e dinamismo de suas fases ou passos". Este processo é então distribuido em seis fases: histórico, diagnóstico, plano assistencial, prescrição, evolução e prognóstico.

Segundo Cruz (1993), ao abordar o processo de enfermagem, " existe uma tendência mundial em estabelecer como tripé da prática profissional o diagnóstico, as prescrições e os resultados destas prescrições".

Para Gordon,(1994), “o diagnóstico de enfermagem ou diagnóstico clínico feito por enfermeiros, descreve problemas de saúde reais ou potenciais, os quais os enfermeiros em razão de sua formação e experiência são capacitados e autorizados a dar tratamento". 
Acreditamos baseados em nossa experiência profissional e no estudo da literatura de enfermagem mundial que a necessidade do enfermeiro estar habilitado a diagnosticar, prescrever ações e avaliá-las é o meio pelo qual a enfermagem vai poder firmar-se cada vez mais como uma ciência cuidativa, diferenciando-a das outras profissões da área da saúde.

Temos vivenciado no ensino da prática da disciplina Administração aplicada à Enfermagem, tanto em nivel de Graduação como em Pós-Graduação Senso-Lato (Carmagnani et al., 1996), a experiência de utilizar a fase de diagnóstico de enfermagem na Sistematização da Assistência de Enfermagem como uma ferramenta necessária para o gerenciamento juntamente com os recursos físicos, financeiros, humanos materiais e os de informação. Consideramos que o enfermeiro como responsável pelo gerenciamento da assistência de enfermagem dos pacientes sob seus cuidados deve utilizar um planejamento adequado para propor suas açōes e o diagnóstico constitui-se em fase indispensável nesse contexto.

Todavia no Brasil ainda é necessário que os enfermeiros sejam preparados para diagnosticar, uma vez que ainda não existe consenso sobre seu ensino em nível de graduação, e muitas escolas não o incluem em seus planos de curso. E mesmo na pós-graduação, onde muitas pesquisas já foram e estão sendo desenvolvidas nesta área, ainda se fazem 
necessários mais estudos que levem a cabo a tarefa de testar e aprimorar novos modelos para subsidiar esta prática em nosso meio.

\subsection{CONSIDERAÇÕES SOBRE A HIPERTENSÃO ARTERIAL}

A hipertensão arterial é uma doença crônica e pode ser definida como pressão sanguínea arterial elevada (Oparil, 1993) e considerada como uma desordem hemodinâmica caracterizada não apenas por um aumento da pressão arterial, mas ainda na resistência periférica total, refletindo em uma redução do calibre das artérias (Safar e Frohlich, 1995).

Para Esteves et al.(1995), a hipertensão arterial permanece como uma das doenças de maior prevalência em nosso meio, e suas conseqüências sistêmicas representam uma grande preocupação em termos de saúde pública.

Oparil (1993) relata que a hipertensão arterial é o distúrbio cardiovascular mais prevalente nos Estados Unidos, afetando mais de 60 milhöes de norte-americanos, e que apesar da crescente conscientização por parte das pessoas, ainda mais da metade da população com mais de 60 anos e quase $40 \%$ da população adulta negra tem hipertensão. 
Medel (1997) ao analisar a incidência desta patologia no Chile, afirma que entre $10-20 \%$ da população chilena tem hipertensão.

O Ministério da Saúde (Brasil , 1993) ao propor medidas para o controle da hipertensão, enfatizou que ela constitui-se num dos mais graves problemas de saúde pública, afetando cerca de 20 milhões de indivíduos acima dos vinte anos. Labbadia e Cury Jr (1997) afirmam que no Brasil se pode "estimar em torno de 15 a $20 \%$ de nossa população adulta a prevalência da hipertensão arterial, algo em torno de 20 milhões de pessoas portadoras da doença, cuja prevalência nas regiōes urbanas é mais significanten.

Ribeiro et al. (1981,) e Lolio (1990,) citados por Araújo (1999, p.34-35) desenvolveram trabalhos em São Paulo e no Rio Grande do Sul, onde foram encontrados taxa de prevalência de hipertensão de $18,1 \%$ nos homens e $6,6 \%$ nas mulheres no primeiro e em $11 \%$ da população no segundo.

Baise et al. (1995) ao realizarem um estudo aleatório num serviço de pronto atendimento hospitalar na zona sul da cidade de São Paulo, encontraram a prevalência de $38,8 \%$ de hipertensão arterial nesta população, com predomínio no sexo masculino.

Cury Jr (1996) alerta que o maior problema da hipertensão arterial é que grande parte das pessoas hipertensas não sabem que o são e 
não fazem portanto o tratamento adequado e por outro lado metade dos que procuram atendimento, não seguem as recomendações de forma adequada. Esses dados são corroborados por Medel (1997), que relatando estudos feitos no Chile mostraram que cerca de $1 / 3$ dos hipertensos urbanos e mais da metade dos rurais não tinham conhecimento da doença e mesmo dos que conheciam sua condição, apenas $35,6 \%$ dos urbanos e $26,1 \%$ dos rurais estava em tratamento.

Por ser uma doença na maioria das vezes de caráter assintomático, o paciente só percebe alteraçōes quando existem órgãos comprometidos, ou vai a uma consulta médica por outra razão. Os sintomas frequentemente relatados são a cefaléia occipital matinal, escotomas tontura, rubor facial, epistaxe e fadiga ( Castro, Costa e Luna , 1998 ).

As principais complicações incluem insuficiência cardiaca, acidentes vasculares cerebrais e periféricos e insuficiência renal. $O$ aumento nos valores da pressão arterial, têm contribuído para o aumento do risco de morte por doenças coronárias e choque ( Antikainen, Jousilahti e Tuomilehto, 1998 ), de evolução para insuficiência renal crônica (Klag et. al.,1996 ) e risco para acidentes vasculares ( Staessen, 1997).

Kiiskinen et al.(1998) ao analisarem os efeitos da hipertensão, encontraram a redução de 2,7 anos de vida perdidos para 
homens e 2 para mulheres, e 2,6 anos anos de trabalho perdidos para homens e 2,2 para mulheres, em estudo realizado na Finlândia.

A hipertensão arterial pode ser classificada como essencial, primária ou idiopática, quando ela não tem uma causa conhecida, e é a que acomete a maior parte das pessoas, em cerca de $90-95 \%$. A forma secundária é a que tem causa conhecida, podendo ser por problemas renais, endócrinos, neurológicos, gravidez, entre outras (Oparil, 1993 ). Esta mesma autora cita ainda a hipertensão do avental branco, que diz respeito à elevação da pressão arterial do paciente quando em situação de stress e ansiedade em razão de consulta médica.

O diagnóstico em adultos é baseado na medida da pressão arterial obtida em pelo menos duas consultas, sendo considerada hipertensão arterial quando os valores médios da pressão arterial sistólica (PAS) estão acima de $140 \mathrm{mmHg}$ e da pressão arterial diastólica (PAD) em $90 \mathrm{mmHg}$ ou mais (Oparil, 1993; II Consenso Brasileiro de Hipertensão Arterial, 1994 ; Araújo,1999 ). Além disso, uma anamnese e um exame físico apurados podem identificar outras alteraçōes e fatores de risco, indicando a necessidade de exames subsidiários( Kaplan, 1999 ).

Araújo (1999) cita ainda o critério de classificação usado pela Organização Mundial de Saúde para classificar a hipertensão: 


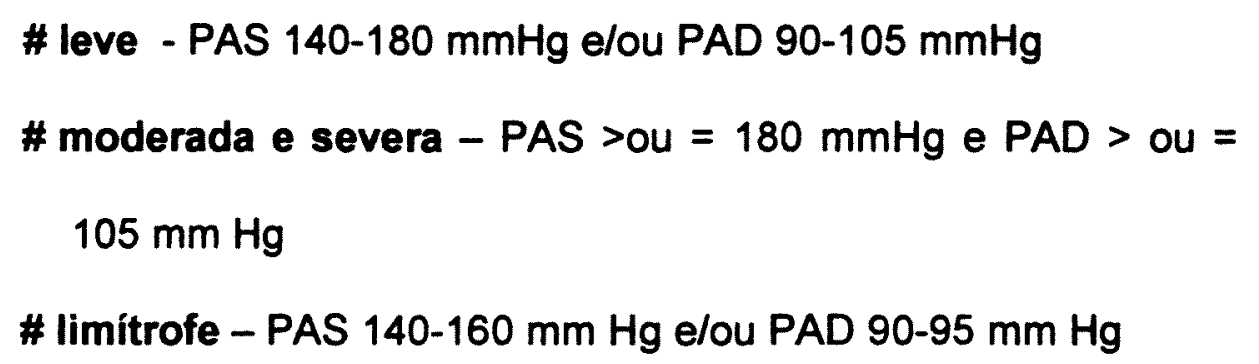

Fuchs et al. ( 1997 ), sugerem a medição da pressão arterial pelo menos 5 a 6 vezes em até três consultas médicas, para 0 estabelecimento do diagnóstico de hipertensão arterial.

A verificação da pressão arterial reveste-se de importância principalmente se considerarmos que pacientes hipertensos podem não ser tratados e outros tratados sem necessidade, se esta verificação não estiver adequada. Normalmente é utilizado o método indireto de verificação, com o auxilio de um esfigmomanômetro aneróide ou com coluna de mercúrio e um estetoscópio.

Estudos de Arcuri ( 1985,1989) e Araújo, Arcuri e Martins (1998) enfatizam que esta verificação é ação de enfermagem e alertam para a necessidade de se praticar esta medição utilizando instrumental adequado, como esfigmomanômetros constantemente calibrados com largura correta do manguito, sendo este o ideal $20 \%$ maior do que a circunferência do braço, e o uso correto do estetoscópio. Tal cuidado deve-se à possibilidade grande de mediçōes erradas por instrumental inadequado, que podem muitas vezes alterar os valores normais da pressão arterial. 
A publicação do Comitê americano para o tratamento da Hipertensão Arterial (The Sixth Report of the Joint National Committee on Detection, Evaluation and Treatment of High Blood Pressure, 1997) estabelece tres grupos de risco nos quais o paciente hipertenso pode ser enquadrado a fim de que possa ter um tratamento adequado. Para determinar-se o risco para a doença cardiovascular, deve-se levar em conta os valores da pressão arterial, eventuais lesões em órgãos vitais e presença de múltiplos fatores de risco.

O tratamento da hipertensão arterial divide-se entre o uso ou não de medicamentos. A base do tratamento não farmacológico é a mudança no estilo de vida do paciente, sendo recomendada inclusive para os que fazem uso de medicamentos. Paffensbarger Jr e Lee, (1998 ) afirmam que estilos de vida saudáveis "podem prevenir o aparecimento da hipertensão e afetar de forma benéfica os niveis de pressão arterial entre individuos hipertensos". Entre as mudanças mais indicadas estão a redução de peso, parar de fumar e beber álcool, iniciar dieta alimentar com baixa quantidade de sal e de gorduras, programa de exercícios físicos e redução do nivel de stress ( Castro, Costa e Luna, 1998 ). A estes, Oparil (1993) acrescenta a suplementação de cálcio e potássio na dieta e a restrição da cafeína.

As terapias medicamentosas mais utilizadas para os pacientes portadores de hipertensão arterial são com os anti-hipertensivos 
e os diuréticos, conforme mostram as Tabelas 1 e 2. Estes podem ser usados em monoterapia ou com associações ( Ribeiro, 1997 ; Castro et al.,1998).Todos os medicamentos possuem reações adversas que podem dificultar o cumprimento do tratamento proposto, uma vez que o paciente entende que piorou ao invés de melhorar, e pára de tomá-lo. É fundamental que os profissionais conheçam estas reações para que possam orientar o paciente e assim contribuir para a melhor adesão deste ao tratamento.

Tabela 1 - Anti-hipertensivos mais utilizados no tratamento da hipertensão arterial. São Paulo, 1999.

\begin{tabular}{|c|c|c|}
\hline $\begin{array}{l}\text { Grupo } \\
\text { Farmacológico } \\
\end{array}$ & $\begin{array}{l}\text { Nome } \\
\text { Genérico }\end{array}$ & Reações Adversas \\
\hline Alfa bloqueadores & Prazosina & Hipotensão, cefaléia, retençäo hídrica \\
\hline Betabloqueadores & $\begin{array}{l}\text { Atenolol } \\
\text { Propanolol }\end{array}$ & Bradicardia, insônia, fadiga, disfunção sexual \\
\hline $\begin{array}{l}\text { Inibidores da Enzi- } \\
\text { ma Conversora da } \\
\text { Angiotensina-ECA }\end{array}$ & $\begin{array}{l}\text { Captopril } \\
\text { Enalapril } \\
\text { Lisinopril }\end{array}$ & Tosse seca contínua \\
\hline $\begin{array}{|ll|}\text { Antagonistas } & \text { do } \\
\text { receptor } & \text { da } \\
\text { Angiotensina II } & \\
\end{array}$ & Losartano & Enupção cutânea, diarréia, cólica \\
\hline $\begin{array}{l}\text { Bloqueadores dos } \\
\text { canais de cálcio }\end{array}$ & $\begin{array}{l}\text { Amlodipina } \\
\text { Nifedipina } \\
\text { Diltiazem } \\
\text { Verapamil }\end{array}$ & $\begin{array}{l}\text { Cefaléia, hipotensäo, bradicardia, constipação, } \\
\text { tonteira }\end{array}$ \\
\hline $\begin{array}{l}\text { Agonistas alfa } 2 \text { de } \\
\text { açäo central }\end{array}$ & $\begin{array}{l}\text { Clonidina } \\
\text { Metildopa }\end{array}$ & Edema, impotência, disfunção sexual \\
\hline \begin{tabular}{|l|} 
Antagonistas \\
adrenérgicos de \\
ação peniférica
\end{tabular} & $\begin{array}{l}\text { Hidralazina } \\
\text { Minoxidil } \\
\text { Reserpina } \\
\end{array}$ & Hipertricose \\
\hline
\end{tabular}

Fonte: Korolkovas, 1998. 
Tabela 2 - Diuréticos mais utilizados no tratamento da hipertensão arterial. São Paulo, 1999.

\begin{tabular}{|c|c|c|}
\hline \begin{tabular}{|l|} 
Grupo \\
Farmacológico \\
\end{tabular} & \begin{tabular}{|l|}
$\begin{array}{l}\text { Nome } \\
\text { Genérico }\end{array}$ \\
\end{tabular} & Reacões Adversas \\
\hline $\begin{array}{l}\text { Tiazidas } \\
\text { compostos } \\
\text { relacionados }\end{array}$ & $\begin{array}{l}\text { Clortalidona } \\
\text { Hidroclorotiazida }\end{array}$ & $\begin{array}{l}\text { Hipopotassemia, hipocalemia, aumento } \\
\text { do colesterol e dos triglicérides, } \\
\text { intolerância à glicose impotência , } \\
\text { diminuição do libido, cäimbras } \\
\text { musculares, fadiga e disfunção sexual }\end{array}$ \\
\hline $\begin{array}{l}\text { Diuréticos } \\
\text { Alça }\end{array}$ & $\begin{array}{l}\text { Furosemida } \\
\text { Bumetanida }\end{array}$ & $\begin{array}{l}\text { Hipopotassemia, hipocalemia, aumento } \\
\text { do colesterol e dos triglicérides, } \\
\text { intolerância à glicose, impotência , } \\
\text { diminuição do libido, cãimbras } \\
\text { musculares, fadiga , disfunção sexual, } \\
\text { vertigem, visão obscurecida e anorexia }\end{array}$ \\
\hline \begin{tabular}{|l|} 
Diuréticos \\
conservantes de \\
potássio
\end{tabular} & $\begin{array}{l}\text { Espironolactona } \\
\text { Amilorida } \\
\text { Triantereno }\end{array}$ & 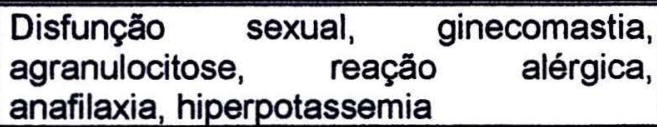 \\
\hline
\end{tabular}

Fonte: Korolkovas, 1998.

As medidas terapêuticas apresentam-se eficazes se seguidas corretamente, todavia para que estas sejam realmente eficientes é fundamental que o paciente tenha confiança no tratamento e se proponha a segui-lo. " Infelizmente cerca de $50 \%$ dos pacientes que iniciam o tratamento acabam por interrompê-lo ou não o fazem corretamente" ( Cury Jr, 1996).

"Compliance" é o termo que os autores de língua inglesa utilizam para o estudo do relacionamento médico-paciente e todos os aspectos que influenciam a confiança no tratamento e o correto cumprimento da prescrição médica. Observância, obediência, adesão e aderência são tentativas de tradução para o portugues, do termo "compliance" ( Paulo e Zanini, 1997 ). 
Guerra, Araújo (1999) enfatizam em estudo realizado em Fortaleza, Ceará, que "a problemática da não aderência ao tratamento da hipertensão arterial é bastante complexa, pois..., trata-se de uma situação que envolve aspectos biológicos, psicológicos, culturais e sociais".

O trabalho da equipe multiprofissional junto aos pacientes tem sido destacado como muito importante para que a adesão destes ao tratamento possa ocorrer. Medel (1997) encontrou alta aderência ao tratamento em cerca de $62,50 \%$ de pacientes hipertensos num estudo no Chile, e relacionou esta alta aderência com modalidades de educação em saúde, educação recebida pelo paciente da equipe de saúde e a adaptação daqueles à uma enfermidade crônica. Paulo e Zanini ( 1997 ), destacam a importância de enfermeiros, assistentes sociais e farmacêuticos, para juntamente com médicos participarem da instrução e seguimento de pacientes no atendimento ambulatorial de hipertensos pois existem provas de que esta atuação conjunta eleva o "compliance" em comparação à atuação solitária do médico. Corroborando com estes autores, Labbadia e Cury Jr (1997), relatam experiência com equipe multiprofissional composta por médico, enfermeira, psicóloga e nutricionista, no atendimento de hipertensos, com resultados positivos.

Os pacientes portadores de hipertensão arterial necessitam conhecer a sua patologia, seus riscos, seu tratamento, a fim de poderem 
se auto-cuidar. O grande desafio para os profissionais de saúde, notadamente para os enfermeiros, é poder atender a essas necessidades da clientela por meio de programas de orientação e acompanhamento, objetivando a adesão do paciente ao tratamento proposto e conseqüente controle da patologia.

\subsection{CONSIDERAÇÕES SOBRE DIAGNÓSTICOS E INTERVENÇÕES DE ENFERMAGEM}

O enfermeiro ao planejar a assistência de enfermagem para a sua clientela utiliza o Processo de Enfermagem para de forma ordenada e científica organizar suas açōes e atingir seus objetivos (George, et. al.,1993).

Barros (1998),considera que "o processo de enfermagem é um método através do qual a estrutura onde as necessidades individualizadas do cliente, familiares e comunidade possam ser satisfeitas é aplicada à prática de enfermagem “. Essa mesma autora enfatiza ainda que "trata-se de uma abordagem deliberativa de solução de problemas, que exige habilidades cognitivas, técnicas e interpessoais e está voltada à satisfação do cliente/familia."

Horta (1979), precursora de um modelo no Brasil baseado 
na Teoria das Necessidades Humanas Básicas, propõe fases para ação do enfermeiro, que são: o histórico de enfermagem, o diagnóstico de enfermagem, um plano assistencial, um plano diário de cuidados, a evolução, e o prognóstico. Este modelo, norteou o ensino da assistência de enfermagem desde a década de setenta, constituindo-se num referencial para a enfermeira brasileira.

O modelo de Horta requer segundo palavras de Fugulin et.al (1998), " o raciocínio e a utilização permanente do saber, do fazer e dos dados do paciente/cliente, num continuo fluir de informaçōes, coordenadas pelo enfermeiro e transformadas em açōes".

Cruz ( 1993 ) destaca que apesar da forte influência que este modelo teve para as enfermeiras em nosso pais, é consenso que a fase de diagnosticar foi esquecida ou colocada como sem maior importância ao se aplicar o processo de enfermagem na prática. Estudos que constataram essa dissociação foram desenvolvidos por Campedelli e Gaidzinski (1987) e Maria et.al. (1987). Todavia Cruz (1995) ressalta a contribuição positiva para a autonomia do enfermeiro que os diagnósticos de enfermagem podem trazer, uma vez que estes referenciam as intervençōes de enfermagem, exigem um julgamento, favorecendo a exposição das ações do enfermeiro. 
O diagnóstico no entender de Carmagnani (1999), pode ser abordado como um resultado, ou seja, a segunda etapa do processo de enfermagem, ou como um processo complexo de decisões que exige um corpo de conhecimentos especificos e habilidades cognitivas.

"Estruturalmente os diagnósticos de enfermagem são compostos por : título, definição, características definidoras e fatores relacionados. O título traz sempre um qualificador preciso como alterado, prejudicado ou ineficaz. A definição deve ser coerente com o título e as características definidoras. As caracteristicas definidoras nos diagnósticos reais referem-se a sinais e sintomas, que podem ser maiores, menores ou críticas. Quando uma característica é chamada de crítica deve estar presente para validação do diagnóstico. Os fatores relacionados nos diagnósticos reais são os fatores etiológicos ou contribuintes. Os fatores relacionados são muito importantes o planejamento das intervenções de enfermagem uma vez que determinam a causa do fenômeno( Carmagnani, 1999).

O enfermeiro ao prestar a assistência cuidativa que caracteriza sua atuação profissional, tem encontrado dificuldades em efetuar o registro de suas ações pela falta de uma terminologia especifica que descreva de modo preciso os problemas do paciente e a própria intervenção do enfermeiro. A nominação dos problemas necessita de uma uniformidade 
de linguagem para que sejam possíveis comparações, pesquisas , avaliações, cobranças e o desenvolvimento de sistemas informatizados, visando a compreensão do seu significado e conseqüente determinação das ações de enfermagem.

A necessidade da uniformização da linguagem desencadeou no Conselho Internacional de Enfermeiros - ICN, um movimento para se elaborar um sistema de classificação internacional para a prática de enfermagem, que já identificou catorze taxonomias. Estas nomenclaturas classificam os problemas ou diagnósticos, as intervenções e os resultados que se esperam, em diferentes idiomas, voltados para diferentes clientelas (ICN,1993 ; Affara e Oguisso, 1995; Clark, 1996; Maria, 1998 ; Nielsen e Mortesen, 1996,1998).

O esforço de enfermeiras americanas e canadenses, desde a década de setenta, em procurar unificar a terminologia utilizada pela enfermagem resultou na criação em 1982 da North American Nursing Diagnosis Association - NANDA, para sistematizar os avanços nesta área. Esta associação estruturou uma taxonomia de enfermagem com base na Teoria do Homem Unitário de Martha Rogers. Esta taxonomia tem sido revista e atualizada nas conferências bianuais que mobilizam enfermeiros de diversos paises. Os diagnósticos de enfermagem propostos tem como base nove padrões de resposta humana (Trocar, Comunicar, Relacionar, 
Valorizar, Escolher, Mover, Perceber, Conhecer, Sentir), constituindo-se na taxonomia I posteriormente revisada , (Cruz ,Cruz e Secaf, 1991; Gordon, 1994; Nanda, 1992-1993). Esta classificação foi traduzida para nosso meio pelo trabalho de Nóbrega e Garcia (1994) e resultou na fonte de muitos trabalhos para o aprimoramento dos diagnósticos de enfermagem na prática diária do enfermeiro.

Em estudos da enfermagem mundial, e de modo especial da americana (Karsbmer,1991; lyer, Taptich e Bernocchi-Losey, 1993; Gordon,1994; Sparks e Taylor, 1995), existe a evidente necessidade de se melhorar os conhecimentos na área de diagnóstico de enfermagem, considerada a fase de maior dificuldade para a elaboração de um planejamento da assistência ao cliente e familia. Autores europeus também confirmam esta preocupação (Doenges e Moorhouse, 1992).

Tem sido crescente o número de trabalhos desenvolvidos por enfermeiras brasileiras que relatam o uso dos diagnósticos de enfermagem como referencial para sistematizar a assistência, confirmando a tendência mundial e estabelecendo cada vez de maneira mais concreta o àmbito de ação do enfermeiro. Cruz (1989) elaborou diagnósticos de enfermagem de pacientes portadores de cardiopatia chagásica crônica. Cruz, (1993) caracterizou os diagnósticos de enfermagem em clientes com hipertensão arterial, fazendo sua validação. Pelá , Jesus e Carvalho, em 
1994 analisaram as categorias diagnósticas da sexualidade., Robazzi et.al. (1995) estudaram os diagnósticos de enfermagem de coletores de lixo, Carmagnani, 1999, propõe diagnósticos para pacientes laringectomizados, entre muitos outros.

Todos estes estudos tem em comum o uso da taxonomia da Nanda para caracterizar os diagnósticos de enfermagem e esta parece ser o referencial mais utilizado em nosso país.

O crescente interesse pelo uso deste referencial para a prestação da assistência, tem resultado em um significativo aumento de traduçōes sobre o tema (lyer, Taptich e Bernocchi-Losey, 1993; Carpenito,1997,1998; Doenges e Moorhouse, 1999), o que certamente constitui-se em um auxílio para aquelas enfermeiras que o utilizam.

Apesar de serem considerados elementos importantes para - planejamento da assistência de enfermagem, as intervenções e os resultados também ainda são objeto de poucas pesquisas em nosso meio. Essa necessidade fica contudo evidente em publicaçōes americanas que já classificam estas fases e que tem servido de guia para outros paises.

Da mesma maneira que os diagnósticos, as açōes de enfermagem a serem direcionadas à clientela e os seus resultados 
necessitam de uniformização a fim de se constituirem em referencial do corpo de conhecimentos da profissão. A proposta de um grupo de enfermeiros americanos da Universidade de lowa conhecida como Nursing Interventions Classification - NIC (McCloskey e Bulechek, 1996), reconhece essa necessidade e oferece este corpo de ações, classificando as intervenções feitas na prática diária do enfermeiro. Esta classificação contém 433 intervenções e foi estruturada para ser usada com várias classificações de diagnósticos, incluindo a da Nanda.

Outro grupo da mesma Universidade de lowa organizou ainda uma classificação para os resultados das intervenções - o NOC Nursing Outcomes Classification (Johnson e Maas, 1997). Esta classificação contém 190 indicações específicas para mensurar os efeitos das intervençōes (Johnson e Maas, 1998).

Estas classificaçōes são importantes para a documentação das ações dos enfermeiros e facilitar a uniformidade da linguagem. Todavia ainda não estão traduzidas para $\circ$ português, razão pela qual existe dificuldade em se utilizar este referencial. Acreditamos que mais estudos devam ser desenvolvidos objetivando a aquisição de maiores conhecimentos sobre a utilização destes modelos na prática assistencial.

A fase seqüencial à da elaboração dos diagnósticos de 
enfermagem é a da definição das intervençōes que serão propostas ao cliente com vistas a atingir os resultados esperados.

Mc Closkey e Bullechek (1996) definem as intervençōes de enfermagem como sendo " cada tratamento baseado no julgamento clínico e no conhecimento, que a enfermeira executa para intensificar os resultados do cliente."

Ainda para aquelas autoras as intervenções incluem cuidados diretos e indiretos, ações oriundas das prescrições médicas, de enfermagem e de outros profissionais que são executados pelo enfermeiro.

Iyer, Taptich e Bernocchi-Losey (1993), relatam que o êxito nas intervenções dependem da habilidade da enfermeira em gerar e escolher alternativas que tenham maior probabilidade de eficácia e que para exercitar a capacidade de propor e escolher alternativas deve-se usar técnicas como o brainstorming e a formulação de hipóteses.

A proposta apresentada pelo grupo de trabalho da Universidade de lowa, com os trabalhos de Mc Closkey e Bullechek (1996), apresenta uma taxonomia para as intervenções - NIC - já citado, que inclue ações para problemas fisiológicos e psicológicos, para tratamento de 
doenças, e para a promoção da saúde de indivíduos, familias e comunidades. Ela está organizada em três níveis de taxonomia . O nível mais abstrato constitui-se de domínios, numerados de 1 a 6 . Cada domínio inclui classes ou grupos de intervenções.

Esta proposta parece atender as necessidades dos enfermeiros, mas não existem ainda estudos sobre a utilização desta classificação em nosso país. A maior dificuldade para seu uso é a falta de tradução para o português, em razão da necessidade de adequação de termos.

Isto posto, optamos por não utilizar classificação para propormos as intervençōes ao cliente hipertenso, e apenas nos basearmos na nossa experiência anterior, no relato de especialistas e em referencial bibliográfico.

Compartilhamos das crenças de diversos autores citados sobre a importância de se oferecer uma assistência de enfermagem com qualidade para os nossos clientes e que para isso uma sistematização deve ser implementada com as fases de levantamento de dados, diagnóstico, prescrição e evolução. O levantamento de dados deve reunir informações confiáveis e suficientes para a elaboração do diagnóstico de enfermagem. A prescrição das intervençōes deve objetivar resultados 
concretos e mensuráveis pela evolução constante do paciente. Todavia acreditamos que como escreveu Cianciarullo (1997), que embora tenha direcionado uma nova forma de atuação do enfermeiro com competência, tanto o uso do processo como dos diagnósticos, "não asseguram a qualidade da assistência”. É necessário que todo o processo seja controlado e avaliado constantemente para que as possiveis distorções sejam identificadas rapidamente e correções possam ser efetuadas, pois é responsabilidade do enfermeiro assegurar a qualidade na assistência de enfermagem prestada ao cliente.

Procuramos desenvolver este estudo com pacientes hipertensos tratados em ambulatório a fim de, a partir de uma proposta de identificação de diagnósticos de enfermagem pela taxonomia da Nanda, poder propor intervenções passíveis de serem realizadas pelo enfermeiro, como uma forma de contribuir para a discussão de novos modelos assistenciais. 


\section{OBJETIVOS DO ESTUDO}

2.1. Identificar os diagnósticos de enfermagem segundo a Taxonomia I da North American Nursing Diagnosis Association - NANDA apresentados por pacientes adultos portadores de hipertensão arterial em acompanhamento ambulatorial;

2.2. Relacionar os diagnósticos identificados à variáveis demográficas , sinais e sintomas, medicamentos em uso e fatores de risco; e

2.3. Propor intervenções de enfermagem. 


\section{METODOLOGIA}

Esta pesquisa caracterizou-se como um estudo exploratório com pacientes adultos portadores de hipertensão arterial em tratamento ambulatorial.

\subsection{POPULAÇÃo E AMOSTRA}

A população constituiu-se em pacientes atendidos no Centro de Saúde - Escola da Universidade de Santo Amaro, matriculados no Grupo de Hipertensão Arterial.

A amostra constituiu-se de 50 pacientes adultos matriculados no serviço e que já tivessem passado pela primeira consulta anteriormente a fim de facilitar $\mathrm{o}$ acesso a dados de prontuário.

\subsection{LOCAL DO ESTUDO}

O Centro de Saúde Escola da Universidade de Santo Amaro está localizado dentro do próprio campus I, na zona sul da cidade de São Paulo e atende pacientes de diferentes especialidades médicas, em regime de consulta bimensal. As consultas para os pacientes hipertensos ocorrem sempre as terças-feiras das $11: 30$ às 13:30 horas, com agendamento prévio e são feitas feitas por dois médicos clínicos. 
Neste Centro de Saúde existe uma equipe multiprofissional uante formada por médicos, enfermeira, nutricionista, odontólogo, assistente social, psicóloga, terapeuta ocupacional e educadora em saúde. A linha de trabalho desenvolvida privilegia a prevenção por meio da educação e os pacientes são convidados a participar dos muitos grupos de orientação, como o de adolescentes, hipertensos, diabéticos, entre outros.

$\mathrm{Na}$ área da enfermagem não existe a consulta como forma sistematizada de trabalho, mas a enfermeira atua na área assistencial e educativa.

\subsection{COLETA DE DADOS}

Foi feita solicitação para a coleta de dados junto à Diretoria do Centro de Saúde-Escola, tendo sido autorizada (Anexo I). Não foi feito encaminhamento à Comissão de Ética pois à época da coleta de dados esta ainda não havia sido formada na Universidade.

A coleta de dados foi realizada pela própria pesquisadora com a ajuda de enfermeiros docentes e assistenciais da própria instituição, no período de outubro de 1997 a outubro de 1998. Não foram coletados dados nos meses de férias (dezembro, julho, janeiro e fevereiro). 
A pesquisadora previamente ao horário das consultas consultava os prontuários dos pacientes que seriam atendidos no dia mediante a agenda prevista e coletava os dados de identificação. Cerca de quarenta minutos antes do horário da primeira consulta agendada a pesquisadora começava a coleta de dados, seguindo a ordem do próprio agendamento. Conseguiu-se atender à cada dia de coleta no máximo cinco pacientes pois as consultas médicas eram muito mais rápidas e o paciente ia embora imediatamente após, não sendo possivel consultá-lo. Outra razão é que na maioria dos dias a pesquisadora estava sozinha. Houve ainda dificuldade dos pacientes entenderem a atuação da enfermeira principalmente na consulta de enfermagem e por isso muitas vezes este verbalizava o medo de nossa entrevista se prolongar e ele perder a consulta médica.

A coleta de dados consistiu numa abordagem inicial ao paciente que estava aguardando a consulta médica, informando-o sobre a pesquisa e sobre seus direitos, solicitando a autorização do mesmo para a realização. Dois pacientes recusaram-se a participar, não justificando suas decisōes. O paciente era então encaminhado ao consultório para assegurar sua privacidade, onde se procedia a consulta de enfermagem (entrevista e exame físico). 


\subsection{INSTRUMENTO DA PESQUISA}

$O$ instrumento utilizado foi o Histórico de Enfermagem modificado do proposto por Cruz (1993) (anexo II). As modificações dizem respeito à adequação deste após pré-teste, e consistiram de retirada da parte auto-aplicável, uma vez que a população do estudo tinha baixa escolaridade, sendo dificultado o auto-preenchimento. 0 conteúdo desta parte foi realocado no questionário. Este modelo segundo Cruz (1993) tem seu foco de atenção no cliente e suas potencialidades para se cuidar, numa abordagem de auto-cuidado, contemplada na teoria do déficit de autocuidado de Orem (1985).

No instrumento são destacados duas partes:

\section{I - Entrevista de Enfermagem}

A parte inicial relacionava - se a dados de identificação do paciente, como nome, endereço, idade, sexo, escolaridade, profissão, ocupação, se trabalha atualmente e faixa salarial.

A parte I constou de blocos de 46 perguntas abertas ou não, orientados pelos nove Padrões de Respostas Humanas que classificam os Diagnósticos de Enfermagem pela Taxonomia da Nanda (Anexo II), a fim de facilitar a identificação posterior destes. Assim, registramos para : 


\section{Padrão PERCEBER - questões de 1 a 5 \\ Padrão CONHECER - questões 6 a 15 \\ Padrão COMUNICAR - questão 16 \\ Padrão VALORIZAR - questões 17 a 20 \\ Padrão RELACIONAR - questões 21 a 26 \\ Padrão SENTIR - questōes 27 a 29 \\ Padrão ESCOLHER - questōes 30 a 31 \\ Padrão MOVER - questões 32 a 42 \\ Padrão TROCAR - questões 43 a 46}

\section{li - Exame físico direcionado para a patologia hipertensão arterial}

O Exame Físico era efetuado com o paciente sentado na cadeira, após a realização da entrevista, estando o paciente portanto descansado. A verificação da pressão arterial era efetuada conforme a técnica do manguito (Atkinson e Murray, 1989), utilizando-se esfigmomanômetro aneróide, previamente calibrado, com a braçadeira de largura aproximada a dois terços do comprimento do braço e comprimento para padrão adulto, tendo sido colocado a quatro centimetros da dobra do cotovelo. O manguito era insuflado até trinta milimetros de mercúrio acima da pressão sistólica detectada pela palpação da artéria radial. $\mathrm{O}$ valor da pressão sistólica correspondeu ao primeiro ruído de Korotkoff e o valor da pressão diastólica correspondeu ao quinto ruído. Após a verificação da pressão arterial, ainda 
com o paciente sentado, verificava-se o pulso radial e a respiração. A seguir o paciente era pesado e medida a sua altura em balança antopométrica de adulto. A consulta de enfermagem demora em média 25 minutos para ser realizada, sendo realizado o preenchimento dos impressos concomitantemente.

\subsection{PRÉ-TESTE}

Um pré-teste do instrumento foi aplicado pela pesquisadora nos meses de março e abril, em 8 pacientes (Anexo V). Foram detectados erros de interpretação por parte dos pacientes na parte I que se referia a questionário auto-aplicado a ser preenchido pelos mesmos, tendo sido necessário a reformulação deste, retirando-se esta parte. Foram ainda alterados a sequências de ítens a serem perguntados para facilitar a proposição dos diagnósticos.

\subsection{ELABORAÇÃO DOS DIAGNÓSTICOS}

As fichas com os dados sobre os pacientes foram então lidas e analisadas pelo pesquisador que após julgamento identificou os diagnósticos de enfermagem face aos problemas apresentados, registrandoos no impresso próprio (anexo IV), utilizando o referencial da Taxonomia I revisada da Nanda (1994) (Anexo II). Optou-se pelo uso deste referencial 
uma vez que é ainda o mais conhecido em nosso meio, apesar de em ingles já existir versão revisada (Nanda, 1997) .Foram listados 31 Diagnósticos de Enfermagem nesta primeira fase.

Os diagnósticos foram a seguir submetidos à análise e apuração. Os especialistas escolhidos foram dois enfermeiros formados há mais de 15 anos, atuando no ensino e na assistência, com conhecimento clínico, participantes de grupo de estudos de diagnóstico de enfermagem e com pesquisas na área de diagnóstico utilizando este referencial, ligados a um Hospital de Ensino e a uma Escola de Enfermagem. Estes analisaram todos os históricos de enfermagem e os exames físicos documentados, bem como os diagnósticos que foram propostos pela pesquisadora e fizeram as propostas de alterações nos mesmos impressos, em tinta de outra cor. Foram rejeitados 19 diagnósticos apresentados de um total de $236(8,05 \%)$ e propostos 6 diagnósticos de um total de $197(2,76 \%)$, que não haviam sido identificados.

Não foram aceitos os seguintes diagnósticos pelos juízes :

1. Disfunção Sexual - não foi aceito em 8 pacientes pois considerou-se que a idade destes também interferiria na diminuição da atividade sexual e que a verbalização dos pacientes só ocorreu após terem sido indagados e as respostas não foram enfáticas . Não foram encontrados ainda características definidoras suficientes para suportá-lo. 
2. Comunicação Alterada - não foi aceito este diagnóstico em 5 pacientes pois os juizes analisaram que as informaçōes prestadas pelo paciente eram boas, não podendo caracterizar uma alteração significativa na comunicação.

3. Comportamento para elevar nível de saúde - não houve concordância em um paciente que apresentava desejo expresso de aumentar a prática de controle de saúde sendo considerado como um comentário sobre a sua falta de cuidado até aqui, relacionado à falta de recursos materiais e deficit de conhecimento.

4.Déficit no auto cuidado: higiene corporal-foi modificada para manutenção da saúde alterada, pois o paciente apresentava outras caracteristicas definidoras que justificavam.

5.Potencial para infecção - este diagnóstico não foi aceito em um paciente, uma vez que as características definidoras e os fatores relacionados justificavam melhor o diagnóstico de proteção alterada também identificado.

6. Eliminação urinária alterada - não houve concordância em relação às características definidoras listadas, pois foi considerado que a informação prestada pelo paciente só dizia respeito à urinar demais e não à disúria e urgência para urinar, em um paciente.

7. Isolamento Social - considerou-se que não havia dados suficientes para este diagnóstico, em dois pacientes.

Os juizes propuseram ainda diagnósticos que não tinham sido elencados pela pesquisadora : 
Manutenção do lar alterado - proposto para o sujeito 48 pois não havia sido considerado pela pesquisadora dado que dizia respeito à problemas de ordem financeira e marido desempregado.

Padrão respiratório ineficaz - foi proposto para os sujeitos 2 e 36 , pois os mesmos apresentavam características de tosse, expectoração e dispnéia.

Manutenção da Saúde Alterada-não havia sido considerado pela pesquisadora dado que dizia respeito à problemas de ordem financeira e marido desempregado. Entrou em substituição à comportamento para elevar nível de saúde.

Déficit de lazer-sugeridos para os sujeitos 47 e 49 não havia sido considerado pela pesquisadora como característica definidora o desejo verbalizado de alguma atividade e de viajar.

As mudanças propostas pelos especialistas foram novamente analisadas pela pesquisadora e aceitas, tendo sido procedidas as correções pertinentes nos documentos coletados, definindo-se os diagnósticos que seriam considerados para fins deste estudo.

\subsection{TRATAMENTO ESTATÍSTICO}

Após a coleta dos dados, retirou-se das fichas de histórico de enfermagem alguns dados significativos demográficos e de interesse, como medicamentos que o paciente fazia uso, outras doenças que 
relatasse, história familiar quanto à algumas doenças, e dados do exame físico como valor da pressão arterial na consulta, olhar, movimentos e expressão do paciente, e submeteu-se à análise estatística. Foram ainda feitos cruzamentos com os 29 Diagnósticos de Enfermagem encontrados. Para o tratamento estatístico foram então nomeadas variáveis.

Foram consideradas na análise as seguintes variáveis:

- Sexo (masculino e feminino)

- Idade (em anos)

- Estado civil (casado, solteiro, viúvo, divorciado)

- Escolaridade (analfabeto,alfabetizado, $1^{\circ} \mathrm{grau}$ )

- Problemas de saúde relatados (aberta)

- Salário (não tem, menos de $1 \mathrm{sm}, 1$ a 5 sm)

- Profissão (aberta)

- Tipo de medicamento (aberta)

- Obesidade, Diabetes, Alcoolismo, Doenças cardíacas e derrame como antecedentes familiares( presentes)

- Fatores de risco do paciente, (presentes)

- Pressão arterial máxima (em $\mathrm{mmHg}$ )

- Pressão arterial mínima (em mmHg)

- Pulso

- Respiração

- Peso (em kg) 
- Altura (em m)

- Queixas verbalizadas pelo paciente(aberta)

- Olhar (sim ou não)

- Movimentos (sim ou não)

- Expressão facial (triste, angustiada ou tranqüila)

- DIAGNÓSTICOS DE ENFERMAGEM (presente ou ausente)

Para estudar a associação entre os diagnósticos e as demais variáveis, comparamos as proporções de pacientes com 0 diagnóstico entre as categorias de cada variável. Na maioria dos casos foi utilizado o Teste Exato de Fisher, uma vez que o número de observações era insuficiente para aplicação do teste Qui-quadrado. Para algumas situaçōes em que as freqüências esperadas eram superiores a 5, o teste de Fisher foi substituido pelo teste Qui-quadrado de Pearson.

Assim, foram construidas as tabelas que apresentam as freqüências (em número de pacientes e percentual relativo à categoria) e os respectivos niveis descritivos (valores de $p$ ) que correspondem às "significâncias" referentes ao teste exato de Fisher ou Qui-quadrado. Os casos em que utilizou-se o teste Qui-quadrado são indicados por asteriscos. 
arterial, pulso e respiração) apresentamos os resultados em termos de médias, medianas, desvio padrão, mínimo e máximo. O nível de significância adotado foi de $5 \%$ sendo considerados estatisticamente significantes os resultados cujos valores de $p$ foram inferiores a esse valor.

O programa utilizado para os cálculos foi o SPSS for Windows versão 6.0 e contamos com o auxílio técnico de uma estaticista com experiência na área de pesquisa em saúde. 


\section{RESULTADOS E DISCUSSÃO}

Objetivando caracterizar a amostra estudada, apresentamos a seguir para o total de pacientes, as distribuições segundo características demográficas de sexo, faixa etária, estado civil, escolaridade, situação em relação ao trabalho, faixa salarial e profissão, que podem ser visualizadas nas Tabelas 3 a 9.

T a bela 3 - D istribu ição da percentagem de pacientes segundo o sexo. São Pa ulo, 1999 .

\section{$22 \%$}

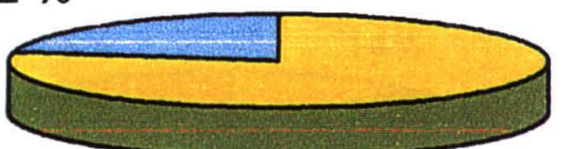

Tabela 4 - Distribuição do número de pacientes segundo a faixa etária. São Paulo, 1999.

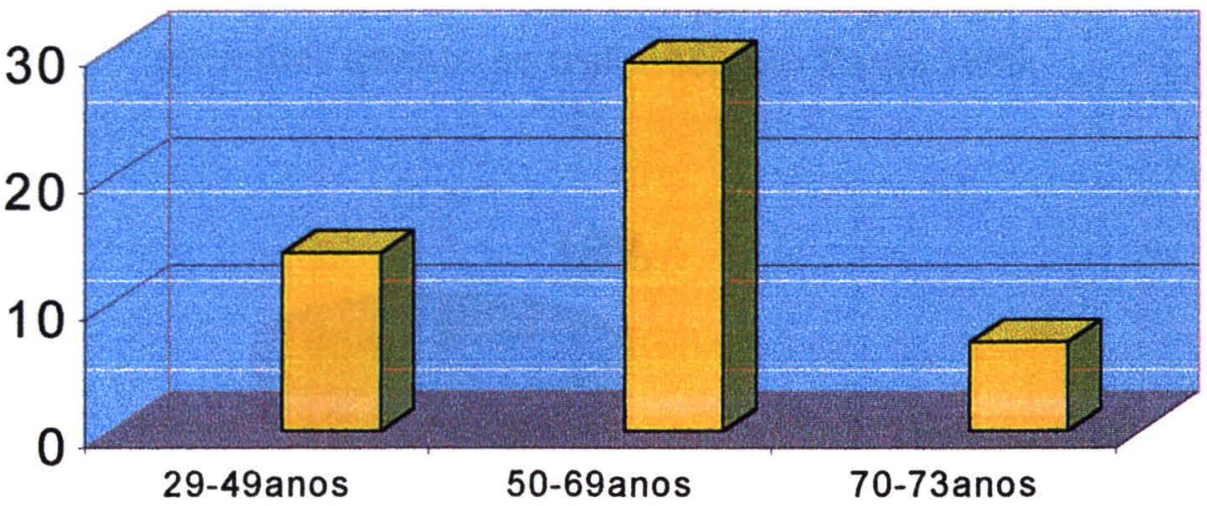


Tabela 5- Distribuição da percentagem de pacientes segundo estado civil. São Paulo, 1999.

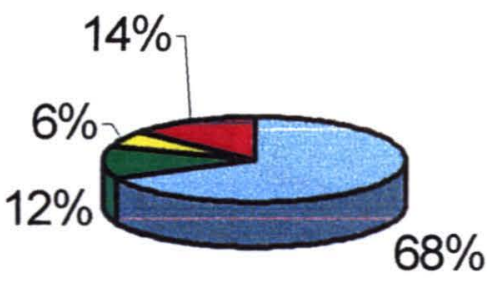

Tabela 6 - Distribuição da percentagem dos pacientes em relação a escolaridade. São Paulo, 1999.

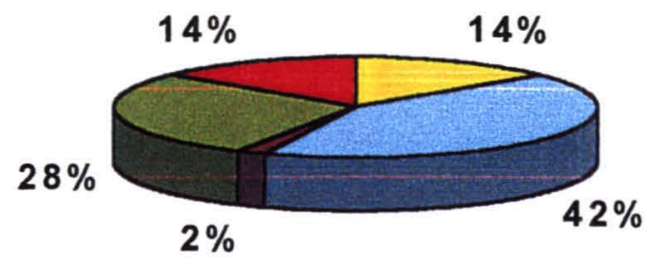

Tabela 7 - Distribuição da percentagem dos pacientes quanto ao trabalho. São Paulo,1999.

$18 \%$

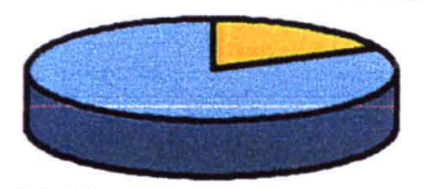

$82 \%$

Trabalha 口Não trabalha 
Tabela 8 - Distribuição da percentagem de pacientes segundo a faixa salarial. São Paulo, 1999.

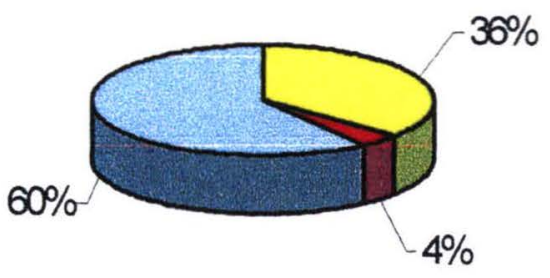

\section{Tabda9-Dstribuicãodonúntrodepacientessegnndbaprofissãa SñoPala, 1999.}

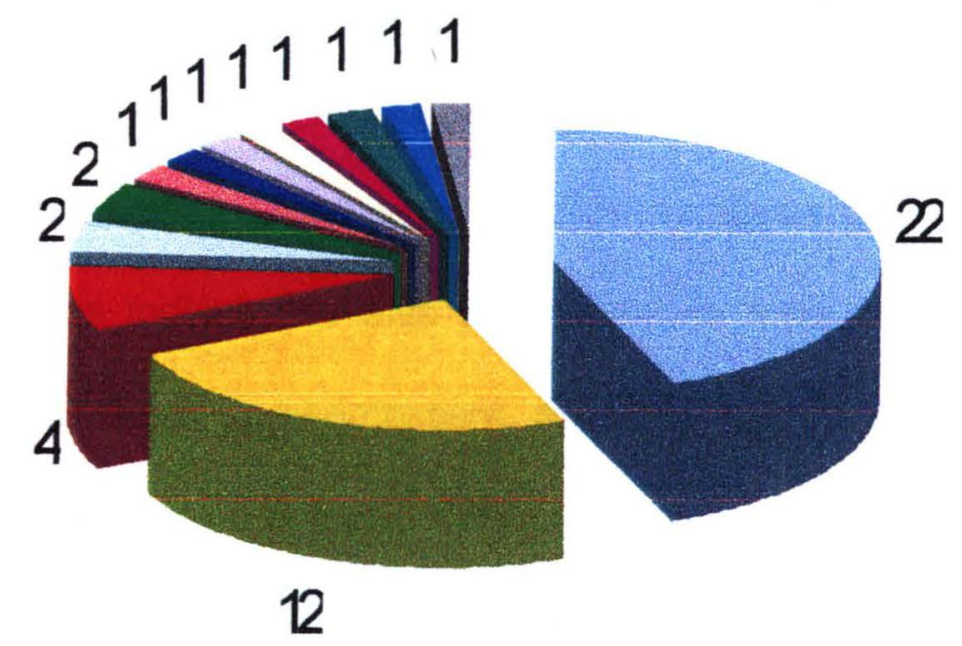

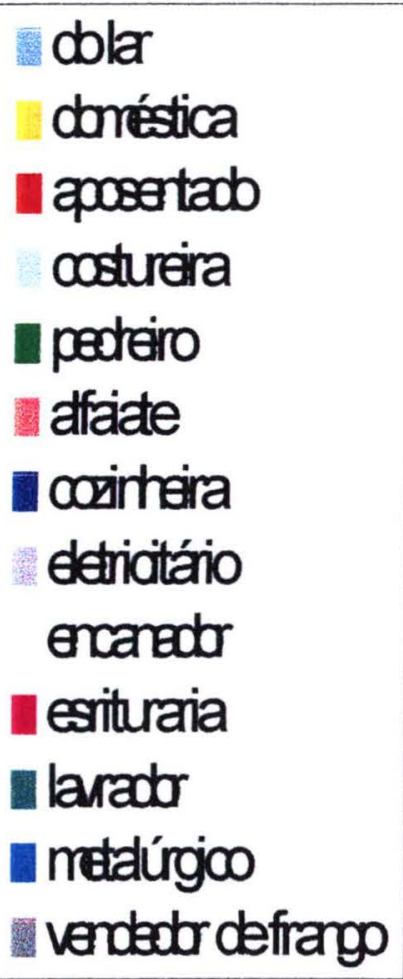


Os pacientes eram em sua maioria, do sexo feminino $(78 \%)$, tinham em média 57 anos (desvio padrão $=11,9$ anos) e a maioria estava na faixa dos 50-69 anos. Destes, $68 \%$ eram casados e a grande maioria tinha baixa escolaridade ( $84 \%$ não haviam completado o $1^{\circ} \mathrm{grau}$ ), e a maioria não trabalhava (82\%).

Com relação à profissão, $22 \%$ eram do lar, e é interessante observar se analisarmos só as mulheres, 32 (82\%) eram donas de casa ou trabalhavam como domésticas. O nível salarial também era muito baixo sendo que $64 \%$ não tinham salário ou ganhavam menos de 1 salário mínimo

A amostra estudada pode ser considerada peculiar e especifica para a região - zona sul da cidade de São Paulo, onde foi realizada a pesquisa, que é extremamente carente e com alta densidade populacional. O maior número de mulheres já próximas da terceira idade parece indicar que elas preocupam-se mais em cuidar da saúde ou que talvez elas apresentassem maiores indices de hipertensão do que os homens. Outro aspecto a considerar é o fato de que a maioria das mulheres entrevistadas não trabalhar, o que justificaria a disponibilidade de tempo para a procura do serviço de saúde. Fator relevante a ser destacado é que os pacientes recebem a maior parte da medicação no próprio local, o que aumentaria a procura e justificaria o baixo índice de faltas às consultas. 
Estudo anterior de Baise et al. (1995) analisando a epidemiologia da hipertensão arterial no pronto socorro da mesma Universidade, mostrou que de 500 pacientes atendidos, a maioria era de mulheres, mas o número maior de hipertensos era de homens até os 60 anos. Após esta idade ocorreu 0 inverso e as mulheres apareceram em maior número. Este achado está em consonância com dados da literatura que dão conta de que a hipertensão afeta mais homens do que mulheres, todavia apenas até os 50 anos de idade e após esta idade afeta mais as mulheres. Esta prevalência em mulheres após a menopausa tem relação com alterações hormonais e ganho de peso (Ayres, 1991; Magrini e Peggiani,1992; Oparil, 1993; Labbadia e Cury Jr, 1997).

Os dados apresentados na tabela 10 a seguir, mostram uma média de idade próxima dos 60 anos, com sobrepeso em relação à altura. Este dado contrapõe-se ao analisar-se os diagnósticos identificados que mostraram obesidade na maioria.

Tabela 10 - Distribuição dos Valores de idade, peso e altura apresentados pelos pacientes, segundo o cálculo da média, mediana, desviopadrão, mínima e máxima. São Paulo, 1999.

\begin{tabular}{|l|c|c|c|c|c|}
\hline Variável & Média & Mediana & Des.Padrão & Minima & Maxima \\
\hline Idade & 57,00 & 60,00 & 11,91 & 29,0 & 73,00 \\
\hline Peso & 70,94 & 67,25 & 22,01 & 45,50 & 121,30 \\
\hline Altura & 1,60 & 1,60 & 0,07 & 1,43 & 1,72 \\
\hline
\end{tabular}


Estudo de Fuchs et. al. na cidade de Porto Alegre, encontrou dados semelhantes, onde predominava pacientes era do sexo feminino, com médias de idade de 50 anos, altura de $1.61 \mathrm{~m}$ e peso de $77,2 \mathrm{~kg}$, onde podemos sugerir que talvez seja uma característica mais comum em nosso povo.

Tabela 11 - Distribuição do Número e Percentagem de pacientes segundo os problemas de Saúde referidos. São Paulo, 1999.

\begin{tabular}{|l|c|c|}
\hline Problemas & N & $\%$ \\
\hline Diabetes & 11 & 22,0 \\
\hline Colesterol alto & 6 & 12,0 \\
\hline Bronquite & 4 & 8,0 \\
\hline Alergia & 3 & 6,0 \\
\hline Reumatismo & 3 & 6,0 \\
\hline Osteoporose & 2 & 4,0 \\
\hline Nervosismo & 2 & 4,0 \\
\hline Mioma uterino & 2 & 4,0 \\
\hline Labirintite & 2 & 4,0 \\
\hline Gastrite & 2 & 4,0 \\
\hline Amigdalite & 1 & 2,0 \\
\hline Artrite & 1 & 2,0 \\
\hline Artrose & 1 & 2,0 \\
\hline Catarata & 1 & 2,0 \\
\hline Cefaléia & 1 & 2,0 \\
\hline Dificuldade de deglutição & 1 & 2,0 \\
\hline Dor na perna & 1 & 2,0 \\
\hline Dor no joelho & 1 & 2,0 \\
\hline Falta de ar & 1 & 2,0 \\
\hline Problema no coração & 1 & 2,0 \\
\hline Schistosoma & 1 & 2,0 \\
\hline Surdez & 1 & 2,0 \\
\hline Toxoplasmose oftalmica & 1 & 2,0 \\
\hline Tuberculose & 1 & 2,0 \\
\hline Úlcera gastrica & 1 & 2,0 \\
\hline Bas Sopacios & & \\
\hline
\end{tabular}

Base: 50 pacientes (100\%) 
Quanto aos problemas de saúde relatados pelos pacientes na Tabela 11, nota-se que os mais citados foram doenças como o diabetes, o colesterol elevado e a bronquite, na forma de livre citação. Foram identificados ainda nos históricos seis portadores de doenças cardíacas que não foram citadas aumentando seu total para $7(14 \%)$.

A literatura estudada aponta a relação entre os tres primeiros diabetes, colesterol alto e doenças cardíacas - e a hipertensão arterial, no sentido de favorecer sua elevação (VI Joint National Committeé, 1997), caracterizando diferentes grupos de risco conforme a presença ou não de lesões em órgãos-alvo. Dos outros problemas apontados, merecem análise o reumatismo, osteoporose e nervosismo, que podem estar relacionados à menopausa, levando-se em conta a faixa etária estudada, o que segundo Oparil (1993) já citado, estaria relacionada ao aumento da pressão arterial.

Tabe la 12 - D is tribuição do núme ro de pacientes segundo os fatores de risco identificados. São Paulo, 1999.

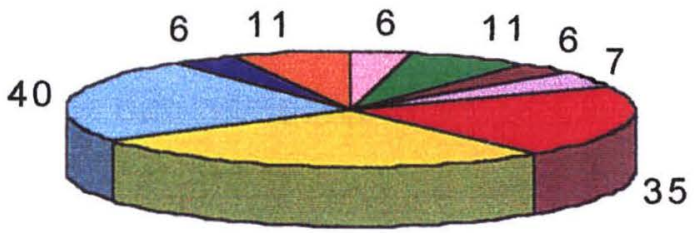

45

$\begin{array}{lll}\square \text { d. cardiaca } & \square \text { diabetes } & \text { colesterol alto } \\ \text { fumo } & \square \text { stress } & \square \text { sedentarismo } \\ \square \text { dieta inadeq. } & \text { não toma med. } & \square \text { ant.fam.de HAS }\end{array}$


A presença de fatores de risco (Tabela 12) nos indivíduos hipertensos tem sido descrita na literatura como fator preponderante de complicações no estado de saúde do indivíduo favorecendo o aparecimento de patologias como o infarte,e os acidentes vasculares e as nefropatias. A presença de aumento da pressão é mais comum nos diabéticos do que no restante da população (Oparil, 1993).

Neste grupo pesquisado, o sedentarismo que foi identificado em 45 pacientes (90\%) parece estar relacionado ao estilo de vida pois como a maioria não trabalha ou está aposentado, não existiria impedimento para a prática de exercício físico.

A dieta inadequada apareceu em 40 pacientes $(80 \%)$, pois estes relataram que apesar de terem conhecimento da necessidade do controle da alimentação ou da supressão de itens como sal, açúcar e gorduras, não conseguia fazê-lo. A experiência relatada por Labbadia e Cury Jr ( 1997) mostrou uma adesão maior à dieta quando os pacientes foram acompanhados por uma nutricionista que orientava alternativas para os alimentos. Este modelo de atendimento em equipe multiprofissional parece ser o caminho que muitos serviços tem procurado implantar, muitos com bons resultados, ainda não relatados.

O fator de risco relacionado a não seguir a terapia medicamentosa, não tomando os remédios ou não os fazendo de forma correta tem como causa a dificuldade financeira, pois a maioria não tem 
recursos suficientes para a compra destes e quando não os recebem na consulta, ou os recebem em quantidade insuficiente e acaba, não tomam os remédios, ou passam a tomar em quantidade menor para durar mais.

Por outro lado é exatamente nos fatores de risco que podese atuar para o controle eficaz da pressão. Orientação e acompanhamento dos pacientes quanto à alimentação adequada, atividade física, redução do nivel de stress, perda de peso, cessação do hábito de fumar , diminuição dos níveis de colesterol e controle de patologias associadas tem sido relatadas como benéficas no controle da pressão arterial (Oparil , 1993; Labbadia e Cury Jr ,1997; Castro, Costa e Luna,1998).

Tabela 13 - Distribuição do Número e Percentagem dos pacientes segundo a presença de Antecedentes Familiares de Doenças. São Paulo, 1999.

\begin{tabular}{lll}
\hline Antecedentes & $\mathbf{N}$ & $\%$ \\
\hline Doenças cardiacas & 17 & 34,0 \\
Alcoolismo & 13 & 26,0 \\
Diabetes & 12 & 24,0 \\
Obesidade & 12 & 24,0 \\
Derrame & 11 & 22,0 \\
\hline
\end{tabular}

Base: 50 pacientes

Em relação aos antecedentes familiares (Tabela 13), é interessante notar que o percentual de alcoolismo, diabetes e obesidade são 
próximos, acompanhados de doenças cardiacas em patamar superior.

Como todos estes fatores são considerados de risco para a hipertensão , é importante a análise destes antecedentes familiares, pois eles contribuem para o desencadeamento desta patologia, podendo servir como mecanismo para a detecção precoce e o conseqüente tratamento adequado. Oparil (1993) chama a atenção para os fatores genéticos, relatando que "estudos em parentes de primeiro grau normotensos, de indivíduos hipertensos essenciais, mostraram diferenças significativas na excreção de eletrólitos e niveis circulantes de renina que tornariam esse grupo suscetivel ao desenvolvimento da hipertensão".

Estes achados são pertinentes para os portadores de hipertensão arterial, uma vez que doenças como o diabetes e alterações como o aumento dos níveis de colesterol podem estar associados tanto com os fatores de risco como com as complicações. As doenças cardiacas como antecedentes familiares podem contribuir para 0 aparecimento da hipertensão. Todos estes aspectos já foram elencados por Castro, Costa e Luna (1998) entre outros autores que tratam do tema alertando para a maior possibilidade de desenvolvimento de doença cardiovascular com maior morbimortalidade. 
Tabela 14 - Distribuição do número e percentagem dos pacientes segundo as queixas verbalizadas. São Paulo, 1999.

\begin{tabular}{|l|c|c|}
\hline \multicolumn{1}{|c|}{ Queixas } & $\mathbf{N}$ & $\%$ \\
\hline Cansaço & 15 & 30,0 \\
\hline Dispnéia -pequenos esforços & 5 & 10,0 \\
\hline Dor nos membros inferiores & 2 & 4,0 \\
\hline Fraqueza & 2 & 4,0 \\
\hline Cefaléia & 1 & 2,0 \\
\hline Depressão & 1 & 2,0 \\
\hline Desânimo & 1 & 2,0 \\
\hline Dor no peito & 1 & 2,0 \\
\hline Engordando & 1 & 2,0 \\
\hline Ferida no dedão & 1 & 2,0 \\
\hline Indisposição & 1 & 2,0 \\
\hline Insônia & 1 & 2,0 \\
\hline Moleza & 1 & 2,0 \\
\hline Peso do corpo & 1 & 2,0 \\
\hline Dor nos joelhos & 1 & 2,0 \\
\hline
\end{tabular}

Base: 50 pacientes

A maior parte das queixas (Tabela 14) apresentadas pelos pacientes pode estar relacionada à sinais e sintomas da própria hipertensão arterial, pois grande parte já possuia lesão em órgãos-alvo como complicação, tendo em vista que a maior parte dos pacientes apresentou valores elevados da pressão durante a consulta, todavia não podem ser desconsideradas outras complicações de saúde. A queixa de cansaço acreditamos não poder ser em razão da distância percorrida para vir ao Centro de Saúde, pois todos os pacientes estavam sentados aguardando a 
consulta médica, estando portanto em situação de repouso ou descanso. Podemos também associa-lo às doenças relatadas como outros problemas de saúde, como o diabetes, colesterol alto e bronquite. Sabe-se que alguns dos sinais e sintomas da hipertensão são tontura, rubor facial, cefaléia e presença de perturbações visuais, o que não foi detectado neste grupo de paciente.

Tabela 15 - Distribuição do número e percentagem dos pacientes segundo o fixar o olhar durante a entrevista analisado pelo Enfermeiro. São Paulo, 1999.

\begin{tabular}{lrr}
\hline Fixar o olhar & $\mathbf{N}^{\circ}$. & $\%$ \\
\hline Sim & 48 & 96,0 \\
Não & 2 & 4,0 \\
\hline Total & 50 & 100,0 \\
\hline
\end{tabular}

Tabela 16 - Distribuição do número e percentagem dos pacientes segundo a presença de movimentos durante a entrevista analisado pelo Enfermeiro. São Paulo, 1999.

\begin{tabular}{lrc}
\hline Movimentos & No. & $\%$ \\
\hline Sim & 43 & 86,0 \\
Não & 7 & 14,0 \\
\hline Total & 50 & 100,0 \\
\hline
\end{tabular}

Tabela 17 - Distribuição do número e percentagem dos pacientes segundo a expressão facial durante a entrevista analisado pelo Enfermeiro. São Paulo, 1999.

\begin{tabular}{lcc}
\hline Expressão & $\mathbf{N}$ & $\%$ \\
\hline Tranquila & 27 & 54,0 \\
Tensa & 12 & 24,0 \\
Angustiada & 11 & 22,0 \\
\hline Total & 50 & 100,0 \\
\hline
\end{tabular}


Tabela 18 - Distribuição dos Valores de Pressão Arterial, Pulso e Respiração apresentados pelos pacientes segundo o cálculo da Média, Mediana, Desvio-Padrão, Mínimo e Máximo. São Paulo, 1999.

\begin{tabular}{|l|c|c|c|c|c|}
\hline Variável & Média & Mediana & Desvio Padrão & Mínimo & Maximo \\
\hline PA Max & 15,18 & 15,00 & 1,59 & 11,50 & 18,00 \\
\hline PA Min & 9,66 & 9,75 & 1,30 & 6,00 & 12,00 \\
\hline Pulso & 88,78 & 88,00 & 13,89 & 58,00 & 124,00 \\
\hline$R$ & 18,52 & 18,00 & 3,44 & 14,00 & 28,00 \\
\hline
\end{tabular}

Em relação às tabelas 15,16 e 17 , onde se registrou o olhar, os movimentos e a expressão dos pacientes durante a entrevista, a maioria tinha olhar e movimentos normais (respectivamente $96 \%$ e $86 \%$ ) e pouco mais da metade apresentava expressão facial tranqüila (54\%), o que contrasta com os níveis de pressão arterial apresentados no Tabela 18, que estavam acima da média normal. Pode-se inferir que estes pacientes escondiam nervosismo, ou que a pressão arterial elevada não alterava 0 comportamento dos mesmos. Fuchs et.al. (1997) e Khattar, Senior e Lahiri (1999), relatam a chamada Síndrome do Avental Branco, que é caracterizada pela elevação da pressão arterial dos pacientes por ocasião da consulta médica, fato este não explicado a não ser pela ansiedade e stress. Neste estudo a média apresentada pelos pacientes foi de $15 \times 9,5$ $\mathrm{mmHg}, \mathrm{o}$ que é considerada alta para os padrōes já mencionados. Todavia esta elevação não foi acompanhada de alteração no pulso e na respiração, 0 que parece contrastante, pois o esperado era o inverso, ou seja, que a hipertensão fosse acompanhada de taquicardia e dispnéia. 
Tabela 19 - Distribuição do número e percentagem dos pacientes segundo os medicamentos que fazem uso. São Paulo, 1999.

\begin{tabular}{|l|c|c|}
\hline Medicamento & $\mathbf{N}$ & $\%$ \\
\hline Aldomet (metildopa) & 21 & 42,0 \\
\hline Clorana ( hidroclorotiazida) & 15 & 30,0 \\
\hline Higroton ( clortalidona) & 12 & 24,0 \\
\hline Lasix(furosemida) & 5 & 10,0 \\
\hline Capoten(captopril) & 5 & 10,0 \\
\hline Adalat(nifedipina) & 4 & 6,0 \\
\hline Dienpax(diazepan) & 3 & 6,0 \\
\hline Moduretic(hidroclor+amilorida) & 3 & 6,0 \\
\hline Renitec(inalapril) & 3 & 6,0 \\
\hline AAS(ac.acetilsalicílico) & 1 & 2,0 \\
\hline Aerolin(salbutamol) & 1 & 2,0 \\
\hline Atrovent(brom.ipratrópio) & 1 & 2,0 \\
\hline Atensina(clonidina) & 1 & 2,0 \\
\hline Burinax(bumetamida) & 1 & 2,0 \\
\hline Diabinese(glibenclamida) & 1 & 2,0 \\
\hline Lacipil(lacidipina) & 1 & 2,0 \\
\hline Passiflorine( pass.maracujina) & 1 & 2,0 \\
\hline Propanolol(propanolol) & 1 & 2,0 \\
\hline Serenius(pas.alata) & 1 & 2,0 \\
\hline Strugeron(cinarisina) & 1 & 2,0 \\
\hline Tenadren(propan+hidroclor) & 2,0 \\
\hline
\end{tabular}

Base : 50 pacientes

Em relação aos medicamentos, nota-se que a maior parte dos pacientes verbalizou os nomes comerciais dos remédios, apesar de muitas vezes receberem no Centro de Saúde pelo nome genérico. O uso de 
agentes anti-hipertensivos como é o caso do aldomet (metildopa), capoten (captopril) e adalat ( nifedipina )bem como o de diuréticos como a clorana (hidroclorotiazida), o higroton (clortalidona) e o lasix (furosemida), estão em conformidade com o tratamento medicamentoso habitualmente utilizado e já apresentados nas Tabelas 1 e 2 (Batista et.al.,1996; Castro, Costa e Luna, 1998 ; Korokolvas, 1998 ).

Fator relevante talvez seja o custo destes agentes farmacológicos, uma vez que variam muito entre si, sendo que o primeiro custa o dobro do que os últimos. Em junho de 1999 o preço de uma caixa de metildopa com 30 comprimidos era de $\mathrm{R} \$ 11,75$ (Brasíndice, 1999), o que representa muito em termos financeiros para esta população, pois em sua maioria , tomam outros medicamentos associados. Numa população de baixa renda como à analisada, o custo do medicamento é sem dúvida fator essencial na escolha da terapêutica. Apesar de no centro de saúde estudado haver a distribuição destes medicamentos aos pacientes, a mesma está muitas vezes condicionada ao fornecimento da rede pública, o que às vezes faz com que faltem. O paciente quando acaba o remédio ou não o recebe, não toma a medicação, pois não tem dinheiro para comprar, conforme foi verbalizado por 6 pacientes durante as consultas de enfermagem.

A droga mais utilizada é a metildopa (aldomet), que tem sido uma das primeiras drogas escolhidas no tratamento da hipertensão arterial. 
Esta droga apresenta como principais efeitos colaterais a tontura, o cansaço e a diminuição da libido. Podemos ainda destacar que os primeiros seis medicamentos citados, são todos utilizados no tratamento da hipertensão e distúrbios cárdiocirculatórios, o que mostra que todos os pacientes estavam recebendo tratamento adequado.

Após a caraterização da população e das variáveis foram identificados os diagnósticos de enfermagem, que como já relatamos, foram purificados por dois especialistas. A pesquisadora elencou 236 diagnósticos de enfermagem que após a análise dos especialistas reduziram-se para 197.

Desta maneira, foram identificados um total de 197 diagnósticos em 29 categorias, dentro de 8 padrões de resposta humana , 364 características definidoras em 96 categorias e 271 fatores relacionados em 63 categorias conforme demonstrado nas Tabelas 20 a 22. Os padrões que mais apareceram foram o TROCAR (29\%), o MOVER (27\%) e o CONHECER (24\%).

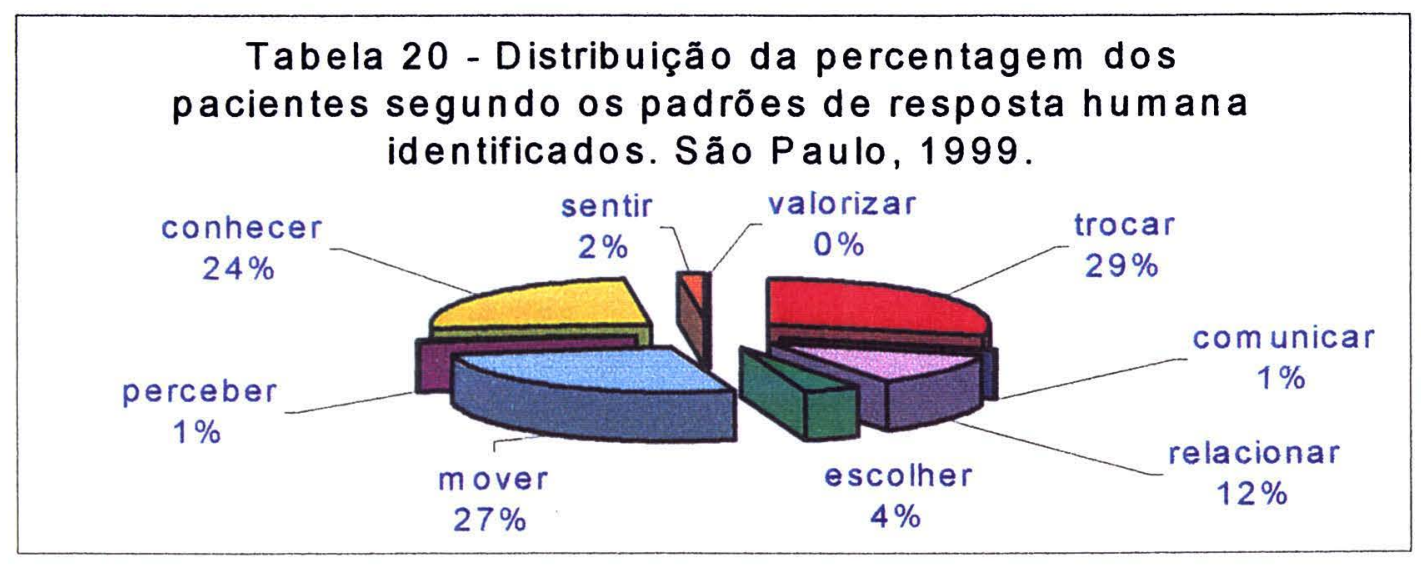


O maior número de diagnósticos identificados foi no padrão de resposta humana TROCAR. Este achado é semelhante ao que estamos acostumados a acompanhar na prática do ensino, pois é neste padrão que são caracterizados a maior parte dos diagnósticos. Talvez tenha influência o fato de o enfermeiro estar melhor preparado para diagnosticar nos padrões relacionados à problemas no campo biológico.

Outros estudos como o de Cruz (1983), Cruz, (1989), Maria (1997) e Carmagnani (1999) também identificaram o maior número de diagnósticos nas necessidades físicas do que nas psicossociais. À esse propósito esta última autora relata que " as enfermeiras são tradicionalmente reconhecidas como protagonistas do cuidado e historicamente envolvidas em ações educativas como orientar, treinar e encaminhar, mas parece que não conseguem dar a mesma prioridade para os problemas emocionais dos pacientes como dão aos físicos".

Apesar de concordarmos com o referencial de Carpenito (1997) que nomeia de problemas colaborativos os diagnósticos médicos, não o utilizamos em nosso estudo. Em outros problemas relacionados foram agrupados tanto os diagnósticos médicos como outros fatores/problemas identificados nos pacientes.

Na Tabela 21, apresentada a seguir, encontram-se todos os 
diagnósticos de enfermagem identificados nos pacientes. $O$ que apareceu em maior número foi o de déficit de conhecimento sobre a doença, dentro do padrão de resposta humana CONHECER, seguido do de distúrbio no padrão do sono e nutrição alterada : ingestão maior do que as necessidades corporais.

Foi a seguir feito o agrupamento dos diagnósticos de enfermagem, as características definidoras e os fatores relacionados identificados e também acrescentado outros problemas relacionados identificados nos históricos de enfermagem e propostas as intervenções, conforme demonstrado na Tabela 22. Pela dificuldade em apresentar de forma suscinta e agrupada um grande volume de dados, optamos por apenas incluir após cada aspecto identificado, o número de vezes em que foi identificado, sem percentual. As letras e números que iniciam cada aspecto são a codificação usada para a tabulação eletrônica dos dados. 
TABELA 21 - Distribuição do número e percentagem dos pacientes segundo os diagnósticos de enfermagem identificados. São Paulo, 1999.

\begin{tabular}{|c|c|c|}
\hline Diagnóstico & $\mathbf{N}$ & $\%$ \\
\hline Déficit de conhecimento sobre a doença & 48 & 96,0 \\
\hline Distúrbio no padrăo do sono & 26 & 52,0 \\
\hline $\begin{array}{l}\text { Nutrição alterada: ingestão maior do que as } \\
\text { necessidades }\end{array}$ & 25 & 50,0 \\
\hline Disfunção sexual & 21 & 42,0 \\
\hline Potencial para intolerância a atividade & 9 & 18,0 \\
\hline Constipaçăo & 8 & 16,0 \\
\hline Estratégias ineficazes de resolução individual & 7 & 14,0 \\
\hline Intolerância a atividade & 6 & 12,0 \\
\hline Excesso de volume de líquidos & 6 & 12,0 \\
\hline Déficit de lazer & 5 & 10,0 \\
\hline Manutenção da saúde alterada & 5 & 10,0 \\
\hline $\begin{array}{l}\text { Nutrição alterada: ingestão menor que as } \\
\text { necessidades }\end{array}$ & 4 & 8,0 \\
\hline Mucosa oral alterada & 3 & 6,0 \\
\hline Débito cardiaco diminuído & 2 & 4,0 \\
\hline Constipação colônica & 2 & 4,0 \\
\hline Distúrbio na auto estima & 2 & 4,0 \\
\hline Proteção alterada & 2 & 4,0 \\
\hline Ansiedade & 2 & 4,0 \\
\hline Manutenção do lar prejudicada & 2 & 4,0 \\
\hline Isolamento social & 2 & 4,0 \\
\hline Padrão respiratório ineficaz & 2 & 4,0 \\
\hline Comunicação alterada & 1 & 2,0 \\
\hline Estratégias ineficazes de resolução familiar & 1 & 2,0 \\
\hline Fadiga & 1 & 2,0 \\
\hline Eliminação tráqueo-brônquica ineficaz & 1 & 2,0 \\
\hline Constipaçăo percebida & 1 & 2,0 \\
\hline Integridade tissular prejudicada & 1 & 2,0 \\
\hline Disfunçăo na reação de pesar & 1 & 2,0 \\
\hline Reação de pesar antecipada & 1 & 2,0 \\
\hline
\end{tabular}


TABELA 22 - Relação dos Padrões de Resposta Humana, Diagnósticos de Enfermagem, Características Definidoras e Outros Problemas Relacionados nos pacientes e as Intervenções de Enfermagem propostas. São Paulo, 1999.

\begin{tabular}{|c|c|c|c|c|c|}
\hline $\begin{array}{l}\text { Padrão de } \\
\text { Resposta } \\
\text { Humana }\end{array}$ & $\begin{array}{l}\text { Diagnósticos de } \\
\text { Enfermagem }\end{array}$ & Carateristicas Definidoras & Fatores Relacionados & $\begin{array}{l}\text { Outros problemas } \\
\text { relacionados }\end{array}$ & Intervenções de Enfermagem \\
\hline TROCAR & $\begin{array}{l}\text { DE } 4 \text { - NUTRIÇĀO } \\
\text { ALTERADA: ingestão } \\
\text { maior do que as } \\
\text { necessidades corporais:25 }\end{array}$ & $\begin{array}{l}\text { Cd4a- peso corporal } 20 \% \text { acima do } \\
\text { ideal para estatura e idade } 22 \\
\text { Cd4b-peso corporal } 10 \% \text { acima do } \\
\text { ideal para estatura e idade } 2\end{array}$ & \begin{tabular}{|l|} 
Fr4a -Ingesta de dietas \\
qualitativamente inadequadas 22 \\
Fr4b-Estilo de vida sedentária \\
13 \\
Fr4c-Disfunçáo do padrăo \\
alimentar relatado 3
\end{tabular} & $\begin{array}{l}\text { Não adesão à dieta } \\
\text { prescrita } \\
\text { Dieta inadequada } \\
\text { Diabetes } \\
\text { Colesterol elevado } \\
\text { Uso de chás }\end{array}$ & $\begin{array}{l}\text { Encaminhar paciente para a nutricionista para } \\
\text { elaboraçăo de dieta adequada quando possivel } \\
\text { Orientar o paciente quanto ds alteraçäes } \\
\text { provocadas pelo excesso de peso e dos maus } \\
\text { hábitos alimentares } \\
\text { Orientar sobre o valor nutritivo dos alimentos e } \\
\text { suas combinaçaes } \\
\text { Orientar o paciente a manter um diário do que } \\
\text { come } \\
\text { Orientar o paciente a procurar outras fontes de } \\
\text { satisfação com alimentos que contenham menos } \\
\text { gordura e calorias e usando linhas lightdiet } \\
\text { Orientar o paciente a levar sempre consigo } \\
\text { pequenos lanches com pouca caloria para que não } \\
\text { necessite alimentar-se fora de casa } \\
\text { Orientar o consumo de água e chás } \\
\text { Fazer o controle do peso corporal pelo menos uma } \\
\text { vez por mês } \\
\text { Orientar e supervisionar a perda de peso } \\
\text { Orientar o controle das patologias associadas } \\
\text { Encaminhar o paciente ao medico para medicaçăo } \\
\text { associada quando for necessário } \\
\text { Orientar e supervisionar a adesão ao tratamento } \\
\text { Orientar a necessidade de atividade fisica } \\
\text { Encaminhar o paciente para grupos de auto-ajuda } \\
\text { Orientar o paciente a solicitar ajuda da familia e } \\
\text { amigos }\end{array}$ \\
\hline & $\begin{array}{l}\text { DE 6-CONSTIPAÇÃO } \\
8\end{array}$ & $\begin{array}{l}\text { Cd6a-eliminaçăo menor que o padrão } \\
\text { usual } 8 \\
\text { Cd6b-esforço para evacuar } 6 \\
\text { Cd6c- uso de laxante } 1\end{array}$ & $\begin{array}{l}\text { Frba -Alteraçăo no padrão } \\
\text { alimentar } 7 \\
\text { Frob-Alteraçăo no estilo de vida } \\
6\end{array}$ & $\begin{array}{l}\text { Dieta inadequada } \\
\text { Uso de medicamentos } \\
\text { Sedentarismo }\end{array}$ & $\begin{array}{l}\text { Encaminhar paciente para a nutricionista para } \\
\text { elaboração de dieta adequada quando possivel } \\
\text { Orientar o paciente quanto à dieta laxante e } \\
\text { diminuição do uso de laxantes } \\
\text { Orientar o paciente a aumentar o consumo de água } \\
\text { se permitido } \\
\text { Orientar a necessidade de atividade fisica } \\
\text { Orientar o paciente a controlar o nivel de stress } \\
\end{array}$ \\
\hline
\end{tabular}




\begin{tabular}{|c|c|c|c|c|c|}
\hline & & & & & \begin{tabular}{|l} 
Encaminhar o paciente ao médico para medicaçăo \\
associada quando for necessário
\end{tabular} \\
\hline \multirow[t]{5}{*}{ TROCAR-Cont } & $\begin{array}{l}\text { DE 9-EXCESSO DE } \\
\text { VOLUME DE } \\
\text { LfQUIDOS } 6\end{array}$ & $\begin{array}{l}\text { Cd9a- edema } 6 \\
\text { Cd9b-respiraçăo curta } 3 \\
\text { Cd9c- ortopneia } 1 \\
\text { Cd9d- ganho de peso } 3 \\
\text { Cd9e- varią̧̧o da pressåo arterial } 1\end{array}$ & $\begin{array}{l}\text { Frag-Comprometimento de } \\
\text { mecanismos reguladores } 6 \\
\text { Frgb-Ingeståo de excesso de } \\
\text { liquidos } 5 \\
\text { Fr9c- Ingestão excessiva de } \\
\text { sódio } 3\end{array}$ & $\begin{array}{l}\text { Não tomar correta- } \\
\text { mente a medicação } \\
\text { prescrita } \\
\text { Dieta inadequada } \\
\text { Obesidade } \\
\text { Diabetes } \\
\text { Doenças cardiacas }\end{array}$ & \begin{tabular}{|l|} 
Encaminhar paciente para a nutricionista para \\
elaboraçăo de dieta adequada quando possivel \\
Orientar a restriçao de sal \\
Orientar quanto a restriç̃o e controle de liquidos \\
diariamente \\
Orientar e supervisionar a perda de peso \\
Orientar o controle das patologias associadas \\
Orientar e supervisionar a adesła ao tratamento \\
\end{tabular} \\
\hline & 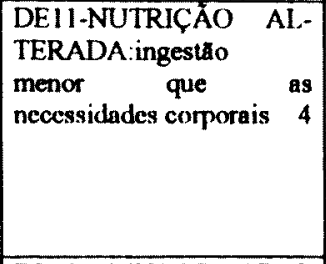 & 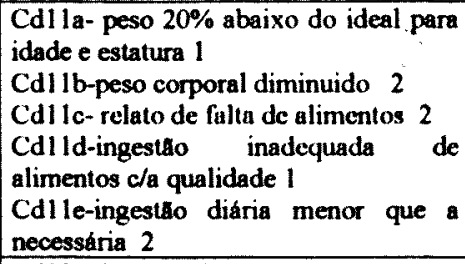 & \begin{tabular}{|l|} 
Frl la -Falta ou deficit de \\
informação 3 \\
Frl lb- lnabilidade para ingerir \\
alimentos devido a fatores \\
econômicos 3 \\
Frl le - Inabilidade para ingerir \\
alimentos devido a fatores \\
biologicos 1 \\
\end{tabular} & $\begin{array}{l}\text { Stress } \\
\text { Falta de conhecimento } \\
\text { sobre dicta adequada }\end{array}$ & \begin{tabular}{|l|} 
Encaminhar paciente para a nutricionista para \\
elaboração de dieta adequada quando possivel \\
Orientar sobre o valor nutritivo dos alimentos e \\
suass combinaçjes \\
Orientar o paciente a solicitar ajuda da famillia e \\
amigos \\
Encaminhar paciente para recursos sociais da \\
comunidade
\end{tabular} \\
\hline & $\begin{array}{l}\text { DE13-MUCOSA ORAL } \\
\text { ALTERADA } 3\end{array}$ & $\begin{array}{l}\text { Cd13a- lingua saburrosa } 3 \\
\text { Cd13b-lesăo oral } 3 \\
\text { Cd13ch-halitose } 2 \\
\text { Cd13d-xerostomia } 2 \\
\text { Cd13e-placa branca 1 } \\
\text { Cd 9-edema 1 }\end{array}$ & 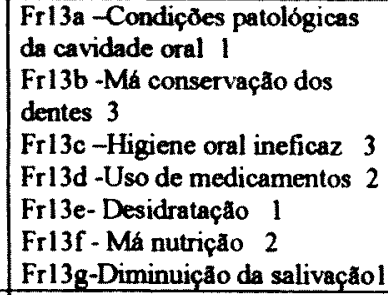 & \begin{tabular}{|l|} 
Diabeles \\
Situą̧ăo econômica \\
desfavorável \\
Stress \\
Fumo
\end{tabular} & $\begin{array}{l}\text { Encaminhar paciente para a nutricionista para } \\
\text { elaboraçao de dieta adequada quando possivel. } \\
\text { Encaminhar ao dentista } \\
\text { Orientar a cessaçąo do hábito de fumar } \\
\text { Orientar medidas para reduzir o nivel de stress } \\
\text { Orientar o controle das patologias associadas }\end{array}$ \\
\hline & $\begin{array}{l}\text { DE15 - DÉBITO } \\
\text { CARDIACO } \\
\text { DIMINUIDO } 2\end{array}$ & 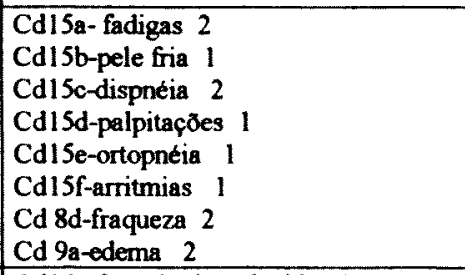 & A serem desenvolvidos & \begin{tabular}{|l|} 
Dieta inadequada \\
Bronquite \\
Não tomar correta- \\
mente a medicação \\
Doença cardiaca
\end{tabular} & $\begin{array}{l}\text { Encaminhar paciente para a nutricionista para } \\
\text { elaboração de dieta adequada quando possivel. } \\
\text { Orientaro o controle das patologias associadas } \\
\text { Orientar e supervisionar a adesâo ao tratamento }\end{array}$ \\
\hline & $\begin{array}{l}\text { DEI6 - CONSTIPAÇÃO } \\
\text { COLÓNICA } 2\end{array}$ & $\begin{array}{l}\text { Cd16a-frequência redurida } 2 \\
\text { Cd16b-fezes secas } 2 \\
\text { Cd16c-dor para evacuar } 2 \\
\text { Cd 6b-esforco para evacuar 1 }\end{array}$ & $\begin{array}{l}\text { Friba-Ingestão de líquidos e } \\
\text { fibras menor do que as adequa- } \\
\text { das } 2 \\
\text { Fr16b-Imobilidade } 1 \\
\text { Fr16c -Uso crônico de medica- } \\
\text { çå } 2\end{array}$ & \begin{tabular}{|l}
$\begin{array}{l}\text { Falta de conhecimento } \\
\text { sobre dieta adequada }\end{array}$ \\
\end{tabular} & \begin{tabular}{|l|} 
Encaminhar paciente para a nutricionista para \\
elaboração de dieta adequada quando possivel \\
Orientar o paciente quanto d dieta laxante \\
Orientar o paciente a aumentar o consumo de água \\
se permitido \\
Orientara a necessidade de atividade física \\
Orientar o paciente a controlad o nivel de stress \\
Encaminhar o paciente ao médico para medicą̧óo \\
associada quando for necessário
\end{tabular} \\
\hline
\end{tabular}




\begin{tabular}{|c|c|c|c|c|c|}
\hline \multirow[t]{5}{*}{ IROCAR Cont } & $\begin{array}{l}\text { DE23 - PROTEÇAO } \\
\text { ALTERADA } 2\end{array}$ & $\begin{array}{l}\text { Cd23a-resposta ineficaz de stress } 1 \\
\text { Cd23b-inquietação } 2 \\
\text { Cd23c-insônia 1 } \\
\text { Cd23d-tosse 1 } \\
\text { Cd23e-imunidade insuficiente } 2 \\
\text { Cd 8d-fraqueza 1 } \\
\text { Cd15c-dispnéia 1 } \\
\end{array}$ & $\begin{array}{l}\text { Frl3d-Uso de medicamentos } 2 \\
\text { Fr23a -Doença crônica em } \\
\text { atividade } 1 \\
\text { Fr23b-Nutrição inadequada } 1\end{array}$ & $\begin{array}{l}\text { Bronquite } \\
\text { Hábitos alimentares } \\
\text { inadequados }\end{array}$ & $\begin{array}{l}\text { Encaminhar o paciente ao médico para medicaçào } \\
\text { associada quando for necessário } \\
\text { Orientar o controle das patologias associadas } \\
\text { Encaminhar paciente para a nutricionista para } \\
\text { elaboraçăo de dieta adequada quando possivel }\end{array}$ \\
\hline & $\begin{array}{l}\text { DE29 - PADRAOO RES- } \\
\text { PIRATORIO INIFICAY } \\
2\end{array}$ & $\begin{array}{l}\text { Cd29a-roncos pulmonares } 2 \\
\text { Cd29c-cansaço } 2 \\
\text { Cd23d-tosse I } \\
\text { Cd15c-dispnéia ! }\end{array}$ & $\begin{array}{l}\text { Fr29a-Diminuição da retraçáo } \\
\text { clástica do pulmão } 2\end{array}$ & $\begin{array}{l}\text { Bronquite } \\
\text { Fumo } \\
\text { Penengias cardfacas }\end{array}$ & $\begin{array}{l}\text { Encaminhar o paciente ao médico para medicaçăo } \\
\text { associada quando for necessário } \\
\text { ( rientar o controle dus patolengias associadas } \\
\text { Orientar a cessaça do hábito de fumar }\end{array}$ \\
\hline & $\begin{array}{l}\text { DE22-CONSTIPAÇÃO } \\
\text { PIRCIBIISA I }\end{array}$ & $\begin{array}{l}\text { Cd22a-expectativa de eliminação diária } \\
\text { de fezes com laxante }\end{array}$ & Fr22a -Crenças de saúde 1 & & 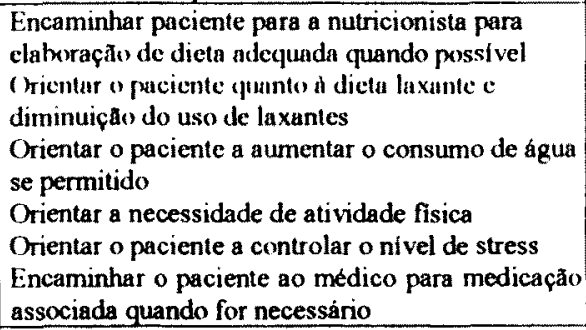 \\
\hline & $\begin{array}{l}\text { DE21 - ELIMINAÇÃO } \\
\text { TRAQUEO- } \\
\text { BROONQUICA } \\
\text { INEFICAZ } 1\end{array}$ & $\begin{array}{l}\text { Cd2la-estertores } 1 \\
\text { Cd21b-tosse produtiva insuficientel } \\
\text { Cd15c-dispnéia } 1\end{array}$ & $\begin{array}{l}\text { Fr2la- Fadiga } 1 \\
\text { Fr21b-Infecção traqueo- } \\
\text { bronquica } 1\end{array}$ & Fumo & $\begin{array}{l}\text { Orientar a cessação do hábito de fumar } \\
\text { Orientar o paciente a aumentar o consumo de água } \\
\text { se permitido } \\
\text { Orientar o controle das patologias associadas } \\
\text { Encaminhar o paciente ao medico para medicação } \\
\text { associada quando for necessário } \\
\text { Orientar medidas para facilitar a expectoração }\end{array}$ \\
\hline & $\begin{array}{l}\text { DE24 - INTEGRIDADE } \\
\text { TISSULAR } \\
\text { PREJUDICADA I }\end{array}$ & Cd24a-tecido do artelho pé D lesado 1 & \begin{tabular}{|l|} 
Fr24a-Circulação alterada \\
Fr24b-Excesso nutricional 1 \\
Fr 5a-Deficit de conhecimentol \\
Fr24c-Mobilidade fisica preju- \\
dicada I
\end{tabular} & \begin{tabular}{|l|} 
Diabetes \\
Fumo \\
Não adesão à dieta \\
prescrita
\end{tabular} & $\begin{array}{l}\text { Encaminhar o paciente ao médico para medicação } \\
\text { associada quando for necessário } \\
\text { Orientar o controle das patologias associadas } \\
\text { Encaminhar paciente para a nutricionista para } \\
\text { elaboraçăo de dieta adequada quando possível } \\
\text { Orientar a cessação do hábito de fumar } \\
\text { Orientar a necessidade de atividade fisica } \\
\text { Orientar cuidados com extremidades } \\
\text { Fazer curativo e orientar seu seguimento } \\
\end{array}$ \\
\hline COMUNICAR & $\begin{array}{l}\text { DE 5-COMUNICAÇÃO } \\
\text { PREJUDICADAI }\end{array}$ & $\begin{array}{l}\text { Cd5a- dificuldade em manter padrão } \\
\text { usual de comunicação I }\end{array}$ & $\begin{array}{l}\text { Fr5a-Déficit de informaçðes } 1 \\
\text { Fr5b-Diferenças culturais I }\end{array}$ & $\begin{array}{l}\text { Escolaridade } \\
\text { Nervosismo } \\
\text { Stress }\end{array}$ & $\begin{array}{l}\text { Encaminhar para grupo de apoio psicológico } \\
\text { Orientar o paciente a se comunicar com a equipe } \\
\text { de saude } \\
\text { Orientar o paciente a controlar o nivel de stress }\end{array}$ \\
\hline RELACIONAR & $\begin{array}{l}\text { DE 2 - DISFUNÇÃO } \\
\text { SEXUAL } 21\end{array}$ & $\begin{array}{l}\text { Cdla verbalização do problema } 21 \\
\text { Cd2a- relato de dificuldade na } \\
\text { atividade sexual } 3\end{array}$ & $\begin{array}{l}\text { Fr2a -Alteração na função pela } \\
\text { doença } 17 \\
\text { Fr2b-Falta de pessoa significa- }\end{array}$ & \begin{tabular}{|l|} 
Fumo \\
Diabetes \\
Stress \\
\end{tabular} & $\begin{array}{l}\text { Orientar sobre possiveis efeitos colaterais dos } \\
\text { medicamentos, notadamente a metil-dopa }\end{array}$ \\
\hline
\end{tabular}




\begin{tabular}{|c|c|c|c|c|c|}
\hline & & $\begin{array}{l}\text { Cd2b-limitaçdo da atividade sexual } \\
\text { imposta pela doença } 10 \\
\text { Cd2c- inabilidade para alcançar } \\
\text { satisfação } 6 \\
\text { Cd2d-relato de dor } 1 \\
\text { Cd2e- relato de limitaçăo imposta pela } \\
\text { idade } 1\end{array}$ & $\begin{array}{l}\text { tiva } 11 \\
\text { Fr2c-Diminuiçăo do interesse } 1 \\
\text { Fr2d-Alteração por medica- } \\
\text { mentos } 10\end{array}$ & & $\begin{array}{l}\text { Orientar o paciente a nào ter vergonha e procurar } \\
\text { ajuda, avaliando os efeitos dos tratamentos } \\
\text { Orientar o paciente a controlar o nivel de stress } \\
\text { Encaminhar o paciente ao médico para medicaçăo } \\
\text { associada quando for necessário } \\
\text { Orientar o controle das patologias associadas } \\
\text { Orientar cuidados com extremidades } \\
\text { Orientar a cessaçào do hábito de furnar }\end{array}$ \\
\hline & $\begin{array}{l}\text { DE14 - ISOLAMENTO } \\
\text { SOCIAL } 2\end{array}$ & $\begin{array}{l}\text { Cd14a-ausência de } \\
\text { significativo de outros 1 } \\
\text { Cd14b-ausência de } \\
\text { significativo da familia 1 } \\
\text { Cd14c-falta de afeto 1 } \\
\text { Cd14d-evidência de bem estar alterado } \\
\text { I }\end{array}$ & $\begin{array}{l}\text { Fr14a -Sentimentos de solidxo } \\
\text { expresso imposto por outros } 1\end{array}$ & Dificuldade financeira & $\begin{array}{l}\text { Encaminhar o paciente para grupo de apoio } \\
\text { psicologico }\end{array}$ \\
\hline \multirow[t]{2}{*}{ ESCOI.HER } & $\begin{array}{l}\text { DE18 - ESTRATEGIAS } \\
\text { INEFICAZES D DE } \\
\text { RESOLUCAO } \\
\text { INDIVIDUAL } 7\end{array}$ & $\begin{array}{l}\text { Cd18a- verbalizaçăo de inabilidade } \\
\text { para resolver problemas } 7 \\
\text { Cd18b-mudaç̧a nos padróes de } \\
\text { comunicaçăo } 1 \\
\text { Cd18c-doenças frequentes } 1\end{array}$ & $\begin{array}{l}\text { Fr18a-Distúrbio na auto estima } \\
5 \\
\text { Fr18b-Vulnerabilidade pessoal } \\
1 \\
\text { Fr18c-Crise existencial } \\
\text { situacional } 4 \\
\end{array}$ & \begin{tabular}{|l|} 
Stress \\
Escolaridade \\
Crença religiosa
\end{tabular} & $\begin{array}{l}\text { Encaminhar o paciente para grupo de apoio } \\
\text { psicologico } \\
\text { Orientar o paciente a controlar o nivel de stress }\end{array}$ \\
\hline & $\begin{array}{l}\text { DE19-ESTRATEGIAS } \\
\text { INEFICAZES DE } \\
\text { RESOLUÇAO } \\
\text { FAMILIAR } 1\end{array}$ & $\begin{array}{l}\text { Cd19a- preocupaçà sobre resposta da } \\
\text { filha ao problema de saúde 1 } \\
\text { Cd19b-Pessoa significativa tenta } \\
\text { comportamento de assistência e apoio } \\
\text { sem resultado positivo 1 }\end{array}$ & $\begin{array}{l}\text { Fr19a-Informação ou } \\
\text { compreensão inadequada da } \\
\text { pessoa significativa } 1 \\
\text { Fr19b-Preocupação e crise da } \\
\text { pessoa significativa 1 }\end{array}$ & & $\begin{array}{l}\text { Encaminhar o paciente para grupo de apoio } \\
\text { psicologico }\end{array}$ \\
\hline MOVER & $\begin{array}{l}\text { DE 3-DISTÚRBIO NO } \\
\text { PADRÃO DO SONO } 26\end{array}$ & $\begin{array}{l}\text { Cd3a- queixas verbalizadas de } \\
\text { dificuldade para adormecer } 18 \\
\text { Cd3b-sono interrompido } 20 \\
\text { Cd3c-queixa de não sentir-se bem } \\
\text { repousado } 19 \\
\text { Cd3d- queixa verbalizada de demora } \\
\text { para adormecer } 5 \\
\text { Cd3e-queixa de acordar cansado } 1\end{array}$ & $\begin{array}{l}\text { Fr3a -Alteraçðes sensoriais } \\
\text { internas causadas pela doença } \\
\text { e/ou drogas } 25 \\
\text { Fr3b-Alteraçðes sensoriais } \\
\text { externas ( situação social ) 1 }\end{array}$ & \begin{tabular}{|l|} 
Sedentarismo \\
Fumo \\
Doenças cardiacas \\
Hábito alimentar \\
Inadequado \\
Ingestão excessiva de \\
liquidos
\end{tabular} & $\begin{array}{l}\text { Orientar o paciente a manter hábitos constantes de } \\
\text { sono, com horários fixos para o repouso. } \\
\text { Orientar a necessidade de atividade fisica } \\
\text { Orientar o paciente a controlar o nivel de stress } \\
\text { Orientar o paciente quanto à terapias alternativas } \\
\text { como uso de chás e massagens de conforto. } \\
\text { Orientar sobre a iniportância do local onde } \\
\text { paciente repousa, em reluçào a estar sem harulho e } \\
\text { claridade cm demasia. ser ventilado c sem } \\
\text { presença de agentes causadores de alergias. } \\
\text { Orientar o paciente a promover um rela vamento } \\
\text { das atividades do dia antes de ir deitar-se } \\
\text { Orientar o paciente quanto à estratégias para } \\
\text { induzir o sono } \\
\text { Orientar a colaboraçào da familia para evitar } \\
\text { interrupcóes no momento de repouso } \\
\text { Orientar o paciente a evitar descansar de dia }\end{array}$ \\
\hline
\end{tabular}




\begin{tabular}{|c|c|c|c|c|c|}
\hline \multirow[t]{6}{*}{$\begin{array}{l}\text { MOVER } \\
\text { cont }\end{array}$} & $\begin{array}{l}\text { DE 7-POTENCIAL } \\
\text { PARA INTOI.ERAANCIA A } \\
\text { ATIVIDADE } 9\end{array}$ & $\begin{array}{l}\text { Cd7a-presença de problema } \\
\text { respiratório } 5 \\
\text { Cd7b-estado de nðo condiciomamento } \\
\text { fisico } 8 \\
\text { Cd7c-inexperiéncia com atividude I } \\
\text { Cd7d-prublema circulatório } 5\end{array}$ & & Obesidade & $\begin{array}{l}\text { Encaminhar o paciente ao médico para medicaçào } \\
\text { associada quando for necessário } \\
\text { Fncaminhar paciente para a nutricionista para } \\
\text { elaboraçáo de dieta adequada quando possivel } \\
\text { ( Trientar a necessiducte de utividade fisica } \\
\text { Orientar e supervisionar a perda de peso }\end{array}$ \\
\hline & $\begin{array}{l}\text { DE } 8 \text { - INTOIFRAंNCIA } \lambda \\
\text { AIIVIINAII: } 6\end{array}$ & 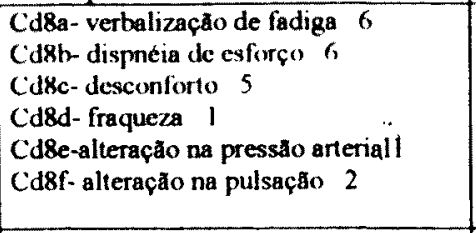 & $\begin{array}{l}\text { Fr8a-Fraqueza } 3 \\
\text { Fr4h-Fstilo de vida sodentárias } \\
\text { Fr\&b-Desequilibrio entre o } \\
\text { suprimento e a demanda de } 02 \text { e } \\
\text { glicose } 1 \\
\text { Fr8c-Depressăo } 3 \\
\text { Fr8d-Fator de risco alterado } 1 \\
\end{array}$ & $\begin{array}{l}\text { Drenças cardiacas } \\
\text { IBronquite } \\
\text { Otxsididude }\end{array}$ & $\begin{array}{l}\text { Encaminhar o paciente ao médico para medicaçáo } \\
\text { associada cuando for necessário } \\
\text { (rientar o controle das patologias associadas } \\
\text { Orientar e supervisionar a perda de peso }\end{array}$ \\
\hline & $\begin{array}{l}\text { DE10- DEFICIT DE } \\
\text { LAZER } 5\end{array}$ & $\begin{array}{l}\text { Cd10a-desejo de ter algo para fazer } 5 \\
\text { Cdlob-verbalizaçao de tedio } 1 \\
\text { Cdloc-desejo de viajar } 2\end{array}$ & $\begin{array}{l}\text { Frl0a-Falta de atividade de } \\
\text { lazer no ambiente } 2 \\
\text { Frlob-Falta de condiços } \\
\text { financeiras } 2\end{array}$ & & Encaminhar para grupos de apoio da comunidade \\
\hline & $\begin{array}{l}\text { DE12 MANUTENÇĀO DA } \\
\text { SAÚDE ALTERADA } 5\end{array}$ & $\begin{array}{l}\text { Cd12a- falta de conhecimento de } \\
\text { praticas de saúde } 5 \\
\text { Cd12b-desinteresse } 2\end{array}$ & $\begin{array}{l}\text { Fr12a-Estratégias ineficazes de } \\
\text { resoluçăo } 2 \\
\text { Fr10b-Falta de condiçōes } \\
\text { financeiras } 2 \\
\text { Frl la Deficit de informaçăo } 3 \\
\text { Fr12b-Baixo nivel sócio- } \\
\text { economico 1 } \\
\text { Frl2c-Diminuiçăo do apoio } \\
\text { familiar 1 }\end{array}$ & $\begin{array}{l}\text { Escolaridade } \\
\text { Stress } \\
\text { Crenças de saúde } \\
\text { Crenças religiosas }\end{array}$ & Orientar o paciente a controlar o nivel de stress \\
\hline & $\begin{array}{l}\text { DE28 - MANUTENÇÃO } \\
\text { DO LAR PREJUDICADA } 2\end{array}$ & $\begin{array}{l}\text { Cd28a-relato de problemas financeiros } \\
2 \\
\text { Cd28b-desempregado } 2 \\
\text { Cd28c- mora com parente } 1\end{array}$ & $\begin{array}{l}\text { Fr10b -Falta de condiçóes } \\
\text { financeiras } 2 \\
\text { Fr28a-Sistema de apoio } \\
\text { inadequado } 1\end{array}$ & & $\begin{array}{l}\text { Encaminhar paciente para recursos sociais da } \\
\text { comunidade }\end{array}$ \\
\hline & DE20 - FADIGA 1 & $\begin{array}{l}\text { Cd20a-verbalizaçăo de falta de energia } \\
1 \\
\text { Cd20b-aumento de queixas } 1 \\
\text { Cd20c-diminuiçáo desempenho } 1 \\
\text { Cd20d-diminuição da libido } 1 \\
\end{array}$ & $\begin{array}{l}\text { Fr20a -Alteraçăo quimica do } \\
\text { corpo } 1\end{array}$ & \begin{tabular}{|l|} 
Obesidade \\
Doenças cardiacas \\
Diabetes \\
Depressåo
\end{tabular} & $\begin{array}{l}\text { Encaminhar o paciente ao médico para medicação } \\
\text { associada quando for necessário } \\
\text { Orientaro controle das patologias associadas } \\
\text { Orientar e supervisionar a perda de peso l }\end{array}$ \\
\hline PERCEBER & $\begin{array}{l}\text { DE17 - DISTÚRBIO } \\
\text { NA AUTO-ESTIMA } 2\end{array}$ & $\begin{array}{l}\text { Cd17a- verbalizaçăo negativa sobre si } \\
\text { mesmo } 2 \\
\text { Cd17b- avaliação como incapaz de } \\
\text { lidar com situaçđes } 2\end{array}$ & $\begin{array}{l}\text { Frl7a-Avaliação como incapaz } \\
\text { de resolver problemas } 2\end{array}$ & \begin{tabular}{|l|} 
Falta de condições \\
financeiras \\
Depressão \\
Doença crônica \\
\end{tabular} & $\begin{array}{l}\text { Encaminhar para grupo de apoio psicologico } \\
\text { Encaminhar paciente para recursos sociais da } \\
\text { comunidade } \\
\text { Orientar o controle das patologias associadas } \\
\end{array}$ \\
\hline
\end{tabular}




\begin{tabular}{|c|c|c|c|c|c|}
\hline CONHECER & $\begin{array}{l}\text { DE I-DEFICIT DE } \\
\text { CONHECIMENTO SO- } \\
\text { BRE A DOENCCA } 48\end{array}$ & Cdla- verbalização do problems 48 & $\begin{array}{l}\text { Frla-Falta de experiência prévia } \\
48 \\
\text { Frlb-Deficit cognitivo } 2\end{array}$ & $\begin{array}{l}\text { Escolaridade } \\
\text { Desinteresse }\end{array}$ & $\begin{array}{l}\text { Orientar o paciente e familiares em relação a } \\
\text { patologia, alertando para as possiveis } \\
\text { intercorréncias, os fatores de risco para outras } \\
\text { doenças e as complicaç̃̃es.e mudanças no cstilo } \\
\text { de vida } \\
\text { Orientar a leitura de folhetos explicativos sobre a } \\
\text { doença } \\
\text { Orientar e supervisionar o uso correto dos } \\
\text { medicamentos prescritos :quanto ao horário, } \\
\text { conservação, efeitos colaterais } \\
\text { Orientar e supervisionar o paciente a verificar a } \\
\text { sua própria pressão arterial } \\
\text { Orientar a manter um registro frequente das } \\
\text { medidas de pressão tomadas } \\
\text { Orientar o paciente sobre que providências tomar } \\
\text { quando tiver crise de hipertensão } \\
\text { Encaminhar o paciente para os Grupos de } \\
\text { Orientaçãode Hipertensos }\end{array}$ \\
\hline \multirow[t]{3}{*}{ SENTIR } & $\begin{array}{l}\text { DE } 25 \text { DISFUNCCÃO NA } \\
\text { REAÇÅO DE PESAR } 1\end{array}$ & $\begin{array}{l}\text { Cd25a -Expressão verbal de angústia } \\
\text { diante da perda } 1 \\
\text { Cd25b -Choro 1 } \\
\text { Cd25c-Recordaçðes de expectativas } \\
\text { passadas 1 }\end{array}$ & Fr25a-Morte de filho único 1 & & $\begin{array}{l}\text { Encaminhar paciente para grupo de apoio } \\
\text { psicologico }\end{array}$ \\
\hline & \begin{tabular}{|lll} 
DE26 REACANO & DF \\
PESAR ANTECIPADA & 1 \\
\end{tabular} & $\begin{array}{l}\text { Cd26a - Verbalizaça do possibilidade } \\
\text { de perda de objeto significativo । }\end{array}$ & $\begin{array}{l}\text { Fr26a -1 Doença crônica fatal da } \\
\text { filha } 1\end{array}$ & & $\begin{array}{l}\text { Fincaminhar paciente para grupo de apoio } \\
\text { psicológico }\end{array}$ \\
\hline & DE27 - ANSIEDADE 2 & $\begin{array}{l}\text { Cd27a-incerteza 2 } \\
\text { Cd27b-medo 1 } \\
\text { Cd27c-tagarelice 1 } \\
\text { Cd27d-angustia 2 } 2 \text { com falta de } \\
\text { Cd27e-preocupação } \\
\text { comida 1 } \\
\text { Cd27f-tensão aumentada 1 } \\
\text { Cd27g-apreensão 1 } \\
\text { Cd27h-temor 1 } \\
\text { Cd27i-pobre no contato no olho 1 } \\
\text { Cd27j-tremor nas mãos 1 } \\
\text { Cd23d-tosse 1 }\end{array}$ & $\begin{array}{l}\text { Fr18c-Crise situacional l } \\
\text { Fr27a-Necessidades não } \\
\text { atendidas } 2 \\
\text { Fr27b-Mudança no estado de } \\
\text { saúde 1 }\end{array}$ & $\begin{array}{l}\text { Falta de condiçōes } \\
\text { Financeiras }\end{array}$ & $\begin{array}{l}\text { Encaminhar paciente para grupo de apoio } \\
\text { psicológico } \\
\text { Encaminhar paciente para recursos sociais da } \\
\text { comunidade }\end{array}$ \\
\hline TOTAL - 8 & $29 / 197$ & $96 / 364$ & $63 / 271$ & & \\
\hline
\end{tabular}


Analisaremos neste estudo apenas os diagnósticos de enfermagem que foram identificados em mais de 21 pacientes (42\%), apesar de relacionar todos na Tabela 22. São eles o déficit de conhecimento sobre a doença, distúrbio no padrão do sono, nutrição alterada: ingestão maior do que as necessidades corporais, disfunção sexual.

Foram encontradas associações estatisticamente significantes $(p<0,05)$ que podem ser visualizadas nas Tabelas $16^{A}$ à $35^{A}$ nos Anexos que serão discutidas em seguimento aos diagnósticos. São elas:

Sexo e nutrição alterada $(p=0,017$ a ingestão maior que as necessidades corporais é mais presente entre os homens)

Sexo e disfunção sexual ( $p=0.036$ homens apresentam mais disfunção sexual do que mulheres )

Uso de Metildopa e excesso de volume de líquidos ( $p=0,032)$

Uso de Hidroclorotiazida e disfunção sexual( associação inversa os que não usavam o medicamento apresentavam mais disfunção do que os que usavam)

Cansaço e disfunção sexual $(p=0,020)$

Cansaço e constipação $(p=0,006)$

Expressão facial tensa ou angustiada e estratégias ineficazes de resolução individual $(p=0,030)$

Pressão arterial alterada e constipação $(p=0,021)$ 
O déficit de conhecimento sobre a doença é o diagnóstico mais freqüente aparecendo em $96 \%$ dos pacientes analisados. Este diagnóstico refere-se ao Padrão de Resposta Humana CONHECER e significa " um estado no qual o individuo não tem a informação correta ou completa sobre aspectos necessários para manter ou melhorar seu bemestar"( Nóbrega e Garcia, 1994). Este padrão para Maria (1997), envolve a compreensão adequada de uma informação e compreende as variáveis de conhecimento, aprendizagem e o processo de pensamento".

A caracteristica definidora que apareceu em todos os pacientes foi a de verbalização do problema de falta de conhecimento, apesar de todos também terem informado que já tinham recebido orientaçōes à respeito da doença pelo médico. Pode-se inferir que esta orientação não tenha sido suficiente ou adequada. Talvez em razão de a maioria destas orientações ser feita muito rapidamente durante a consulta e um novo contato com o médico só será na próxima consulta após um ou dois meses. Nos fatores relacionados aparecem a falta de experiência prévia com esta patologia em especial, dificultando o conhecimento e o déficit cognitivo em dois pacientes. Têm importâncias os outros problemas relacionados como a escolaridade baixa da maioria dos estudados, que contribue para terem maior dificuldade para aprender sobre a patologia e cuidados, e o desinteresse identificado de alguns, pois mesmo que tenham a informação não parecem interessados em usá-la. 
Pierin em 1985 ao analisar pacientes hipertensos com acompanhamento ambulatorial constatou àquela época que cerca de metade dos entrevistados não tinham conhecimento das possiveis complicações desta patologia.

Estudando pacientes com alterações cardiológicas, Cruz (1989) , identificou em pacientes internados por cardiopatia chagásica crônica este diagnóstico em 63,3 \% dos pacientes . Cruz (1993), também ao analisar os diagnósticos de pacientes hipertensos em acompanhamento ambulatorial, encontrou o déficit de conhecimento sobre a doença como o mais freqüente.

Estes resultados são contrastantes com o descrito por Maria (1997) ao relatar os diagnósticos de pacientes de unidade coronariana, que encontrou 60 num universo de $868(6,91 \%)$. Talvez esta dferença esteja retacionada ao estado dínico dos pacientes pesquisados, uma vez que analisamos paciente ambulatorial, que poderia ester mais preocupado em verbalizar suas dúvidas do que outro internado na unidade coronariana que teria outos agravos como prioritários.

Por auto lado resultados de Costa et al.(1998) com pacientes ambulatoriais portadores de epilepsia chegam a valores próximos (90\%) aos que encontramos. Camagnani (1999) ao estudar pacientes submetidos à laringectomia total identificou apenas 1 paciente (1,6\%) num universo de 61, com este diagnóstion. 
Podemos sugerir que o déficit de conhecimento sobre a doença pode variar em função das patologias associadas, pois em pacientes potencialmente mais graves a orientação seria mais eficiente, talez pelo próprio estado destes.

Cruzando os diagnósticos com algumas variáveis observadas, notamos que o percentual de pacientes com déficit de conhecimento sobre a doença é superior a $90 \%$ nesses cruzamentos, indicando que a presença deste diagnóstico independe de sexo, idade, antecedentes, o que passa a ser preocupante sob o ponto de vista de saúde pública, frente aos danos que esta patologia traz.

O déficit de conhecimento sobre a patologia faz com que o paciente não possa se auto-cuidar, ficando exposto a mais riscos. Sendo a hipertensão uma doença silenciosa, os sinais e sintomas aparecerão quando ela já estiver instalada e provocando danos de maior gravidade.

As intervenções de enfermagem para este diagnóstico junto à pacientes ambulatoriais devem objetivar a identificação de todas as variáveis onde existam dúvidas ou desconhecimento, promovendo a orientação do paciente e familiares de diferentes maneiras e avaliando se estas foram seguidas adequadamente. Ensinar ao paciente a verificar a sua própria pressão arterial é importante, todavia para que isso possa ser viável 
é necessário analisar a disponibilidade financeira para aquisição do instrumental adequado

O segundo diagnóstico caracterizado foi o distúrbio do padrão do sono que apareceu em $52 \%$ dos pacientes. Este diagnóstico pertence ao Padrão de Resposta Humana MOVER e significa "estado no qual o indivíduo apresenta alteração no período do sono, causando desconforto ou interferindo no estilo de vida desejado" (Nóbrega e Garcia, 1994). As caracteristicas definidoras encontradas foram queixas verbalizadas de dificuldade para adormecer, sono interrompido, queixa de não sentir-se bem repousado, queixa de demora para adormecer e de acordar cansado. Estes sinais podem em parte serem creditados a efeitos colaterais de medicamentos anti-hipertensivos ou a outras patologias associadas.

Cruz (1989) encontrou 43,3\% de pacientes com este diagnóstico, e Maria (1997) relata para pacientes em unidade coronariana esse mesmo diagnóstico com menos de $1 \%$ de identificaçāo.

O paciente hipertenso costuma ficar irritadiço pela própria alteração da pressão, e esta iritação associada ao déficit de sono costuma fazer com que o paciente verbalize sensação de malestar. A falta de sono prolongada costuma trazer o cansaço e a perda de concentração resultando em dificuldade de manter o ritmo natural de vida. 
Os fatores relacionados deste diagnóstico dizem respeito à alterações causadas pela própria doença e pela terapia medicamentosa pois como já relatado, alguns agentes anti-hipertensivos podem provocar insônia.

Neste diagnóstico podemos ainda associar como componentes que contribuem para que o mesmo se instale são os outros problemas relacionados, como o sedentarismo, e o hábito alimentar inadequado, identificado em grande parte dos paciente, pois favoreceriam a insônia. As doenças cardíacas às vezes trazem certo desconforto noturno , 0 fumo produz insônia e a ingestão excessiva de liquidos pode contribuir para a necessidade do paciente levantar-se para ir ao banheiro e com isso ter dificuldade para dormir novamente.

As intervenções de enfermagem para este diagnóstico devem objetivar auxiliar o paciente a criar condições que possam favorecer o repouso adequado, e estão centradas nas orientações sobre hábitos necessários para o sono e repouso.

O diagnóstico que apareceu em terceiro lugar foi o de nutrição alterada com ingestão maior do que as necessidades corporais em $\mathbf{5 0 \%}$ dos pacientes. Este diagnóstico situado no Padrão de Resposta Humana TROCAR é definido como "estado no qual o individuo 
tem uma ingestão de nutrientes que excede as suas necessidades metabólicas" (Nóbrega e Garcia ,1994). A característica definidora comum a todos os pacientes foi o peso 10 ou $20 \%$ acima do recomendado para a estatura e idade.

Os fatores relacionados neste diagnóstico são para a alimentação inadequada com outros problemas como a não adesão à dieta prescrita mesmo com a presença de diabetes e colesterol elevado. $O$ excessivo uso de chás para o controle da hipertensão também parece contribuir para o descaso com a dieta, pois os pacientes acreditam que estes os liberam para comer de tudo.

A literatura mostra que a obesidade pode contribuir para o aparecimento da hipertensão arterial e contribuir para outras complicações na saúde (Oparil,1993;Braunwald, 1999 ). O paciente com excesso de peso normalmente tem uma vida mais sedentária e alimenta-se de maneira errada, formando um círculo vicioso de rompimento difícil.

Associação estatísticamente significante existem entre sexo e nutrição alterada (a ingestão maior que as necessidades é mais presente entre os homens) $(p=0,017)$ - Apesar de aparentemente no exame físico as mulheres parecerem ser mais gordas, ao serem comparados, este achado foi maior nos homens. Talvez possa ser explicado pelo padrão estético que a 
sociedade hoje apregoa para a mulher onde excesso de peso não tem sido bem aceito, mais por questões estéticas.

As intervenções de enfermagem devem estar dirigidas a orientação do paciente e familiares, encaminhamento à nutricionista par elaboração de cardápio adaptado às condições de vida destes e a grupos de auto-ajuda para auxílio na redução do peso, e acompanhamento mensal para controle deste mensalmente.

O diagnóstico de disfunção sexual aparece em quarto lugar tendo sido relatado para $42 \%$ dos pacientes. Ele está situado dentro do Padrão de Resposta Humana RELACIONAR e é definido como "estado no qual o indivíduo experimenta uma mudança na função sexual que é vista como insatisfatória ", não compensadora e inadequada " (Nóbrega e Garcia, 1994).

As características definidoras encontradas foram relato de dificuldade na atividade sexual, limitação da atividade sexual imposta pela doença, inabilidade para alcançar satisfação, relato de dor e relato de limitação imposta pela idade.

Este diagnóstico também foi elencado por Cruz (1993), porém em apenas um paciente hipertenso. Maria também menciona este 
diagnóstico encontrado em 7 pacientes num universo de 868 , mas também identifica potencial para disfunção sexual em um caso.

As carateristicas definidoras identificadas são a alteração pela doença e medicamentos, falta de pessoa significativa desinteresse, mesmo sendo o maior número de casados. À elas agregamos outros problemas como diabetes, o alto nivel de stress identificado e o fumo, que contribuem para essa disfunção.

A população estudada é a maior parte constituida por mulheres acima dos 55 anos, que relatam não ter vida sexual ativa e entre as causas citam a doença. Sabe-se que um dos efeitos colaterais do uso de anti-hipertensivos cujo princípio ativo seja a metildopa é a diminuição da libido que interferiria no padrão sexual. Todavia como os pacientes não tem informação suficiente e adequada , a maior parte destes não conhece efeitos colaterais das drogas que faz uso, não relacionando seu desempenho sexual ao uso da mesma. Talvez por vergonha não comunica ao médico , continuando com o problema e absorvendo-o como uma alteração devido doença ou idade. O relato de dor parece estar relacionado a outros problemas de saúde do paciente.

Associações estatisticamentes significantes foram identificadas entre: sexo e disfunção sexual (homens apresentam mais 
disfunção do que mulheres $)(p=0,036)$ - Podemos sugerir que esta associação esteja relacionada ao fato de grande parte das mulheres de meia-idade estudadas não considerasse mais como normal ainda ter atividade sexual plenamente satisfatória, uma vez que verbalizam durante a consulta, o que para os homens normalmente não ocorre, pois a questão da masculinidade permeia a possível queixa nesta área. Todavia ainda existe a considerar os efeitos colaterais dos medicamentos antihipertensivos que causam a impotência, a diminuição da libido e a disfunção sexual; uso de hidroclorotiazida e disfunção sexual $(p=0,041)($ Obs.: associação inversa - os que não usavam o medicamento apresentaram mais disfunção do que os que usavam) - Apesar da falta de evidências que possam comprovar, talvez esta associação possa ter ocorrido em razão de muitos pacientes tomarem inicialmente metildopa e ao apresentarem diminuição da libido, que é um efeito colateral bastante observado, tenham tido sua medicação alterada. Mas isto não foi pesquisado neste estudo;cansaço e disfunção sexual $(p=0,020)$ - Sem evidências, pode-se sugerir que talvez possa haver somatória de sintomas associados a outros problemas de saúde e efeitos colaterais de medicamentos. Não temos dados para afirmar ;idade e disfunção sexual $(p=0,056)$ - Indica apenas uma tendência . Encontramos que a disfunção sexual foi maior nas faixas etárias acima dos 50 anos.Não existe indicação precisa que esta disfunção possa ocorrer sempre, pois existem relatos de ida sexual ativa até idades muito superiores; expressão facial tensa/angustiada e disfunção sexual 
$(p=0,055$ - Indica apenas uma tendência.) Não existem evidências de que a disfunção sexual possa trazer alteraçōes na expressão dos pacientes, todavia sabe-se que a parte sexual integra o rol de necessidades do ser humano e que talvez se esta não estiver sendo atendida o paciente pode Ter alterações que sejam extravasadas na expressão.

As intervenções de enfermagem devem ser direcionadas à orientação do paciente e familiares, na tentativa de identificar as causas da disfunção e o encaminhamento profissional quando necessário.

Parece haver uma certa semelhança entre os achados citados, uma vez que todos referem-se a pacientes com alterações cardiológicas - cardiopatia chagásica, coronariopatias e hipertensão. Outros estudos de caráter comparativo deveriam ser desenvolvidos a fim de se clarear estas semelhanças com amostras maiores e mais abrangentes.

Outras associaçōes embora não sejam significantes a $5 \%$ encontram-se muito próximas ao limite de aceitação indicando uma tendência. São elas: uso de Hidroclorotiazida e excesso de volume de líquidos $(p=0,058)$ - esta associação justifica-se pois clorana, como já descrito é um diurético utilizado no tratamento da hipertensão, que entre os 
seus sinais e sintomas tem o edema que é a retenção de líquidos; cansaço e intolerância à atividade $(p=0,058)$ - 0 cansaço é definido como fator de risco para a intolerância à atividade.

As associaçōes entre variáveis foram analisadas da mesma forma que anteriormente, ou seja, através do teste exato de Fisher ou Quiquadrado. Foram encontradas associações estatisticamente significantes $(p<0,05)$ entre:queixas de cansaço e pressão arterial (os que se queixam apresentam pressão mais alterada). Esta associação pode ser explicada em razão de valores altos de pressão arterial causarem sintoma de cansaço no paciente, devido a alteração circulatória importante; antecedentes de diabetes e pressão arterial (o grupo de pessoas com história familiar de diabetes tem maior proporção de pacientes com pressão alterada). - Existem evidèncias de que pacientes hipertensos com antecedentes familiares de diabetes podem vir a desenvolve-la e vice-versa. Todavia estas evidências carecem de maiores estudos ; e embora não seja significante a $5 \%$ observamos uma tendência $(p=0,083)$ entre o uso de aldomet e a pressão arterial alterada - Este achado é explicado pela necessidade do controle da hipertensão com esta medicação.

As reflexōes com os resultados encontrados neste estudo possibilitaram a elaboração de intervenções de enfermagem para os pacientes portadores de hipertensão arterial em acompanhamento 
ambulatorial, que se constituem num ponto de partida para novo estudo objetivando a sua validação, podendo assim contribuir com o ensino, a pesquisa e a assistência utilizando novos modelos de assistência de enfermagem. 


\section{CONCLUSÃO}

Neste estudo foram identificados nos cinquenta pacientes hipertensos em acompanhamento ambulatorial num centro de saúde escola particular na zona sul da cidade de São Paulo,197 diagnósticos de enfermagem em 29 categorias, em 8 padrões de resposta humana. Identificaram-se ainda 96 características definidoras com 364 categorias e 63 fatores relacionados com 271 categorias. O diagnóstico de enfermagem que foi identificado no maior número de vezes foi o de déficit de conhecimento sobre a doença, em 48 pacientes (96\%), seguido pelo distúrbio no padrão do sono em 26 pacientes (52\%), nutrição alterada:ingestão maior do que as necessidades corporais em 25 pacientes (50\%)e disfunção sexual em 21 pacientes (42\%).

As associaçōes estatísticamente significantes foram entre sexo e nutrição alterada, sexo e disfunção sexual, uso de uso de metildopa e excesso de volume de líquidos, uso de clortalidona e disfunção sexual, cansaço e disfunção sexual, cansaço e constipação, expressão facial tensa ou angustiada e estratégias ineficazes de resolução individual e pressão arterial alterada e constipação, queixas de cansaço e pressão arterial alterada, antecedentes de diabetes e pressão arterial. Algumas associações embora não significantes indicaram tendências : idade e disfunção sexual, uso de hidroclorotiazida e excesso de volume se líquidos e expressão facial tensa e disfunção sexual. 
As intervençōes de enfermagem para os diagnósticos identificados concentraram-se nas ações de orientar, supervisionar e encaminhar o paciente para especialista, objetivando que o paciente alcance autonomia para o seu cuidar de saúde

Outros estudos são sugeridos em outros contextos, na tentativa de discutir nossos achados e preencher lacunas existentes no conhecimento. 


\section{REFERÊNCIAS BIBLIOGRÁFICAS}

Affara $F$, Oguisso $T$. Classificação internacional para a prática de Enfermagem. R Bras Enferm. 1995; 48(4) : 423-435.

Antikainen R, Jousilahti $P$, Tuomilehto J. Systolic blood pressure, isola-ted systolic hypertension and risk of coronary heart disease, strokes,cardiovascular disease and all-cause mortality in middle-aged popu lation. Journal of Hypertension 1998; $16: 577-583$.

Araújo TL, Arcuri EAM, Martins, E. Instrumentação na medida da pressão arterial : aspectos históricos,conceituais e fontes de erro. Rev Esc Enf USP 1998; 32 (1): 33-41.

Araújo, TL . Hipertensão arterial - um problema de saúde coletiva e individual. In: Damasceno, MMC et al. Transtornos vitais no fim do século XX : diabetes mellitus, distúrbios cardiovasculares, câncer, AIDS, tuberculọse e hanseníase. Fortaleza, Fundação Cearense de Pesquisa e Cultura, 1999.Pág 33-38.

Arcuri EAM . Estudo comparativo da medida indireta da pressão arterial com manguito de largura correta e com manguito de largura padrão. São Paulo; 1985. [ Tese de Doutorado . Instituto de Ciências Biomédicas - Universidade de São Paulo ].

Arcuri EAM. Medida indireta da pressão arterial: revisão. Rev Esc Enf USP 1989; 23 : 163-174.

Archer S., Fleshman R. Enfermeria de Salud Comunitaria :Modalidades y practica. USA: OPS/OMS; 1982. 
Atkinson LD, Murray ME. Fundamentos de Enfermagem : introdução ao processo de enfermagem .Rio de Janeiro:Editora Guanabara; 1989.

Ayres JEM. Prevalência da hipertensão arterial na cidade de Piracicaba . Arq.Bras.Cardiol. 1991; $57:$ 33-36.

Baise $C$ et al. Epidemiologia da Hipertensão Arterial entre a população da região atendida pelo Serviço do Pronto Socorro do Hospital Escola da Universidade de Santo Amaro. Iatros 1995; 10 (2):43-48.

Barros, ALBL . Assistência de enfermagem ao paciente portador de hipertensão arterial. São Paulo, 1998. Mimeo.

Barros, ALBL. $O$ trabalho Docente assistencial de enfermagem mo Hospital São Paulo da UNIFES/EPM. São Paulo; 1998. [ Tese de LivreDocência - Universidade Federal de São Paulo ].

Batista MC et. Al. $\mathrm{O}$ uso da associação de nifedipina e atenolol em formulação galênica única na hipertensão arterial essencial lee a moderada. J.Bras.Nefrol. 1996; 18: 340-347.

Brasil, Ministério da Saúde: Anais da VIII Conferência Nacional de Saúde. Brasilia, 1986.

Brasil. Ministério da Saúde. SAS. DPS. CDC. Controle da hipertensão: uma proposta de integração ensino-serviço. Rio de Janeiro: NUTES; 1993.

Brasíndice - Guia Farmacêutico .São Paulo: Andrei;junho,1999.

Braunwald E. Tratado de Medicina Cardiovascular. $5^{\mathrm{a} e d . ~ S a ̃ o ~ P a u l o: ~}$ 
Roca; 1999. Volume 1, Capítulo 26, Pág. 859-888.

Campedelli MC, Gaidzinski RR . A metodologia assistencial de enfermagem na prática : hospital universitário da USP. Rev Esc Enf USP. $1987 ; 21\left(n^{\circ}\right.$ esp ):62-7.

Carmagnani, MIS et al. O ensino do diagnóstico de enfermagem num curso de especialização em gerenciamento de serviços de enfermagem.. In: ANAIS do $48^{\circ}$ Congresso Brasileiro de Enfermagem; 1996 outubro 6 -11; São Paulo, Brasil. São Paulo : Associação Brasileira de Enfermagem; 1996. p.256.

Carmagnani, MIS. Diagnósticos e Intervenções de Enfermagem em pacientes submetidos à laringectomia total e parcial. São Paulo; 1999. [ Tese de Doutorado - Universidade Federal de São Paulo].

Carpenito LJ. Diagnósticos de Enfermagem : aplicação à prática clínica. $6^{a}$ ed. Porto Alegre: Artes Médicas; 1997.

Carpenito LJ. Manual de Diagnósticos de Enfermagem. $6^{\text {a }}$ ed. Porto Alegre: Artes Médicas; 1998.

Castro I, Costa AR, Luna RL. Tratamento da hipertensão arterial não Complicada. Jovem Médico 1998; (2) : 108 - 117.

Cianciarullo TI Teoria e Prática em Auditoria de Cuidados. São Paulo : Ícone Editora; 1997.

Cianciarullo TI. Cidadania e Qualidade de Vida. In:Cianciarullo TI, Fugulin FMT, Andreoni S. A hemodiálise em questão :opção pela qualidade assistencial. São Paulo : Ícone; 1998. Capítulo 3. Páginas 31-36. 
Clark DJ How nurses can participate in the development of an ICNP. Int Nurs Rev. 1996; 43 (6) : 171 - 174.

Clark, MJD. Community Nursing Health Care for today and tomorrow. USA: Seston; 1984.

Il Consenso Brasileiro de Hipertensão Arterial. J Bras Nefrol 1994; 16(supl.2) : 261.

Costa, $\mathrm{CCO}$ et al. Diagnóstico de Enfermagem : déficit de conhecimento entre portadores de epilepsia. In :Anais do IV Simpósio sobre Diagnóstico de Enfermagem; 1998 maio 10-13; Curitiba, Brasil. Paraná: Associação Brasileira de enfermagem; 1998. p.4.

Cruz DALM. Diagnósticos de enfermagem e padrōes funcionais de saúde alterados em pacientes internados por cardiopatia chagásica crônica. São Paulo. 1989.[ Dissertação de Mestrado - Escola de Enfermagem da Universidade de São Paulo ] .

Cruz DALM. Os Diagnósticos de Enfermagem no ensino e na pesquisa. Rev.Esc.Enf.USP $1993 ; 36(3): 427-34$.

Cruz DALM. A introdução do Diagnóstico de Enfermagem no ensino: sua influência no processamento de informações por alunos de Graduação. São Paulo; 1995. [ Tese de Doutorado . Escola de Enfermagem da Universidade de São Paulo - Ribeirão Preto ].

Cruz DALM, Cruz ICF, Secaf, V. Taxonomia dos Diagnósticos de Enfermagem: evolução e razões do uso. Acta Paul. Enf. $1991 ; 4$ (2/4) : 28-34. 
Cruz ICF. Diagnósticos de Enfermagem : estratégia para sua formulação e validação. São Paulo ; 1993. [ Tese de Doutorado - Escola de Enfermagem da Universidade de São Paulo - Ribeirão Preto].

Cury Jr AJ. Hipertensão arterial e qualidade de vida . Âmbito Hospitalar $1996 ; 8: 58-60$.

Doenges ME, Moorhouse MF. Aplicação do Processo de Enfermagem e do Diagnóstico de Enfermagem : um texto interativo. Lisboa: Lusodidacta; 1992.

Esteves SC et al. Hipertensão renovascular. Diagnóstico e Tratamento. RBM Rev Bras Med $1995 ; 52(5): 418-434$.

Fuchs FD et. al. Diagnóstico de hipertensão arterial sistêmica : evidências de que os critérios contemporâneos devem ser revistos. Rev Ass Med Brasil 1997; 43 (3): $223-7$.

Fugulin FMT et: Al. O processo de cuidar. In: Cianciarullo $\mathrm{Tl}$ et.al. A hemodiálise em questão : opção pela qualidade assistencial. São Paulo : Ícone Editora; 1998.

George JB. Teorias de Enfermagem: a base para a prática da profissão. Porto Alegre: Artes Médicas, 1993.

Gordon M . Nursing Diagnosis, Process and Application. 3th.ed. New York: Mosby; 1994.

Guerra EMD , Araújo TL. Aderência ao tratamento da hipertensão arterial : comportamentos observados e causas relacionadas. In : Damasceno, MMC et al. Transtornos vitais no fim do século XX : diabetes mellitus, 
distúrbios cardiovasculares, câncer, AIDS, tuberculose e hanseniase. Fortaleza: Fundação Cearense de Pesquisa e Cultura; 1999.Pág.39-46.

Horta WA. Observação sistematizada como base para o diagnóstico de enfermagem. Rev Bras Enf. 1971 ; 24 : 46-53.

Horta WA. Processo de Enfermagem. São Paulo : EPU, 1979.

International Council of Nurses. Nursing's next advance : an International Classification for Nursing Practice - ICNP. Geneve, 1993.

lyer PW, Taptich BJ , Bernocchi-Losey D. Processo e Diagnóstico em Enfermagem. Porto Alegre : Artes Médicas; 1993.

Johnson M, Maas M. Nursing Outcomes Classification. USA : Mosby; 1997.

Johnson M, Maas M. The Nursing Outcomes Classification. J.Nurs Care Qual. $1998 ; 12(5)$ : 9-20.

Kaplan NM. Hipertensão sistêmica: mecanismos e diagnóstico. In: Braunwald E. Tratado de Medicina Cardiovascular. $5^{\mathrm{a}} \mathrm{ed}$. São Paulo: Roca; 1999. Volume 1, Capitulo 26, Pág. 859-888.

Karsbmer JF. Expert Nursing Diagnoses. The link between Nursing Care Plans and Patient Classification Systems. JONA $1991 ; 21$ (1): 31-39.

Kathar RS, Senior R, Lahir A Cardiovascular outcome in white-coat sustained mild hypertension. A 10 years follow up study. Circulation 1998; 98: 1892-1897. 
Kiiskinen $U$ et. al. Long-term cost and life-expectancy consequences of Hypertension. Journal of Hypertension 1998; 16:1103 - 1112.

Klag MJ et. al. Blood pressure end-stage renal disease in men. $\mathbf{N}$ Eng $\mathbf{J}$ Med 1996; $334: 13$ - 18 [ Resumo de CIS Rodrigues In: J Bras Nefrol $1998 ; 20: 229-231]$.

Korolkovas A Dicionário Terapêtico Guanabara. Rio de Janeiro:

Guanabara Koogan; 1998.

Labbadia EM, Cury Jr AJ. Hipertensão arterial e atendimento multiprofissional: uma nova forma de abordagem e tratamento do paciente hipertenso. RBMP $1997 ; 1: 188-193$.

Macedo CG. In: El derecho a la salud de las Américas - Introducción. Washington, DC: Organizacion Panamericana de la Salud ; 1989.

Magrini F, Peggiani P. Epidemiology of hypertension in Europe. Eur. Heart J. 1992; 13:27-34.

Malik AM. Saúde e desenvolvimento. In: Gonçalves EL et al. Administração de Saúde no Brasil. São Paulo : Pioneira; 1989. Capitulo1, p.1-22.

Maria VLR. et al. Sistematização da assistência de enfermagem no Hospital Dante Pazzanese de Cardiologia :relato de experiência. Rev.Esc Enf USP.1987; 21 ( n/e) : 77-87.

Maria VLR. Elaboração de Diagnósticos de Enfermagem do paciente coronariano em estado crítico. São Paulo; 1998 [ Tese de Doutorado Escola de Enfermagem da Universidade de São Paulo ]. 
Mc Closkey JC, Bulechek GM. Nursing Interventions Classification. 2nd.ed. St.Louis, USA : Mosby, 1996.

Medel ES. Adherencia al control de los pacientes hipertensos y fatores que la influencian. Ciencia y enfermeria. 1997; III (1) : 49-58.

Mendes EV. Brasil. In: Novaes HM; Paganini JM, editores . El Hospital Público. Tendencias y Perspectivas. Washington, USA : OPS/OMS; 1994. p. 77-95.

Mion Jr D, Tinnuci T. $O$ grande desafio : como manter o paciente em tratamento com a pressão normalizada. V.3. São Paulo: DACHA. 1991,p 03-34.

National Institutes of Health National Heart, Lung, and Blood.The Sixth Report of the Joint National Committee on Detection, Evaluation and Treatment of High Blood Pressure ( JNC VI ). Institute National High Blood Pressure Education Program. NIH Publication No 98-4080. Washington,DC, nóvember, 1997.

Nielsen GH , Mortesen RA. The architecture for an International Classification for Nursing Practice ( ICNP). Int Nurs Rev. 1996; 43 ( 6 ): $175-182$.

Nielsen GH , Mortesen RA. The architecture of ICNP: time for outcomes part II. Int Nurs Rev.1998; 45 (1): 27-31.

Nóbrega MML, Garcia TR. Uniformização da Linguagem dos Diag nósticos de Enfermagem da NANDA. Sistematização das propostas do II SNDE. João Pessoa : União; 1994. 
North American Nursing Diagnosis Association. Nursing Diagnoses.St. Louis : Author. 1992-1993.

Novaes HM,Paganini JM,edit. El Hospital Publico tendencias y perspectivas. Washington, DC : OPS/OMS; 1994.

Oguisso T. A Enfermagem e a mudança nos serviços de saúde.

Enfermagem 1998; ( 8 ) $2^{\circ}$ série : $37-44$.

Oparil S. Hipertensão arterial. In: Wyngaarden JB, Smith LH, Bennett JC (Edits.) . Cecil Tratado de Medicina Interna. 19aed. Rio de Janeiro, Guanabara - Koogan, 1993. Vol. 1. Capítulo 44. Pág.258-274.

Organização Mundial de Saúde. Conferência Internacional sobre atención primaria de salud. Alma Ata. Genebra, 1978.

Organização Mundial de Saúde. Estratégias para Salud para todos en el año 2000. Genebra, 1980.

Organização Mundial de Saúde. Extracto del informe de reunión de la OMS sobre Enfermeria en apoyo del objetivo de Salud para todos en el año 2000. Genebra, 1981.

Paffensbarger Jr RS, Lee IM. Relação da intensidade de atividade física com a incidência de hipertensão e a mortalidade em geral : visão epidemiológica. Doença Arterial Coronariana 1998; 1: 92 - 102.

Paulo LG, Zanini AC. Compliance: sobre o encontro pacientemédico.São Paulo: Ipex Editora ; 1997.

Pelá NTR, Jesus CAC, Carvalho EC. As categorias diagnósticas de 
sexualidade: proposta de reorganização. CCS. $1994 ; 13$ (2) : 45-51.

Pierin AMG. A pessoa com hipertensão arterial em tratamento no ambulatório :estudo sobre os problemas, dificuldades e expectativas quanto à doença e ao tratamento. São Paulo;1985. [ Dissertação de Mestrado. Escola de Enfermagem da Universidade de São Paulo ].

Ribeiro, AB. Hipertensão arterial como sindrome - o novo desafio da terapia antihipertensiva [ editorial]. Rev Ass Med Brasil 1997; 43 : 179.

Robazzi MLCC et al. A utilização da Taxonomia I da NANDA na atribuição de Diagnósticos de Enfermagem a uma comunidade de trabalhadores . Revista Baiana de Enfermagem. 1995 ; 8 ( 1 ) : 5 - 20.

Safar ME , Frohlich ED. The arterial system in Hypertension a prospective view. Hypertension $1995 ; 26: 10-14$.

Santello JL, Krasilsic S, Mion Jr D. O papel da Hipertensão Arterial na prevenção primária e secundária das doenças cardiovasculares. Rev.Soc.Cardiol. Estado São Paulo. 1996. 6 ( 5 ) :

Smith TW. Abordagem do paciente com doença cardiovascular. In : Wyngaarden JB, Smith LH, Bennett JC (Edits.) .Cecil Tratado de Medicina Interna. $19^{\circ} \mathrm{ed}$. Rio de Janeiro, Guanabara - Koogan, 1993. Vol. 1. Capítulo 36. Pág 153-157.

Sparks SM , Taylor CM. Nursing Diagnosis Reference Manual. 3th.ed. USA : Pennsylvania, Springhouse Corporation;1995.Staessen JA et al. Randomised double-blind comparison of placebo andactive treatment for older patients with isolated systolic hypertension Lancet 1997; $350: 757$ 64 [ Resumo de A Tavares In J Bras Nefrol 1998; 20 ( 1) : 103 - 105. 
Viniegra L. Hacia un concepto de salud colectiva. Salud Pública de Mexico 1985. 27 ( 5 ) : 410-8. 


\section{ANEXOS}




\section{ANEXO 1}

\section{SOLICITAÇÃO PARA REALIZAR A COLETA DE DADOS}

Ilma.Sra.

Dra.Maria Cristina Faria da Silva Cury

Diretora do Centro de Saúde Escola da UNISA

Senhora Diretora.

Através desta formalizo a solicitação de autorização para coletar dados junto aos pacientes hipertensos tratados com acompanhamento ambulatorial no Centro de Saúde Escola. A coleta de dados destina-se a pesquisa para tese de doutorado que ora desenvolvo sob a orientação da Profa. Dra. Vitória Kedy Cornetta da Faculdade de Saúde Pública da Universidade de São Paulo, intitulada "Diagnósticos e Intervenções de Enfermagem em pacientes com hipertensão arterial em acompanhamento ambulatorial".

No aguardo de vosso deferimento, antecipadamente grata,

Atenciosamente,

Isabel Cristina Kowal Olm Cunha

Enfermeira-pesquisadora 


\section{ANEXO 2 DIAGNÓSTICOS DE ENFERMAGEM SEGUNDO A TAXONOMIA I REVISADA DA NANDA - 1990}

\section{Padrão de Resposta Humana TROCAR}

Envolve os sistemas de controle do corpo num processo de permuta com o meio físico, onde ocorre a captação, a transformação e a eliminação de elementos

1.1.2.1 - Nutrição alterada:ingestão $>$ do que as necessidades corporais

1.1.2.2 - Nutrição alterada: ingestão < que as necessidades corporais

1.1.2.3 - Nutrição alterada:potencial para ingestão $>$ do que as necessidades corporais

1.2.1.1 - Potencial para infecção

1.2.2.1 - Potencial para temperatura corporal alterada

1.2.2.2 - Hipotermia

1.2.2.3 - Hipertermia

1.2.2.4 - Termoregulação ineficaz

1.2.3.1 - Disreflexia

1.3.1.1 - Constipação

1.3.1.1.1 - Constipação percebida

1.3.1.1.2 - Constipação colônica

1.3.1.2 - Diarréia

1.3.1.3 - Incontinência intestinal

1.3.2.1 - Eliminação urinária alterada

1.3.2.1.1 - Incontinência por pressão

1.3.2.1.2 - Incontinência reflexa

1.3.2.1.3 - Incontinência impulsiva

1.3.2.1.4 - Incontinência funcional

1.3.2.1.5 - Incontinência total

1.3.2.2 - Retenção Urinária

1.4.1.1 - Perfusão tissular alterada (renal, cerebral, cardiopulmonar, gastrointestinal,periférica )

1.4.1.2.1 - Excesso do volume de líquido

1.4.1.2.2.1 - Déficit do volume de líquido

1.4.1.2.2.2 - Potencial para déficit do volume de líquido

1.4.2.1 - Débito cardíaco diminuído

1.5.1.1 - Troca de gases prejudicada

1.5.1.2 - Eliminação traqueobrônquica ineficaz

1.5.1.3 - Padrão respiratório ineficaz

1.6.1 - Potencial para injúria

1.6.1.1 - Potencial para sufocação 
1.6.1.2 - Potencial para envenenamento

1.6.1.3 - Potencial para trauma

1.6.1.4 - Potencial para aspiração

1.6.1.5 - Potencial para síndrome do desuso

1.6.2 - Proteção alterada

1.6.2.1 - Integridade tissular prejudicada

1.6.2.1.1 - Mucosa oral alterada

1.6.2.1.2.1 - Integridade da pele prejudicada

1.6.2.1.2.2 - Potencial para integridade da pele prejudicada

2. Padrão de Resposta Humana COMUNICAR

Refere-se à resposta que envolve o envio de mensagens verbais e não verbais

2.1.1.1 - Comunicação prejudicada

\section{Padrão de Resposta Humana RELACIONAR}

Envolve a capacidade de estabelecer vínculos com os seus semelhantes

3.1.1 - Interação social prejudicada

3.1.2 - Isolamento social

3.2.1 - Desempenho de papel alterado

3.2.1.1.1 - Paternidade ou maternidade alterada

3.2.1.1.2 - Potencial para paternidade ou maternidade alterada

3.2.1.2.1 - Disfunção sexual

3.2.2 - Processo familiar alterado

3.2.3.1 - Conflito no desempenho de papéis dos pais

3.3 - Padrão de Sexualidade alterado

\section{Padrão de Resposta Humana VALORIZAR}

Envolve o julgamento sobre o significado ou a importância das coisas, ou seja, daquilo que existe ou pode existir

4.1.1 - Angústia espiritual 


\section{Padrão de Resposta Humana ESCOLHER}

\section{Envolve a seleção de alternativas}

5.1.1.1 - Estratégias ineficazes de resolução individual

5.1.1.1.1 - Adaptação prejudicada

5.1.1.1.2 - Estratégias defensivas de resolução

5.1.1.1.3 - Negação

5.1.2.1.1 - Estratégias ineficazes de resolução familiar : incapacitantes

5.1.2.1.2 - Estratégias ineficazes de resolução familiar :comprometedoras

5.1.2.2 - Estratégias de resolução familiar : potencial para crescimento

5.2.1.1 - Recusa ( especificar)

5.3.1.1 - Conflito de decisão ( especificar )

5.4 - Comportamento para elevar nível de saúde ( especificar )

\section{Padrão de Resposta Humana MOVER}

Envolve a capacidade de executar ações voluntárias
6.1.1.1 - Mobilidade fisica prejudicada
6.1.1.2 - Intolerância a atividade
6.1.1.2.1 - Fadiga
6.1.1.3 - Potencial para intolerância a atividade
6.2.1 - Distúrbio no padrão do sono
6.3.1.1 - Déficit de lazer
6.4.1.1 - Manutenção do lar prejudicada
6.4.2 - Manutenção da saúde alterada
6.5.1 - Déficit no auto-cuidado : alimentação
6.5.1.1 - Deglutição prejudicada
6.5.1.2 - Amamentação ineficaz
6.5.2 - Déficit no auto-cuidado : higiene corporal
6.5.3 - Déficit no auto-cuidado : vestir-se e/ou arrumar-se
6.5.4 - Déficit no auto-cuidado : higiene íntima
6.6 - Crescimento e desenvolvimento alterado

\section{Padrão de Resposta Humana PERCEBER}

Envolve a captação de informações por meio dos órgãos dos sentidos e a interpretação ou formação de idéias com base nestas informações

\subsection{1 - Distúrbio da imagem corporal}


7.1.2 - Distúrbio da auto-estima

7.1.2.1 - Baixa auto-estima : crônica

7.1.2.2 - Baixa auto-estima : situacional

7.1.3 - Distúrbio da identidade pessoal

7.2 - Senso-percepção alterada (visual,auditiva,estética,gusta tiva,tátil,olfativa)

7.2.1.1 - Percepção unilateral alterada

7.3.1 - Desesperança

7.3.2 - Impotência

\section{Padrão de Resposta Humana CONHECER}

Compreensão racional do significado preciso de uma informação

\subsection{1 - Déficit de conhecimento (especificar)}

8.3 - Processo do pensamento alterado

\section{Padrão de Resposta Humana SENTIR}

Envolve a consciência emocional, subjetiva, de uma informação

9.1.1 - Dor

9.1.1.1 - Dor crônica

9.2.1.1 - Disfunção na reação de pesar

9.2.1.2 - Reação de pesar antecipada

9.2.2 - Potencial para violência : direcionada a si e aos outros

9.2.3 - Resposta pós-trauma

9.2.3.1 - Síndrome do trauma de estupro

9.2.3.1.1 - Síndrome do trauma do estupro: reação composta

9.2.3.1.2 - Síndrome do trauma do estupro: reação silenciosa

9.3.1 - Ansiedade

9.3.2 - Medo 
ANEXO 3

\title{
INSTRUMENTO DE COLETA DE DADOS
}

\author{
CONSULTA DE ENFERMAGEM AO CLIENTE \\ COM HIPERTENSÃO ARTERIAL
}

Nome:

Endereço para contato:

Idade:

Sexo ( ) 1 -masculino 2 -femimino
Salário : ( ) Não tem
( ) menos que 1
( ) $1-5$ sal. mín
( ) de 5 a 10
( ) de 10 a 15
( ) acima de 15
Escolaridade: ( ) alfabetizado
( ) $1^{\circ}$ grau incompleto
( ) $1^{\circ}$ grau completo
( ) $2^{\circ}$ grau incompleto
( ) $2^{\circ}$ grau completo
( ) universitária incompleta
( ) universitária completa

Profissão Trabalha atualmente? ( ) sim ( ) não Ocupação:

\section{I- ENTREVISTA DE ENFERMAGEM}

\section{PERCEBER}

1.Como pessoa, como o(a) senhor(a) se descreve?

2.0 que a pressão alta significa para o(a) senhor(a)? 
3.O(a) senhor(a) pensa ser capaz de ajudar no controle da pressão alta?

( ) não( ) sim Como? não como alimentos salgados verifico a pressão regularmente faço exercícios com frequência __ $\mathrm{x} /$ semana medito/relaxo pelo menos $15 \mathrm{~min} /$ dia não fumo reduzí os cigarros para _ /dia tomo remédios conforme prescrição médica

faço tratamento alternativo

_ outras medidas de cuidados gerais:

4.Que outros problemas de saúde o(a) senhor(a) já tem?

5.Nas últimas semanas o(a) senhor(a) teve :
( ) sangramento nasal
( ) palpitações
( ) cãimbras
( ) falta de ar
( ) visão turva
( ) dor de cabeça de manhã
( ) tontura/vertigem
( ) edemas
( ) outros

\section{CONHECER}

6.O(a) senhor(a) foi informado(a) sobre

* o que é hipertensão arterial ? ( ) não( ) sim Por quem?

* seu tratamento ? ( ) não( ) sim Por quem?

* efeito dos medicamentos? ( ) não( ) sim Por quem?

7.Essas orientações foram suficientes ? ( ) não( ) sim Porque?

$\mathrm{O}(\mathrm{a})$ senhor(a) acha que precisa ter informações sobre a sua doença?

( ) não

( ) sim, sobre:

( ) dieta

( ) medicamentos

( ) exercicios físicos

( ) relaxamento muscular

( ) verificação da pressão arterial

( ) outros

9.Qual é o seu valor de pressão arterial ?

Qual o valor ideal? 
10.Onde e com que frequência o(a) senhor(a) verifica a sua pressão?

11.História familiar:

Obesidade?

Diabetes?

( ) não ( ) sim

Quem?

Alcoolismo?

( ) não ( ) sim

Quem?

D. cardíacas?

( ) não ( ) sim

( ) não ( ) sim

Quem?

Derrame cerebral?

( ) não ( ) sim

Quem?

Quem?

12. Quais os medicamentos que o(a) senhor(a) usa para controlar a pressão arterial ? Dosagem e Horário:

13.O(a) senhor(a) aumentou, diminuiu, ou deixou de tomar remédios? Quando e porque?

14. $\mathrm{O}(\mathrm{a})$ senhor(a) toma algum outro remédio além dos para a pressão ?

( ) não ( ) sim

Quais?

15.O(a) senhor(a) tem alguma queixa em relação aos remédios?

\section{COMUNICAR}

16.O(a) senhor(a) tem alguma dificuldade para falar ou ler ou escrever ou compreender o que os profissionais falam ? ( ) não ( ) sim

Qual?

\section{VALORIZAR}

17. O que o(a) senhor(a) considera mais importante em sua vida? 
18.O(a) senhor(a) considera doença uma forma de castigo, de punição?

( ) não ( ) sim

Porquê?

19.O(a) senhor(a) é membro de algum grupo cultural ou étnico?

( ) não ( ) sim qual?

20.O(a) senhor(a) ou sua familia faz uso de algum tratamento caseiro?

( ) não ( ) sim

qual?

Como tomou conhecimento dele?

\section{RELACIONAR}

21.Qual é(são) a(s) pessoa(s) significativa(s) para o(a) senhor(a) em relação ao seu problema de hipertensão arterial?

22.Em geral como o(a) senhor(a) se relaciona com as pessoas? ( ) bem ( ) mal Com quem?

razões:

23.Como o(a) senhor(a) se relaciona com o seu cônjugue? ( ) bem ( ) mal motivo:

24. Como o(a) senhor(a) considera a sua vida sexual?

( ) satisfatória ( ) insatisfatória

Porque ? ( ) diminuição do interesse ( ) dificuldade de orgasmo

( ) outras

25.Qual o seu número de filhos e as condições de saúde deles ?

26.Como é a sua relação com os filhos? ( ) boa ( ) má razões: 


\section{SENTIR}

27.Neste último ano, o(a) senhor(a) teve algum fato estressante (crise familiar ou financeira, morte etc.)? ( ) não ( ) sim Qual? 28.Quando o(a) senhor(a) está tenso(a) ou preocupado(a) o que costuma fazer?

29.O(a) senhor(a) faz uso de algum remédio para ficar calmo ? ( ) não ( ) sim Qual?

Quem indicou?

\section{ESCOLHER}

30.De que modo o(a) senhor(a) costuma resolver os seus problemas?

31.Considera o seu modo de resolver os problemas satisfatórios? ( ) sim ( ) não razões:

\section{MOVER}

32.O(a) senhor(a) tem apresentado algum desconforto, dor ou dificuldade para respirar quando realiza as suas atividades diárias? ( ) não ( ) sim qual?

33.O(a) senhor(a) tem ultimamente sentido cansaço extremo, falta de energia para realizar suas atividades? ( ) não ( ) sim

34. Relate suas atividades diárias típicas:

35.Como o(a) senhor(a) se sente em relação ao seu trabalho?

( ) satisfeito(a) ( ) insatisfeito(a)

motivo: 
36.0 que o(a) senhor(a) gosta de fazer no seu tempo livre?

37. O(a) senhor(a) costuma ir ao médico para exames regulares de rotina?

( ) sim

( ) não

periodicidade:

38.E ao dentista?

( ) $\operatorname{sim}$ ( ) nâo periodicidade:

39. Às mulheres:

Faz exame de Papanicolau? ( ) sim ( ) não Último :

Auto exame de mama mensal ? ( ) sim ( ) não Último :

40.O(a) senhor(a) dorme: ( ) bem ( ) mal ( ) não dorme

E dorme hs/noite hs/dia
41.Quando se deita : ( ) dorme logo ( ) demora a pegar no sono
( ) tem pesadelos
( ) acorda várias vezes ( ) sonha muito

42.Quando acorda : ( ) está descansado ( ) está cansado

\section{TROCAR}

43. Como tem sido as suas eliminações intestinais?

44.Faz uso de laxante ou de constipante com regularidade?
( ) não
( ) sim
qual?

45.Qual o aspecto de sua urina?

46.O que o(a)senhor(a) come diariamente?

No café

No Almoço:

No Jantar:

Outros: 


\section{II-EXAME FÍSICO}

Pressão Arterial Sentado

Frequência Cardiaca Radial

Ritmo:( ) sinusal

() galope

( ) outro

( ) normal

Frequência Respiratória

Sons Respiratórios :
( ) vesiculares
( ) roncos
( ) crepitações
( ) sibilos

\section{ALTURA :}

\section{PESO}

( ) compativel c/altura

( ) obesidade

( ) abaixo recomendável

Enfermeira

COREN
Exames clínicos nos últimos 12 meses:

Queixas atuais:

Mantém contato com o olha:r

$$
\text { () } \operatorname{sim} \text { () não }
$$

Tem movimentos corporais

$$
\text { ( ) sim ( ) não }
$$

Expressão facial( ) tensa

( ) tranquila

( ) angustiada

IMPRESSÕES DO ENTREVTSTADOR 


\section{ANEXO V - REGISTRO DOS DIAGNÓSTICOS}

Paciente

\begin{tabular}{|c|c|c|}
\hline $\begin{array}{c}\text { DIAGNÓSTICO } \\
\text { DE ENFERMAGEM }\end{array}$ & $\begin{array}{c}\text { CARACTERISTICAS } \\
\text { DEFINIDORAS }\end{array}$ & $\begin{array}{c}\text { FATORES } \\
\text { RELACIONADOS }\end{array}$ \\
\hline & & \\
\hline & & \\
\hline & & \\
\hline & & \\
\hline & & \\
\hline & & \\
\hline & & \\
\hline & & \\
\hline & &
\end{tabular}




\section{ANEXO V - PRÉ-TESTE - 8 pacientes}

Diagnósticos de Enfermagem Identificados

TROCAR - Nutrição alterada:ingestão maior

Nutrição alterada: potencial para ingestão maior Integridade da pele prejudicada

Potencial para injúria

Mucosa oral alterada

Proteção alterada

Eliminação brônquica ineficaz

Excesso do volume de líquido

CONHECER - Déficit de conhecimento

SENTIR - Ansiedade

RELACIONAR - Interação social prejudicada

Processo familiar prejudicado

Padrão de sexualidade alterado

Disfunção sexual

VALORIZAR - Angústia espiritual

ESCOLHER - Adaptação prejudicada

MOVER - Distúrbio no padrão do sono

Déficit de lazer

Manutenção da saúde alterada 
Tabela 23 - Associação entre os Diagnósticos de Enfermagem e o Sexo dos pacientes. São Paulo,1999.

\begin{tabular}{|c|c|c|c|}
\hline \multirow[b]{2}{*}{ Diagnóstico } & \multicolumn{2}{|c|}{ Sexo } & \multirow[b]{2}{*}{ Significáncia } \\
\hline & $\begin{array}{c}\text { Homens } \\
\text { (11) }\end{array}$ & $\begin{array}{l}\text { Mulheres } \\
\text { (39) }\end{array}$ & \\
\hline Déficit de conhecimento sobre a doença & $10(90,9)$ & $38(97,4)$ & 0,395 \\
\hline Distúrbio no padrăo do sono & $5(45,5)$ & $21(53,8)$ & $0,623^{*}$ \\
\hline Nutrição alterada: ingestão maior que as necessidades & $9(81,8)$ & $16(41,0)$ & 0,017 \\
\hline Disfunção Sexual & $8(72,7)$ & $13(33,3)$ & 0,036 \\
\hline Potencial para intolerância a atividade & $4(36,4)$ & $5(12,8)$ & 0,093 \\
\hline Constipação & $2(18,2)$ & $6(15,4)$ & 1,000 \\
\hline Estratégias ineficazes de resolução individual & $2(18,2)$ & $5(12,8)$ & 0,641 \\
\hline Intolerância a atividade & $2(18,2)$ & $4(10,3)$ & 0,601 \\
\hline Excesso de volume de líquidos & $3(27,3)$ & $3(7,7)$ & 0,111 \\
\hline Déficit de lazer & 0 & $5(12,8)$ & 0,573 \\
\hline Manutençăo da saúde alterada & $2(18,2)$ & $3(7,7)$ & 0,301 \\
\hline Nutrição alterada: ingestão menor que as necessidades & $1(9,1)$ & $3(7,7)$ & 1,000 \\
\hline Mucosa oral alterada & $1(9,1)$ & $2(5,1)$ & 0,534 \\
\hline Débito cardiaco diminuído & $1(9,1)$ & $1(2,6)$ & 0,395 \\
\hline Constipação colonica & 0 & $2(5,1)$ & 1,000 \\
\hline Distúrbio na auto estima & 0 & $2(5,1)$ & 1,000 \\
\hline Proteçăo alterada & 0 & $2(5,1)$ & 1,000 \\
\hline Ansiedade & 0 & $2(5,1)$ & 1,000 \\
\hline Manutenção do lar prejudicada & $1(9,1)$ & $1(2,6)$ & 0,395 \\
\hline Isolamento social & 0 & $2(5,1)$ & 1,000 \\
\hline Padrão respiratório ineficaz & $1(9,1)$ & $1(2,6)$ & 0,395 \\
\hline Comunicação alterada & $1(9,1)$ & 0 & 0,220 \\
\hline Estratégias ineficazes de resoluçăo familiar & 0 & $1(2,6)$ & 1,000 \\
\hline Fadiga & $1(9,1)$ & 0 & 0,220 \\
\hline Eliminação traqueo brônquica ineficaz & $1(9,1)$ & 0 & 0,220 \\
\hline Constipação percebida & 0 & $1(2,6)$ & 1,000 \\
\hline Integridade tissular prejudicada & 0 & $1(2,6)$ & 1,000 \\
\hline Disfunção na reação de pesar & 0 & $1(2,6)$ & 1,000 \\
\hline Reação de pesar antecipada & $1(9,1)$ & 0 & 0,220 \\
\hline
\end{tabular}


Tabela 24 - Associação entre Diagnósticos de Enfermagem e faixa etária dos pacientes. São Paulo, 1999.

\begin{tabular}{|c|c|c|c|c|}
\hline & & Idade & & $\sqrt{2+20}$ \\
\hline Diagnóstico & $\begin{array}{c}\text { Até } 50 \\
\text { anos } \\
\text { (14) }\end{array}$ & $\begin{array}{c}51 \text { a } 65 \text { anos } \\
\text { (23) }\end{array}$ & $\begin{array}{c}\text { Acima de } 65 \\
\text { anos } \\
\text { (13) }\end{array}$ & $\begin{array}{l}\text { Signifi- } \\
\text { cancia }\end{array}$ \\
\hline Déficit de conhecimento sobre a doença & $13(92,9)$ & $23(100,0)$ & $12(92,3)$ & $0,411^{*}$ \\
\hline Distúrbio no padrão do sono & $6(42,9)$ & $13(56,5)$ & $7(53,8)$ & $0,714^{*}$ \\
\hline Nutrição alterada: ingestão maior que as necessidades & $6(42,9)$ & $11(47,8)$ & $8(61,5)$ & $0,600^{*}$ \\
\hline Disfunção Sexual & $6(42,9)$ & $13(56,5)$ & $2(15,4)$ & $0,056^{*}$ \\
\hline Potencial para intolerância a atividade & $4(28,6)$ & $5(21,7)$ & 0 & $0,127^{*}$ \\
\hline Constipaçăo & $2(14,3)$ & $4(17,4)$ & $2(15,4)$ & $0,967^{*}$ \\
\hline Estratégias ineficazes de resoluçăo individual & $1(7,1)$ & $5(21,7)$ & $1(7,7)$ & $0,346^{*}$ \\
\hline Intolerância a atividade & $1(7,1)$ & $4(17,4)$ & $1(7,7)$ & $0,556^{*}$ \\
\hline Excesso de volume de liquidos & $2(14,3)$ & $3(13,0)$ & $1(7,7)$ & $0,852^{*}$ \\
\hline Déficit de lazer & $2(14,3)$ & $1(4,3)$ & $2(15,4)$ & $0,467^{*}$ \\
\hline Manutençăo da saúde alterada & $1(7,1)$ & $3(13,0)$ & $1(7,7)$ & $0,802^{*}$ \\
\hline Nutrição alterada: ingestão menor que as necessidades & 0 & $3(13,0)$ & $1(7,7)$ & $0,365^{*}$ \\
\hline Mucosa oral alterada & 0 & $2(8,7)$ & $1(7,7)$ & $0,534^{*}$ \\
\hline Débito cardlaco diminuído & 0 & $2(8,7)$ & 0 & $0,294^{*}$ \\
\hline Constipação colonica & $1(7,1)$ & 0 & $1(7,7)$ & $0,411^{*}$ \\
\hline Distürbio na auto estima & $1(7,1)$ & $1(4,3)$ & 0 & $0,635^{\prime \prime}$ \\
\hline Proteção alterada & $1(7,1)$ & 0 & $1(7,7)$ & $0,411^{*}$ \\
\hline Ansiedade & 0 & $1(3,4)$ & $1(7,7)$ & $0,591^{*}$ \\
\hline Manutenção do lar prejudicada & 0 & $2(8,7)$ & 0 & $0,294^{*}$ \\
\hline Isolamento social & 0 & $1(4,3)$ & $1(7,7)$ & $0,591^{\star}$ \\
\hline Padrão respiratório ineficaz & 0 & $1(4,3)$ & $1(7,7)$ & $0,591^{*}$ \\
\hline Comunicação alterada & 0 & $1(4,3)$ & 0 & $0,549^{*}$ \\
\hline Estratégias ineficazes de resoluçăo familiar & 0 & 0 & $1(7,7)$ & $0,234^{*}$ \\
\hline Fadiga & 0 & $1(4,3)$ & 0 & $0,549^{*}$ \\
\hline Eliminação tráqueo brônquica ineficaz & 0 & $1(4,3)$ & 0 & $0,549^{*}$ \\
\hline Constipação percebida & 0 & $1(4,3)$ & 0 & $0,549^{*}$ \\
\hline Integridade tissular prejudicada & 0 & 0 & $1(7,7)$ & $0,234^{*}$ \\
\hline Disfunção na reação de pesar & 0 & $1(4,3)$ & 0 & $0,549^{*}$ \\
\hline Reação de pesar antecipada & 0 & $1(4,3)$ & 0 & $0,549^{*}$ \\
\hline
\end{tabular}


Tabela 25-Associação entre os Diagnósticos de Enfermagem e uso de Metildopa. São Paulo, 1999

\begin{tabular}{|c|c|c|c|}
\hline \multirow{3}{*}{ Diagnóstico } & \multicolumn{2}{|c|}{ Uso de metildopa } & \multirow{3}{*}{$\frac{\text { Signiricancia }}{}$} \\
\hline & Sim & Năo & \\
\hline & (20) & (30) & \\
\hline Déficit de conhecimento sobre a doença & $19(95,0)$ & $29(96,7)$ & 0,645 \\
\hline Distúrbio no padrão do sono & $11(55,0)$ & $15(50,0)$ & $0,729^{*}$ \\
\hline $\begin{array}{l}\text { Nutrição alterada: ingestão maior do que as } \\
\text { necessidades }\end{array}$ & $11(55,0)$ & $14(46,7)$ & $0,564^{*}$ \\
\hline Disfunção sexual & $7(35)$ & $14(46,7)$ & $0413^{*}$ \\
\hline Potencial para intolerância a atividade & $3(15,0)$ & $6(20,0)$ & 0,477 \\
\hline Constipação & $6(30,0)$ & $2(6,7)$ & 0,549 \\
\hline Estratégias ineficazes de resolução individual & $3(15,0)$ & $4(13,3)$ & 0,590 \\
\hline Intolerancia a atividade & $2(10,0)$ & $4(13,3)$ & 0,544 \\
\hline Excesso de volume de líquidos & $5(25,0)$ & $1(3,3)$ & 0,032 \\
\hline Déficit de lazer & $3(15,0)$ & $2(6,7)$ & 0,310 \\
\hline Manutençăo da saúde alterada & 0 & $5(16,7)$ & 0,067 \\
\hline $\begin{array}{l}\text { Nutrição alterada: ingestão menor que as } \\
\text { necessidades }\end{array}$ & $2(10,0)$ & $2(6,7)$ & 0,528 \\
\hline Mucosa oral alterada & 0 & $3(10,0)$ & 0,207 \\
\hline Débito cardiaco diminuído & $1(5,0)$ & $1(3,3)$ & 0,645 \\
\hline Constipação colonica & 0 & $2(6,7)$ & 0,355 \\
\hline Distúrbio na auto estima & $1(5,0)$ & $1(3,3)$ & 0,645 \\
\hline Proteção alterada & $1(5,0)$ & $1(3,3)$ & 0,645 \\
\hline Ansiedade & 0 & $2(6,7)$ & 0,355 \\
\hline Manutençåo do lar prejudicada & $1(5,0)$ & $1(3,3)$ & 0,645 \\
\hline Isolamento social & 0 & $2(6,7)$ & 0,355 \\
\hline Padrăo respiratório ineficaz & 0 & $2(6,7)$ & 0,355 \\
\hline Comunicação alterada & 0 & $1(3,3)$ & 0,600 \\
\hline Estratégias ineficazes de resoluçăo familiar & 0 & $1(3,3)$ & 0,600 \\
\hline Fadiga & 0 & $1(3,3)$ & 0,600 \\
\hline Eliminação tráqueo brônquica ineficaz & 0 & $1(3,3)$ & 0,600 \\
\hline Constipação percebida & 0 & $1(3,3)$ & 0,600 \\
\hline Integridade tissular prejudicada & $1(5,0)$ & 0 & 0,400 \\
\hline Disfunção na reação de pesar & $1(5,0)$ & 0 & 0,400 \\
\hline Reação de pesar antecipada & $1(5,0)$ & 0 & 0,400 \\
\hline
\end{tabular}


Tabela 26- Associação entre os Diagnósticos de Enfermagem e uso de Hidroclorotiazida. São Paulo, 1999.

\begin{tabular}{|c|c|c|c|}
\hline & Uso de & protiazida & (5) \\
\hline Diagnóstico & Sim & Năo & Significancia \\
\hline 8 & (15) & (35) & \\
\hline Déficit de conhecimento sobre a doença & $13(86,7)$ & $35(100,0)$ & 0,086 \\
\hline Distúrbio no padrão do sono & $7(46,7)$ & $19(54,3)$ & $0,621^{*}$ \\
\hline $\begin{array}{l}\text { Nutrição alterada: ingestão maior do que as } \\
\text { necessidades }\end{array}$ & $4(26,7)$ & $21(60,0)$ & $0,310^{*}$ \\
\hline Disfunção sexual & $5(33,3)$ & $16(45,7)$ & $0,416^{*}$ \\
\hline Potencial para intolerância a atividade & $4(26,7)$ & $5(14,3)$ & 0,254 \\
\hline Constipaçăo & $2(13,3)$ & $6(17,1)$ & 0,549 \\
\hline Estratégias ineficazes de resolução individual & 0 & $7(20,0)$ & 0,542 \\
\hline Intolerância a atividade & $2(13,3)$ & $4(11,4)$ & 0,591 \\
\hline Excesso de volume de liquidos & $4(26,7)$ & $2(5,7)$ & 0,058 \\
\hline Desficit de lazer & $2(13,3)$ & $3(8,6)$ & 0,476 \\
\hline Manutenção da saúde alterada & 0 & $5(14,3)$ & 0,153 \\
\hline $\begin{array}{l}\text { Nutrição alterada: ingestão menor que as } \\
\text { necessidades }\end{array}$ & $2(13,3)$ & $2(5,7)$ & 0,346 \\
\hline Mucosa oral alterada & 0 & $3(8,6)$ & 0,334 \\
\hline Débito cardiaco diminuído & 0 & $2(5,7)$ & 0,486 \\
\hline Constipaçăo colonica & $1(6,7)$ & $1(2,9)$ & 0,514 \\
\hline Distúrbio na auto estima & $1(6,7)$ & $1(2,9)$ & 0,514 \\
\hline Proteçăo alterada & 0 & $2(5,7)$ & 0,486 \\
\hline Ansiedade & 0 & $2(5,7)$ & 0,486 \\
\hline Manutenção do lar prejudicada & $1(6,7)$ & $1(2,9)$ & 0,514 \\
\hline Isolamento social & 0 & $2(5,7)$ & 0,486 \\
\hline Padrão respiratório ineficaz & $1(6,7)$ & $1(2,9)$ & 0,514 \\
\hline Comunicação alterada & 0 & $1(2,9)$ & 0,700 \\
\hline Estratégias ineficazes de resolução familiar & 0 & $1(2,9)$ & 0,700 \\
\hline Fadiga & 0 & $1(2,9)$ & 0,700 \\
\hline Eliminação tráqueo brônquica ineficaz & 0 & $1(2,9)$ & 0,700 \\
\hline Constipaçăo percebida & 0 & $1(2,9)$ & 0,700 \\
\hline Integridade tissular prejudicada & $1(6,7)$ & 0 & 0,300 \\
\hline Disfunção na reação de pesar & 0 & $1(2,9)$ & 0,700 \\
\hline Reação de pesar antecipada & 0 & $1(2,9)$ & 0,400 \\
\hline
\end{tabular}


Tabela 27- Associação entre os Diagnósticos de Enfermagem e uso de Clortalidona.São Paulo, 1999.

\begin{tabular}{|c|c|c|c|}
\hline & Uso & ton & 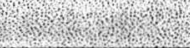 \\
\hline Diagnóstico & $\operatorname{sim}$ & Năo & Significancia \\
\hline & (12) & (38) & \\
\hline Déficit de conhecimento sobre a doença & $12(100,0)$ & $36(94,7)$ & 0,574 \\
\hline Distúrbio no padrão do sono & $8(66,7)$ & $18(47,4)$ & $0,243^{*}$ \\
\hline $\begin{array}{l}\text { Nutrição alterada: ingestão maior do que as } \\
\text { necessidades }\end{array}$ & $6(50,0)$ & $19(50,0)$ & $1,000^{*}$ \\
\hline Disfunção sexual & $2(16,7)$ & $19(50,0)$ & 0,041 \\
\hline Potencial para intolerância a atividade & 0 & $9(23,7)$ & 0,065 \\
\hline Constipação & $2(16,7)$ & $6(15,8)$ & 0,627 \\
\hline Estratégias ineficazes de resolução individual & $2(16,7)$ & $5(13,2)$ & 0,542 \\
\hline Intolerância a atividade & $2(16,7)$ & $4(10,5)$ & 0,447 \\
\hline Excesso de volume de liquidos & 0 & $6(15,8)$ & 0,174 \\
\hline Déficit de lazer & $2(16,7)$ & $3(7,9)$ & 0,345 \\
\hline Manutenção da saúde alterada & 0 & $5(13,2)$ & 0,237 \\
\hline Nutrição alterada: ingestão menor que as necessidades & 0 & $4(10,5)$ & 0,231 \\
\hline Mucosa oral alterada & 0 & $3(7,9)$ & 0,430 \\
\hline Débito cardíaco diminuído & $1(8,3)$ & $1(2,6)$ & 0,426 \\
\hline Constipação colonica & 0 & $2(5,3)$ & 0,574 \\
\hline Distúrbio na auto estima & 0 & $2(5,3)$ & 0,574 \\
\hline Proteção alterada & 0 & $2(5,3)$ & 0,574 \\
\hline Ansiedade & 0 & $2(5,3)$ & 0,574 \\
\hline Manutenção do lar prejudicada & 0 & $2(5,3)$ & 0,574 \\
\hline Isolamento social & 0 & $2(5,3)$ & 0,574 \\
\hline Padrão respiratório ineficaz & 0 & $2(5,3)$ & 0,574 \\
\hline Comunicação alterada & 0 & $1(2,6)$ & 0,760 \\
\hline Estratégias ineficazes de resolução familiar & 0 & $1(2,6)$ & 0,760 \\
\hline Fadiga & 0 & $1(2,6)$ & 0,760 \\
\hline Eliminação tráqueo brônquica ineficaz & 0 & $1(2,6)$ & 0,760 \\
\hline Constipaçăo percebida & 0 & $1(2,6)$ & 0,760 \\
\hline Integridade tissular prejudicada & 0 & $1(2,6)$ & 0,760 \\
\hline Disfunção na reação de pesar & 0 & $1(2,6)$ & 0,760 \\
\hline Reação de pesar antecipada & 0 & $1(2,6)$ & 0,760 \\
\hline
\end{tabular}


Tabela 28- Associafão entre os Diagnósticos de Enfermagem e Diabetes como Problema de Saúde.São Paulo,1999.

\begin{tabular}{|c|c|c|c|}
\hline \multirow{3}{*}{ Diagnostico } & \multicolumn{2}{|c|}{ Diabates (problema de sagido) } & \multirow{3}{*}{ 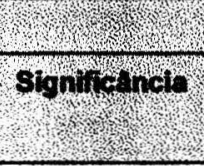 } \\
\hline & $\sin$ & No & \\
\hline & (11) & (39) & \\
\hline Déficit de conhecimento sobre a doença & $10(90,9)$ & $38(97,4)$ & 0,395 \\
\hline Distürbio no padrăo do sono & $4(36,4)$ & $22(56,4)$ & $0,240^{*}$ \\
\hline Nutriçăo alterada: ingestăo maior do que as necessidades & $6(54,5)$ & $19(48,7)$ & $0,733^{*}$ \\
\hline Disfunçăo sexual & $4(36,4)$ & $17(43,6)$ & 0,471 \\
\hline Potencial para intolerancia a atividade & 0 & $9(23,1)$ & 0,085 \\
\hline Constipaçăo & $3(27,3)$ & $5(12,8)$ & 0,236 \\
\hline Estratégias ineficazes de resoluçăo individual & $2(18,2)$ & $5(12,8)$ & 0,487 \\
\hline Intolerância a atividade & $3(27,3)$ & $3(7,7)$ & 0,111 \\
\hline Excesso de volume de liquidos & $1(9,1)$ & $5(12,8)$ & 0,604 \\
\hline Déficit de lazer & $1(9,1)$ & $4(10,3)$ & 0,699 \\
\hline Manutençăo da saúde alterada & $1(9,1)$ & $4(10,3)$ & 0,699 \\
\hline Nutriçăo alterada: ingestăo menor que as necessidades & $2(18,2)$ & $2(5,1)$ & 0,206 \\
\hline Mucosa oral alterada & $2(18,2)$ & $1(2,6)$ & 0,118 \\
\hline Débito cardlaco diminuido & 0 & $2(5,1)$ & 0,605 \\
\hline Constipaçăo colonica & 0 & $2(5,1)$ & 0,605 \\
\hline Distúrbio na auto estima & 0 & $2(5,1)$ & 0,605 \\
\hline Proteção alterada & 0 & $2(5,1)$ & 0,605 \\
\hline Ansiedade & 0 & $2(5,1)$ & 0,605 \\
\hline Manutenção do lar prejudicada & $1(9,1)$ & $1(2,6)$ & 0,395 \\
\hline Isolamento social & $1(9,1)$ & $1(2,6)$ & 0,395 \\
\hline Padrão respiratório ineficaz & 0 & $2(5,1)$ & 0,605 \\
\hline Comunicaçăo alterada & 0 & $1(2,6)$ & 0,780 \\
\hline Estratégias ineficazes de resolução familiar & 0 & $1(2,6)$ & 0,780 \\
\hline Fadiga & 0 & $1(2,6)$ & 0,780 \\
\hline Eliminaçăo tráqueo brônquica ineficaz & $1(9,1)$ & 0 & 0,220 \\
\hline Constipaçăo percebida & $1(9,1)$ & 0 & 0,220 \\
\hline Integridade tissular prejudicada & $1(9,1)$ & 0 & 0,220 \\
\hline Disfunçăo na reaçăo de pesar & 0 & $1(2,6)$ & 0,780 \\
\hline Reaçăo de pesar antecipada & 0 & $1(2,6)$ & 0,780 \\
\hline
\end{tabular}


Tabela 29 - Associação entre os Diagnósticos de Enfermagem e o Salário dos Pacientes.São Paulo, 1999.

\begin{tabular}{|c|c|c|c|}
\hline : & \multicolumn{2}{|c|}{ Salário } & n.t. \\
\hline Diagnostico & $\begin{array}{l}\text { Tem } \\
\text { (20) }\end{array}$ & $\begin{array}{c}\text { Nasotem } \\
(30)\end{array}$ & Signifis noly \\
\hline Déficit de conhecimento sobre a doença & $19(95,5)$ & $29(96,7)$ & 0,645 \\
\hline Distürbio no padrăo do sono & $9(45,0)$ & $17(56,7)$ & $0,419^{*}$ \\
\hline $\begin{array}{l}\text { Nutriçăo alterada: ingestăo maior do que as } \\
\text { necessidades }\end{array}$ & $12(60,0)$ & $13(43,3)$ & $0,248^{*}$ \\
\hline Disfunģăo sexual & $11(55,0)$ & $10(33,3)$ & $0,128^{*}$ \\
\hline Potencial para intolerância a atividade & $6(30,0)$ & $3(10,0)$ & 0,130 \\
\hline Constipaçăo & $2(10,0)$ & $6(20,0)$ & 0,450 \\
\hline Estratégias ineficazes de resoluçăo individual & $2(10,0)$ & $5(16,7)$ & 0,687 \\
\hline Intolerancia a atividade & $3(15,0)$ & $3(10,0)$ & 0,672 \\
\hline Excesso de volume de liquidos & $4(20,0)$ & $2(6,7)$ & 0,208 \\
\hline Deficit de lazer & $2(10,0)$ & $3(10,0)$ & 1,000 \\
\hline Manutençăo da saủde alterada & $3(15,0)$ & $2(6,7)$ & 0,377 \\
\hline Nutriçăo alterada: ingestăo menor que as necessidades & $2(10,0)$ & $2(6,7)$ & 1,000 \\
\hline Mucosa oral alterada & $1(5,0)$ & $2(6,7)$ & 1,000 \\
\hline Débito cardlaco diminuido & $1(5,0)$ & $1(3,3)$ & 1,000 \\
\hline Constipaçăo colonica & $1(5,0)$ & $1(3,3)$ & 1,000 \\
\hline Disturbio na auto estima & 0 & $2(6,7)$ & 0,510 \\
\hline Proteçăo alterada & 0 & $2(6,7)$ & 0,510 \\
\hline Ansiedade & 0 & $2(6,7)$ & 0,510 \\
\hline Manutençăo do lar prejudicada & $1(5,0)$ & $1(3,3)$ & 1,000 \\
\hline Isolamento social & 0 & $2(6,7)$ & 0,510 \\
\hline Padrăo respiratório ineficaz & $1(5,0)$ & $1(3,3)$ & 1,000 \\
\hline Comunicaçăo alterada & $1(5,0)$ & 0 & 0,400 \\
\hline Estratégias ineficazes de resoluçăo familiar & 0 & $1(3,3)$ & 1,000 \\
\hline Fadiga & $1(5,0)$ & 0 & 0,400 \\
\hline Eliminaçăo tráqueo brónquica ineficaz & $1(5,0)$ & 0 & 0,400 \\
\hline Constipação percebida & 0 & $1(3,3)$ & 1,000 \\
\hline Integridade tissular prejudicada & 0 & $1(3,3)$ & 1,000 \\
\hline Disfunção na reaçăo de pesar & 0 & $1(3,3)$ & 1,000 \\
\hline Reaçăo de pesar antecipada & $1(5,0)$ & 0 & 0,400 \\
\hline
\end{tabular}


Tabela 30 Associação entre os Diagnósticos de Enfermagem e a Queixa de Cansaço. São Paulo, 1999.

\begin{tabular}{|c|c|c|c|}
\hline 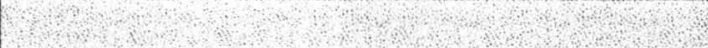 & & & \\
\hline Diagnóstico & Sim & Năo & Significancia \\
\hline & (15) & (35) & \\
\hline Déficit de conhecimento sobre a doença & $15(100,0)$ & $33(94,3)$ & 0,486 \\
\hline Distúrbio no padrão do sono & $9(60,0)$ & $17(48,6)$ & $0,459^{*}$ \\
\hline $\begin{array}{l}\text { Nutrição alterada: ingestăo maior do que as } \\
\text { necessidades }\end{array}$ & $9(60,0)$ & $16(45,7)$ & $0,355^{*}$ \\
\hline Disfunçăo sexual & $10(66,7)$ & $11(31,4)$ & $0,020^{\star}$ \\
\hline Potencial para intolerância a atividade & $5(33,3)$ & $4(11,4)$ & 0,077 \\
\hline Constipação & $6(40,0)$ & $2(5,7)$ & 0,006 \\
\hline Estratégias ineficazes de resoluçăo individual & $3(20,0)$ & $4(11,4)$ & 0,348 \\
\hline Intolerância a atividade & $4(26,7)$ & $2(5,7)$ & 0,058 \\
\hline Excesso de volume de liquidos & $2(13,3)$ & $4(11,4)$ & 0,591 \\
\hline Déficit de lazer & $2(13,3)$ & $3(8,6)$ & 0,476 \\
\hline Manutenção da saúde alterada & $1(6,7)$ & $4(11,4)$ & 0,524 \\
\hline Nutriçăo alterada: ingestăo menor que as necessidades & $1(6,7)$ & $3(8,6)$ & 0,654 \\
\hline Mucosa oral alterada & 0 & $3(8,6)$ & 0,334 \\
\hline Débito cardiaco diminuído & 0 & $2(5,7)$ & 0,486 \\
\hline Constipação colonica & 0 & $2(5,7)$ & 0,486 \\
\hline Distürbio na auto estima & $1(6,7)$ & $1(2,9)$ & 0,514 \\
\hline Proteção alterada & 0 & $2(5,7)$ & 0,486 \\
\hline Ansiedade & $1(6,7)$ & $1(2,9)$ & 0,514 \\
\hline Manutenção do lar prejudicada & $1(6,7)$ & $1(2,9)$ & 0,514 \\
\hline Isolamento social & 0 & $2(5,7)$ & 0,486 \\
\hline Padrão respiratório ineficaz & 0 & $1(2,9)$ & 0,700 \\
\hline Comunicaçăo alterada & 0 & $1(2,9)$ & 0,700 \\
\hline Estratégias ineficazes de resolução familiar & 0 & $1(2,9)$ & 0,700 \\
\hline Fadiga & 0 & $1(2,9)$ & 0,700 \\
\hline Eliminaçåo tráqueo brônquica ineficaz & 0 & $1(2,9)$ & 0,700 \\
\hline Constipaçăo percebida & 0 & $1(2,9)$ & 0,700 \\
\hline Integridade tissular prejudicada & $1(6,7)$ & 0 & 0,300 \\
\hline Disfunçăo na reaçăo de pesar & 0 & $1(2,9)$ & 0,700 \\
\hline Reação de pesar antecipada & 0 & $1(2,9)$ & 0,700 \\
\hline
\end{tabular}


Tabela 31 - Associação entre os Diagnósticos de Enfermagem e a Expressão Facial do Paciente.São Paulo, 1999.

\begin{tabular}{|c|c|c|c|}
\hline \multirow[b]{2}{*}{ Diagnóstico } & \multicolumn{2}{|c|}{ Expressão facial } & \multirow[b]{2}{*}{ Significância } \\
\hline & $\begin{array}{c}\text { Tensal } \\
\text { Angustiada } \\
\text { (23) }\end{array}$ & $\begin{array}{c}\text { Tranquila } \\
\text { (27) }\end{array}$ & \\
\hline Déficit de conhecimento sobre a doença & $23(100,0)$ & $25(92,6)$ & 0,287 \\
\hline Distúrbio no padrão do sono & $15(65,2)$ & $11(40,7)$ & $0,084^{*}$ \\
\hline $\begin{array}{l}\text { Nutrição alterada: ingestão maior do que as } \\
\text { necessidades }\end{array}$ & $11(47,8)$ & $14(51,9)$ & $0,777^{*}$ \\
\hline Disfunção sexual & $13(56,5)$ & $8(29,6)$ & $0,055^{\star}$ \\
\hline Potencial para intolerância a atividade & $5(21,7)$ & $4(14,8)$ & 0,394 \\
\hline Constipação & $6(26,1)$ & $2(7,4)$ & 0,079 \\
\hline Estratégias ineficazes de resolução individual & $6(26,1)$ & $1(3,7)$ & 0,030 \\
\hline Intolerância a atividade & $5(21,7)$ & $1(3,7)$ & 0,064 \\
\hline Excesso de volume de liquidos & $4(17,4)$ & $2(7,4)$ & 0,260 \\
\hline Déficit de lazer & $3(13,0)$ & $2(7,4)$ & 0,422 \\
\hline Manutenção da saúde alterada & $4(17,4)$ & $1(3,7)$ & 0,129 \\
\hline Nutrição alterada: ingestão menor que as necessidades & $2(8,7)$ & $2(7,4)$ & 0,632 \\
\hline Mucosa oral alterada & $3(13,0)$ & 0 & 0,090 \\
\hline Débito cardiaco diminuido & $1(4,3)$ & $1(3,7)$ & 0,713 \\
\hline Constipação colonica & 0 & $2(7,4)$ & 0,287 \\
\hline Distürbio na auto estima & $2(8,7)$ & 0 & 0,207 \\
\hline Proteção alterada & $2(8,7)$ & 0 & 0,207 \\
\hline Ansiedade & $2(8,7)$ & 0 & 0,207 \\
\hline Manutençăo do lar prejudicada & $1(4,3)$ & $1(3,7)$ & 0,713 \\
\hline Isolamento social & $2(8,7)$ & 0 & 0,207 \\
\hline Padrão respiratório ineficaz & $1(4,3)$ & $1(3,7)$ & 0,713 \\
\hline Comunicação alterada & $1(4,3)$ & 0 & 0,460 \\
\hline Estratégias ineficazes de resolução familiar & $1(4,3)$ & 0 & 0,460 \\
\hline Fadiga & $1(4,3)$ & 0 & 0,460 \\
\hline Eliminaçăo tráqueo brônquica ineficaz & $1(4,3)$ & 0 & 0,460 \\
\hline Constipação percebida & $1(4,3)$ & 0 & 0,460 \\
\hline Integridade tissular prejudicada & $1(4,3)$ & 0 & 0,460 \\
\hline Disfunção na reaçăo de pesar & 0 & $1(3,7)$ & 0,540 \\
\hline Reação de pesar antecipada & $1(4,3)$ & 0 & 0,460 \\
\hline
\end{tabular}


Tabela 32- Associação entre os Diagnósticos de Enfermagem e a Pressão Arterial Normal ou Alterada.SPaulo,1999.

\begin{tabular}{|c|c|c|c|}
\hline & & & $x$ \\
\hline Diagnóstico & $\begin{array}{c}\text { Normal } \\
\text { (25) }\end{array}$ & $\begin{array}{c}\text { Alterada } \\
\text { (25) }\end{array}$ & Significância \\
\hline Déficit de conhecimento sobre a doença & $24(96,0)$ & $24(96,0)$ & 0,755 \\
\hline Distúrbio no padrão do sono & $12(48,0)$ & $14(56,0)$ & $0,571^{*}$ \\
\hline $\begin{array}{l}\text { Nutrição alterada: ingestão maior do que as } \\
\text { necessidades }\end{array}$ & $13(52,0)$ & $12(48,0)$ & $0,777^{*}$ \\
\hline Disfunção sexual & $10(40,0)$ & $11(44,0)$ & $0,774^{*}$ \\
\hline Potencial para intolerância a atividade & $5(20,0)$ & $4(16,0)$ & 0,500 \\
\hline Constipação & $1(4,0)$ & $7(28,0)$ & $0,021^{k}$ \\
\hline Estratégias ineficazes de resolução individual & $2(8,0)$ & $5(20,0)$ & 0,209 \\
\hline Intolerância a atividade & $2(8,0)$ & $4(16,0)$ & 0,334 \\
\hline Excesso de volume de liquidos & $2(8,0)$ & $4(16,0)$ & 0,334 \\
\hline Déficit de lazer & $2(8,0)$ & $3(12,0)$ & 0,500 \\
\hline Manutenção da saúde alterada & $3(12,0)$ & $2(8,0)$ & 0,500 \\
\hline Nutrição alterada: ingestão menor que as necessidades & $2(8,0)$ & $2(8,0)$ & 0,695 \\
\hline Mucosa oral alterada & $2(8,0)$ & $1(4,0)$ & 0,500 \\
\hline Débito cardíaco diminuído & 0 & $2(8,0)$ & 0,245 \\
\hline Constipação colonica & $1(4,0)$ & $1(4,0)$ & 0,755 \\
\hline Distúrbio na auto estima & $1(4,0)$ & $1(4,0)$ & 0,755 \\
\hline Proteçăo alterada & $1(4,0)$ & $1(4,0)$ & 0,755 \\
\hline Ansiedade & $2(8,0)$ & 0 & 0,245 \\
\hline Manutenção do lar prejudicada & 0 & $2(8,0)$ & 0,245 \\
\hline Isolamento social & $2(8,0)$ & 0 & 0,245 \\
\hline Padrão respiratório ineficaz & $2(8,0)$ & 0 & 0,245 \\
\hline Comunicação alterada & 0 & $1(4,0)$ & 0,500 \\
\hline Estratégias ineficazes de resolução familiar & $1(4,0)$ & 0 & 0,500 \\
\hline Fadiga & 0 & $1(4,0)$ & 0,500 \\
\hline Eliminação tráqueo brónquica ineficaz & 0 & $1(4,0)$ & 0,500 \\
\hline Constipação percebida & $1(4,0)$ & 0 & 0,500 \\
\hline Integridade tissular prejudicada & 0 & $1(4,0)$ & 0,500 \\
\hline Disfunção na reação de pesar & 0 & $1(4,0)$ & 0,500 \\
\hline Reaçăo de pesar antecipada & $1(4,0)$ & 0 & 0,500 \\
\hline
\end{tabular}


Tabela 33- Associação entre os Diagnósticos de Enfermagem e a queixa de Dispnéia relatada pelos pacientes.São Paulo,199.

\begin{tabular}{|l|c|c|c|}
\hline & \multicolumn{2}{|c|}{ Dispnéla } & \\
\hline Bronquite & Sim & Não & $\begin{array}{c}\text { Teste exato de } \\
\text { Fisher }\end{array}$ \\
\hline Sim & $(5)$ & $(45)$ & $3(6,7)$ \\
\cline { 1 - 2 } Não & $1(20,0)$ & $42(93,3)$ & 0,353 \\
\hline
\end{tabular}

Tabela 34 - Associação entre os Diagnósticos de Enfermagem e a queixa de

\begin{tabular}{|l|c|c|c|}
\hline \multicolumn{2}{|c|}{ Cansaco relatada pelos pacientes.São Paulo, 1999. } \\
\hline Diabetes & \multicolumn{2}{|c|}{ Cansaço } & Teste exato de \\
& Sim & Fasher \\
& $(15)$ & $(35)$ & \\
\hline Sim & $5(33,3)$ & $6(17,1)$ & 0,184 \\
\hline Não & $10(66,7)$ & $29(82,9)$ & \\
\hline
\end{tabular}

Tabela 35- Associação entre Pressão Arterial Normal e Alterada e queixa dos pacientes.

\begin{tabular}{|l|c|c|c|}
\hline & \multicolumn{2}{|c|}{ Cansaģo } & \\
\hline Pressão & $\begin{array}{c}\text { Sim } \\
(15)\end{array}$ & $\begin{array}{c}\text { Năo } \\
(35)\end{array}$ & $\begin{array}{c}\text { Teste Qui- } \\
\text { quadrado }\end{array}$ \\
\hline Normal & $3(20,0)$ & $22(62,9)$ & \\
\hline Alterada & $12(80,0)$ & $13(37,1)$ & 0,005 \\
\hline
\end{tabular}

